


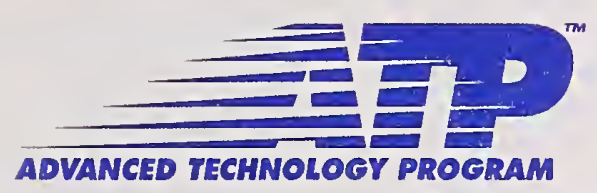

Performance of

50 Completed

ATP Projects

Status Report Number 3

NIST SP $950-3$

August 2005
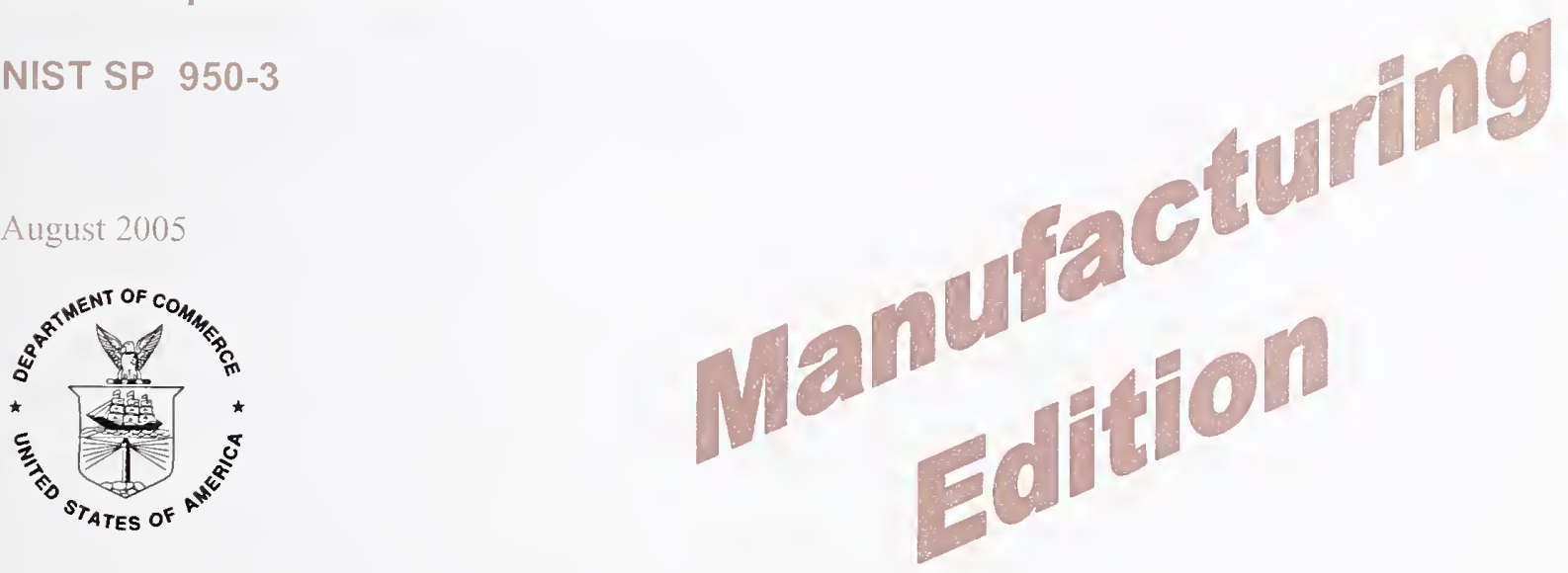

U.S. DEPARTMENT OF COMMERCE

Carlos Gutierrez, Secretary August 2005

TECHNOLOGY ADMINISTRATION

Michelle O'Neill, Acting Under Secretary for Technology

NATIONAL INSTITUTE OF STANDARDS AND TECHNOLOGY

William Jeffrey, Director

ADVANCED TECHNOLOGY PROGRAM

Marc Stanley, Director

NIST 
Certain commercial entities, equipment, or materials may be identified in this doeument in order to describe an experimental procedure or eoncept adequately. Sueh identification is not intended to imply recommendation or endorsement by the National Institute of Standards and Teehnology, nor is it intended to imply that the entities, materials, or equipment are neeessarily the best available for the purpose.

NATIONAL INSTITUTE OF STANDARDS AND TECHNOLOGY Advanced Technology Program, Economic Assessment Office NIST Special Publication

U.S. GOVERNMENT PRINTING OFFICE WASHINGTON, D.C.

For sale by the Superintendent of Documents, U.S. Government Printing Office Internet: bookstore.gpo.gov — Phone: (202) 512-1800 - Fax: (202) 512-2250 Mail: Stop SSOP, Washington, DC 20402-0001 


\section{Table of Contents}

ACKNOWLEDGEMENTS $\mathrm{V}$

INTRODUCTION.

CHAPTER 1: OVERVIEW

Part 1: Project Characteristics ................................................................................. 3

Part 2: Gains in Technical Knowledge........................................................................... 7

Part 3: Dissemination of Knowledge ............................................................................. 9

Part 4: Commercialization of the New Technology ............................................................ 15

Part 5: Overall Project Performance ................................................................................ 19

CHAPTER 2: ADVANCED MATERIALS AND CHEMICALS

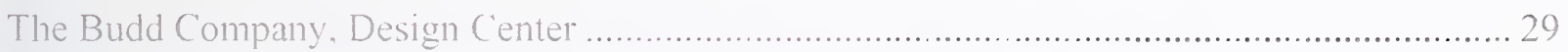

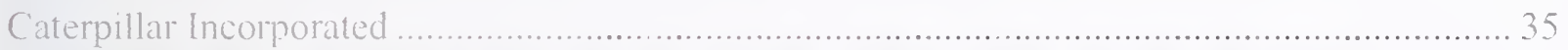

Ebert Composites Corporation .............................................................................. 41

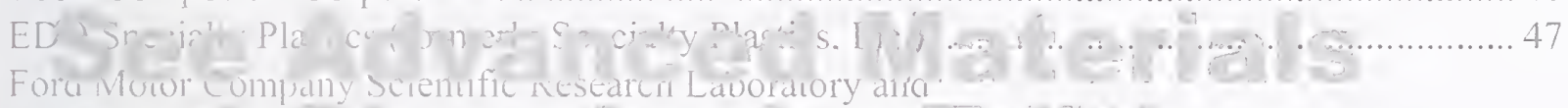

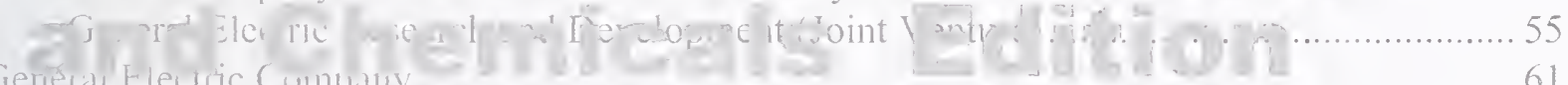

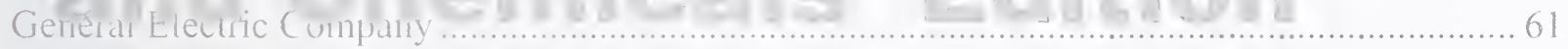

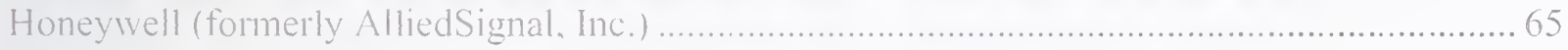

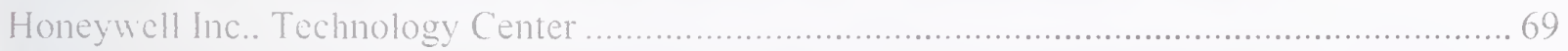

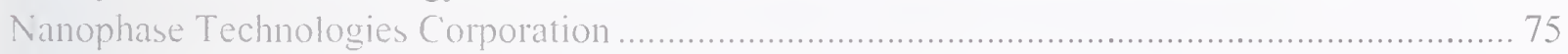

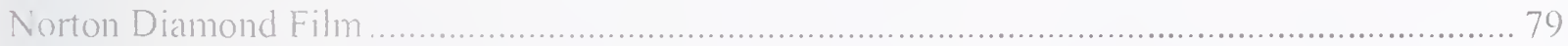

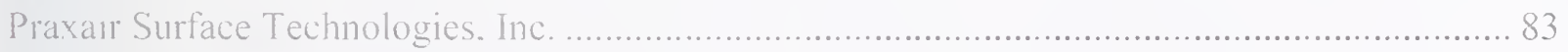

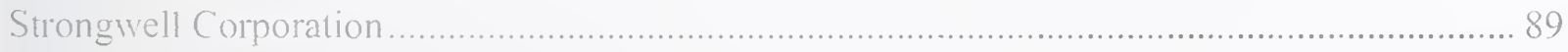

CHAPTER 3: BIOTECHNOLOGY

Genzyme Corporation (formerly GelTex Pharmaceuticals, Inc.) .......................................... 97

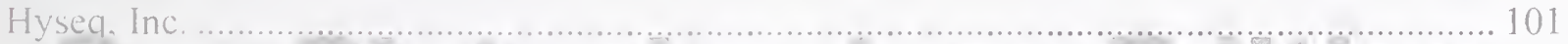

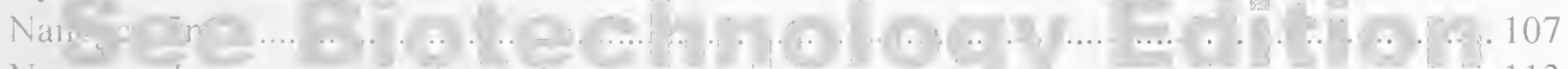

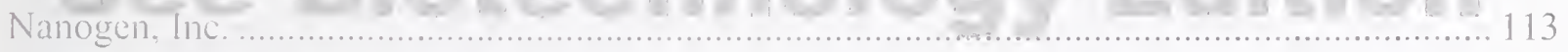

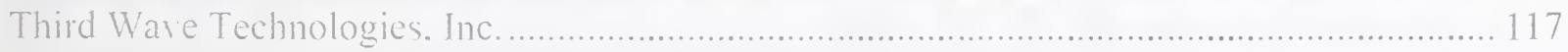

CHAPTER 4: ELECTRONICS, COMPUTER HARDWARE, AND COMMUNICATIONS

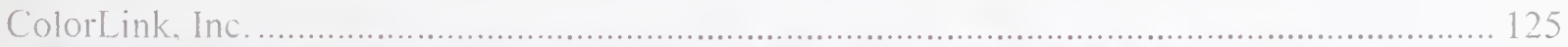

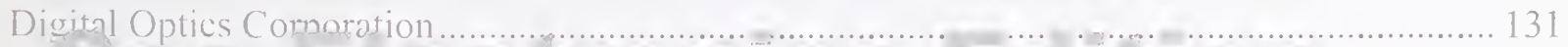

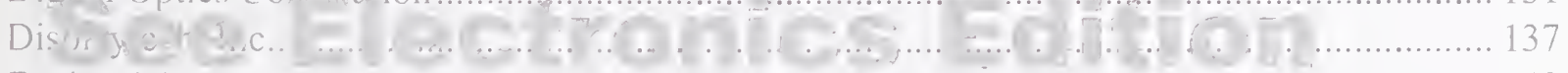

Eagle-Picher Research Laboratory ......................................................................... 143

Elsicon (formerly Alliant Techsystems, Inc. and Hercules) .............................................. 149 


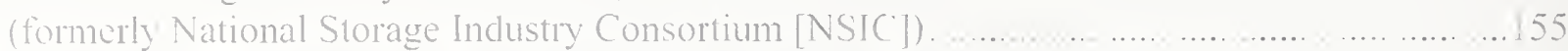

alser Power Corporation ........................................

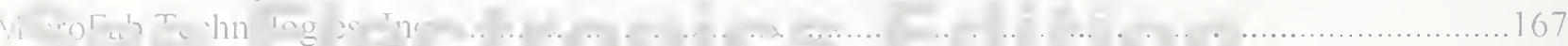

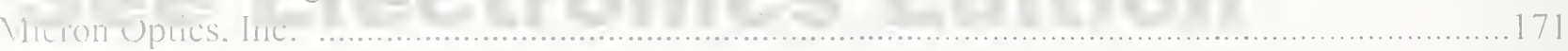

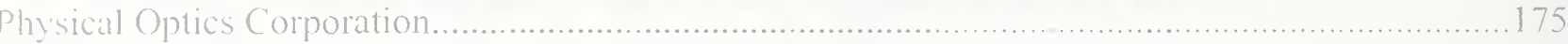

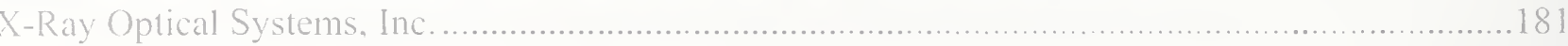

CHAPTER 5: INFORMATION TECHNOLOGY

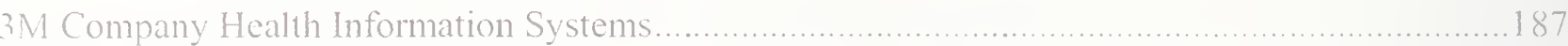

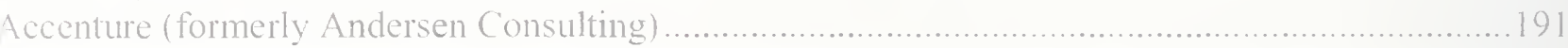

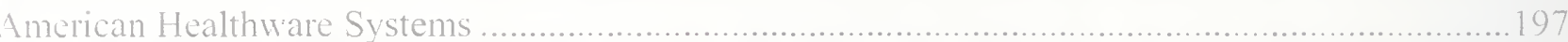

Hynomics (formerly HyBrithms Corporation, formerly Sagent Corporation) ..............................201

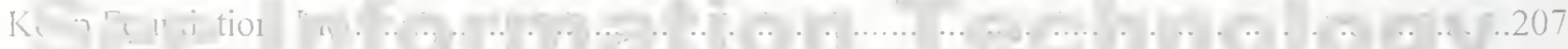

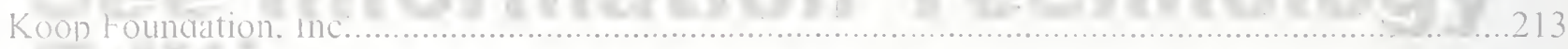

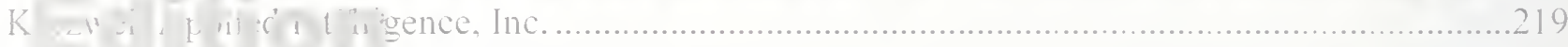

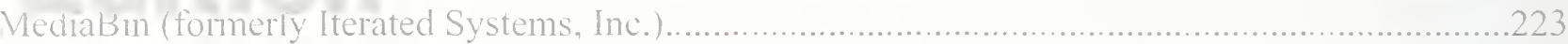

PPD Informatics, a Division of Pharmaceutical Product Development. Inc.

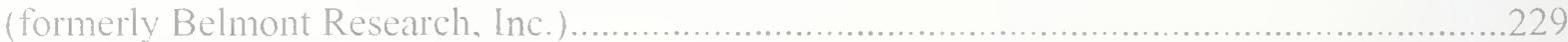

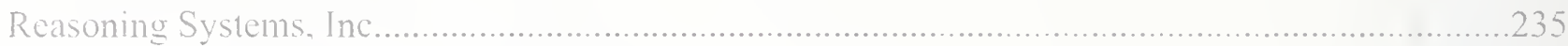

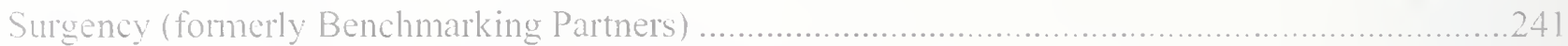

TopicalNet, Inc. (formerly Continutum Software, Inc.) ....................................................2247

TopicalNet, Inc. (formerly Continum Software. Inc.) ....................................................25

CHAPTER 6: MANUFACTURING

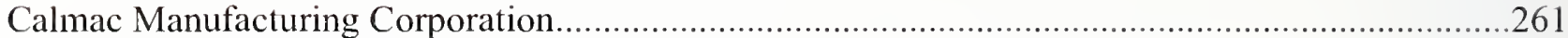

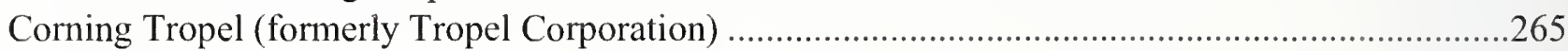

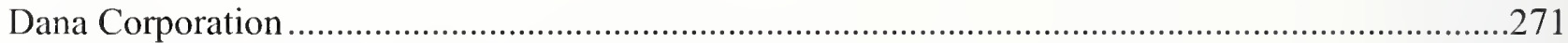

General Electric Corporate Research \& Development ..................................................................275

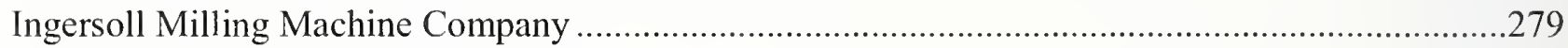

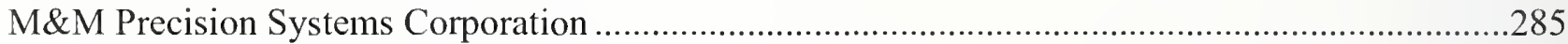

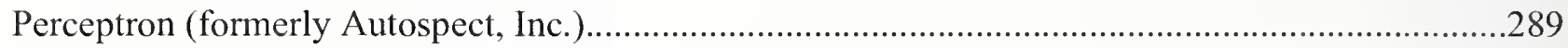

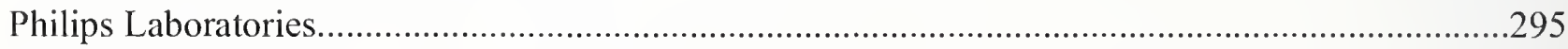

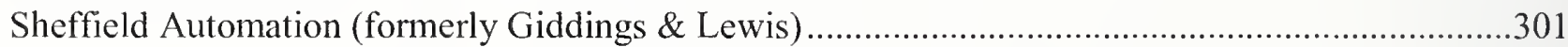

CHAPTER 7: APPENDICES

Appendix A: Development of New Knowledge and Early Commercial

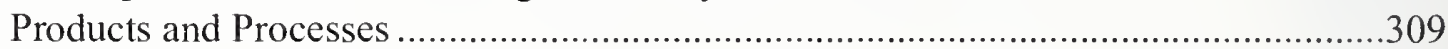

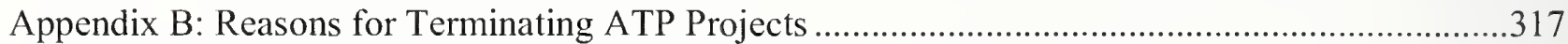

Appendix C: Composite Performance Rating System (CPRS) Star Ratings-

First 100 Completed Projects 


\section{Acknowledgements}

We are pleased to announce the completion of the next chaptcr in ATP's portfolio of status reports for completed projects. This compilation consists of the second batch of 50 "mini case studics" written to investigate the results and impacts of ATP's investment in innovative technologies. The goal of each status report is to provide the reader with a basic understanding of the technology, while also identifying any economic benefits that may have resulted from the ATP-funded project.

This process is a daunting one, requiring the efforts of many both inside and outside of ATP. The majority of the project was made possible by the former and current membcrs of the status report team: Tony Colandrea, Stefanie Cox, David Dashefsky, Kirsten Matsumoto, Nashira Nicholson, Rick Rodman, and Amol Singla. We would especially like to thank ATP Division Directors Linda Beth Schilling (Chemistry and Lifc Sciences Office) and Elissa Sobolcwski (Information Technology and Electronics Office), ATP Deputy Director Lorel Wisniewski, and Rosalie Ruegg (Managing Director, TIA Consulting, Inc.), for their contributions to this project. Much appreciation also goes to the hard work of the others involved in preparing the status reports: project managers, reviewers, copy editors, and company represcntatives.

But these efforts arcn't without rewards. As the portfolio of ATP status reports grows, we gain insight as to the role ATP plays in bridging the funding gap. We are confident this showcase of the second batch of 50 completed projects will hclp build on our understanding of ATP-funded innovations across many technology arcas. We hope that you learn as much about the process of early-stage tcchnology development, commercialization, and outcomes for the cconomy as wc have in preparing these status reports.

Sincerely,

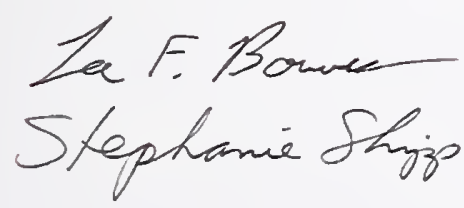

Lee Bowes, Economist Stephanie Shipp, Director, Economic Asscssment Office Advanced Technology Program 


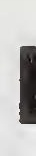

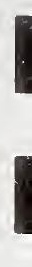

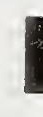




\section{Introduction}

Industry has proposed 6,924 projects to the ATP since 1990, of which 768, or 11 percent, have been selected by the ATP for funding. The number of participants for these funded projects totaled 1,511, with approximately an equal number of subcontractors. This study focuses on the second group of $50^{1}$ projects that were completed and provides combined statistics for all 100 completed projects studied to date.

\section{ATP: A Partnership with Industry}

The ATP attracts challenging, visionary projects with the potential to develop the technological foundations of new and improved products, processes, and even industries. The ATP partners with industry on this research, fostering collaborative efforts and sharing costs to bring down high technical risks and accelerate technology development and application. These are projects that industry in many cases will not undertake without ATP support, or will not develop in a timely manner when timing is critical in the highly competitive global market. The program funds only research, not product development. The ATP is managed by the National Institute of Standards and Technology, an agency of the Commerce Department's Technology Administration.

ATP awards are made on the basis of a rigorous competitive review, which considers the scientific and technical merit of each proposal and its potential benefits to the U.S. economy. The ATP issues a proposal preparation kit that presents and explains the selection criteria to prospective applicants and provides guidance on preparing proposals. ${ }^{2}$ U.S. businesses conceive, plan, propose, and lead the projects. Government scientists and engineers who are expert in the relevant technology fields review all proposals for their technical merit. Business, industry, and economic experts review the proposals to judge their potential to deliver broadly based economic benefits to the nation -including large benefits extending beyond the innovator (the award recipient).

The ATP delivers benefits to the nation along two pathways: 1 ) a direct path by which the U.S. award recipient or innovator directly pursues commercialization of the newly developed technologies; and 2) an indirect path which relies on knowledge transfer from the innovator to others who in turn may use the knowledge for economic benefit. Either path may yield spillover benefits. The ATP looks to the direct path as a way to accelerate application of the technology by U.S. businesses. It looks to the indirect path as a means of achieving additional benefits, or benefits even if the award recipient fails to continue. The ATP's two-path approach to realizing national benefits offers advantages: one path may provide an avenue for benefits when the other does not, and both paths together may yield larger, accelerated benefits as compared to having a single route to impact.

\section{Project Evaluation}

The ATP, like other federal programs, is required by law to report on its performance. ${ }^{3}$ The ATP established its evaluation program soon after it began, even before evaluation was widely required by Congress. The Economic Assessment Office (EAO) of ATP plans and coordinates the evaluation of funded projects. It is assisted in this effort by leading university and consulting economists and others experienced in evaluation.

Performance is measured against the program's legislated mission. Emphasis is placed on attempting to measure benefits that accrue not only to the direct award recipients, but also to a wider population, i.e., spillover benefits. This emphasis reflects the fact the public funding covers part of the costs of these projects, and, therefore, a relevant question is how the broader public benefits from the expenditure. 
This report constitutes one element of the EAO's multi-faceted evaluation plan: status reports. The purpose of status reports is to provide an interim assessment of the status of ATP-funded projects several years after they are completed. Although the ultimate success of the ATP depends on the long-run impacts of the entire portfolio of ATP projects, the performance-to-date of this partial portfolio provides some initial answers. This study contains an evaluation of 100 completed projects: the results of the 50 projects from the Status Report - Number 2, and the results and status reports of a second batch of 50 projects. These reports address the questions of: what has the public investment of $\$ 206$ million in the 100 projects produced several years after completion of the research, and what is the outlook for continued progress?

\section{Study Approach}

From the moment that ATP funded its first group of 11 projects in the 1990 competition, program administrators, the administration, Congress, technology policymakers, industry, and others in this country and abroad were keenly interested in the outcome. But technology development and commercialization are lengthy processes, and it takes time to produce results.

As more ATP-funded projects are completed and move into the post-project period, sufficient time has elapsed for knowledge to be disseminated and progress to be made towards commercial goals. Thus, it is now possible to compile more complete aggregate portfolio statistics and analyze these statistics with regard to implications for overall program success.

At the core of this study are 50 mini-case studies covering each of the completed projects. Each of these briefly tells the project story, recounting its goals and challenges, describing the innovators and their respective roles, and assessing progress to date and the future outlook. Photographs illustrate many of the projects.

Although the particulars vary for each project, certain types of data are systematically collected for all of them. Consistent with ATP's mission, the evaluation focuses on collecting data related to the following dimensions of performance:

- Knowledge creation and dissemination, which is assessed using the following criteria: recognition by other organizations of a project's technical accomplishments; numbers of patents filed and granted; citations of patents by others; publications and presentations; collaborative relationships; and knowledge embodied in and disseminated through new products and processes.

- Commercialization progress, which is gauged in terms of the attraction of additional capital for continued pursuit of project goals, including resources provided by collaborative partners; entry into the market with products and services; employment changes at the small companies leading projects and other indicators of their growth; awards bestowed by other organizations for business accomplishments of project leaders; and the analyst's assessment of future outlook for the technology based on all the other information.

The approach is to provide, in an overview chapter, the aggregate statistics of interest across a set of 100 projects, such as the total number of patents and the percentage of projects whose technologies have been commercialized. In addition, the aggregate statistics are combined to produce composite project metrics for overall performance. The composite performance scores allow one to see at a glance the robustness of a project's progress towards its goals. Underlying the simple scores is a wealth of data.

\section{Sources of Information}

Data for the projects were collected from many sources: ATP project records; telephone interviews with company representatives; interviews with ATP project managers; company websites; the U.S. Patent and Trademark Office; in-depth project studies conducted by other analysts; academic, trade and business literature; news reports; filings at the Securities and Exchange Commission; and business research services, such as Dun and Bradstreet, Hoover's Online, Industry Network, and CorpTech. Each one of the individual project write-ups was reviewed for accuracy by the project's lead company and ATP staff.

\section{Study Limitations and Future Directions}

Since developments continue to unfold for most of these projects, the output measures for the cases may have changed significantly since the data were collected. The cases provide a snapshot of progress several years after the completion of the ATP-funded projects. 
Although undertaken at different calendar dates, the reports are written within about the same interval of time after ATP funding ended. Yet, different points in each technology's life cycle may be captured, depending on the technology area. Information technology projects, for example, may be expected to be further along than advanced materials and chemical projects. Examined at a later time, there may be less (or more) difference in the accomplishments among projects in different technology areas.

This study tracks outputs leading to knowledge dissemination but it does not assess the actual commercialization efforts by others who acquire the knowledge. The tracking of commercialization efforts is limited to the direct path of impact (i.e., commercialization by the award recipients or innovators).

\section{"Completed" and "Terminated" Projects Defined}

Projects do not necessarily finish in the order funded. For one thing, they have different lengths, ranging from approximately two years to no more than five years. For another, they are required to file a final report with the ATP and have financial and other paperwork completed before project closeout. The financial closeout is done through the National Institute for Standards and Technology (NIST) Grants Office, which notifies the ATP that it considers the project completed. This study assesses the first 100 projects the Grants Office declared "completed."

Although most ATP projects reach completion, some are stopped short and are classified as "terminated." Some of these were announced as award winners but never officially started. Other projects got off the ground but were closed for various reasons with a substantial amount of the technical work still unfinished. These terminated projects are assessed according to the principal reasons they stopped before completion. They are treated in Appendix B. While the terminated projects are generally regarded as unsuccessful, some produced potentially useful outputs.

\section{Report Organization}

Chapter 1 provides a summary overview of the performance of the 100 completed projects as a group. It identifies some major outputs that appear useful as indicators of the degree of project success, and it uses these outputs in a prototype project performance rating system. A preview also notes some of the broad-based benefits that this portfolio of projects is producing and likely to produce. For additional background, the make-up of the portfolio of projects in terms of technologies, organizational structure, company size, and other features is provided.

The individual project reports of a second group of 50 are presented in Chapters 2 through 6 , and highlight major accomplishments and the outlook for continued progress. A detailed account of the project under review is given, with attention to technical and commercial goals and achievements, information about technology diffusion, and views about the role played by ATP funding. A performance rating is assigned to each project based on a four-star scoring system. The rating depends on the accomplishments of the project in creating and disseminating new scientific and technical knowledge and in making progress toward generating commercial benefits, as well as the outlook for continued progress.

Three appendices provide supporting information. Appendix A provides a listing of technical and commercial achievements of each completed project. Appendix B provides a discussion of the terminated projects throughout ATP's existence. Appendix $C$ provides a list of the first 100 completed projects and the respective composite performance ratings. The list is sorted in descending order of performance rating, then by company name.

1. For an overview of the first 50 completed projects, see Performance of 50 Completed Projects, Status Report-Number 2, 2001. This study can be found on ATP's website (www.atp.nist.gov).

2. The current edition of the kit and other program materials may be obtained on ATP's website (www.atp.nist.gov), by e-mail (atp@nist.gov), by phone (1-800-ATP-Fund or 1-800-287-3863), or by mail (ATP, NIST, 100 Bureau Drive, Stop 4701, Gaithersburg, MD 20899-4701).

3. The Government Performance and Results Act (GPRA) is a legislative framework for requiring federal agencies to set strategic goals, measure performance, and report on the degree to which goals are met. An overview of the GPRA is provided in Appendix 1 of the General Accounting Office Executive Guide, Effectively Implementing the Government Performance and Results Act, GAO, Washington, D.C., GGD-96-118, 1996 
PART 1

\section{Project Characteristics}

This report provides an overview of the first 100 ATP-funded projects to reach completion. These projects reflect an investment of more than $\$ 408$ million that was shared about equally by ATP and industry.

Of the initial 100 projects, 60 were led by small businesses that submitted single-company-applicant proposals to ATP. Eighty-two involved collaborative relationships with other firms, universities, or both. Slightly more than 75 percent were funded in ATP's General Competitions.

\section{In terms of classification by type, 30 percent of the technologies were "Electronics, Computer Hardware, or Communications." "Manufacturing," "Advanced Materials and Chemicals," and "Information Technology" each accounted for about 20 percent, and "Biotechnology" projects constituted the remaining.}

\section{Single Applicants and Joint Ventures}

"Single-applicant projects," which make up 84 percent of the total included in this report, are those proposed by a single company; these projects were subject to an upper limit on ATP funding of $\$ 2$ million and a time limit of 3 years. The predominance of single-applicant projects in this report occurs for two reasons. First, projects led by single companies make up the majority of all projects. Second, the constraint on the length of single-applicant projects means they end sooner than most joint ventures; thus, they reached completion sooner.

Sixteen percent of the 100 projects were joint ventures. Each of these projects had a minimum of two for-profit companies sharing research and costs for up to 5 years. Typically, the joint-venture membership included other forprofit companies, universities, and nonprofit laboratories. These projects, free of the funding constraint, tended to take on larger problems for longer periods of time.

\section{Project Leaders}

Figure 1.1 illustrates how project leadership of singleapplicant and joint-venture projects was distributed among the various types of organizations. Small companies led most of the projects -60 of the 84 singleapplicant projects and 4 of the 16 joint-venture projects. "Small" follows the Small Business Administration's definition and includes companies with fewer than 500 employees. Large companies-defined as Fortune 500 or equivalent firms-led 15 of the single-applicant projects, or 18 percent, and 4 of the joint ventures, or 25 percent. Medium-sized companies led only seven single-applicant projects and one joint venture. Consortia led four of the joint-venture projects. Nonprofit institutions led two of the single-applicant projects ${ }^{1}$ and three joint ventures.

\section{A Variety of Technologies}

The 100 completed projects fall into the five technology areas used by ATP for classification purposes.

Figure 1.1 Distribution of Single Applicant and Joint Venture Projects by Type of Leadership

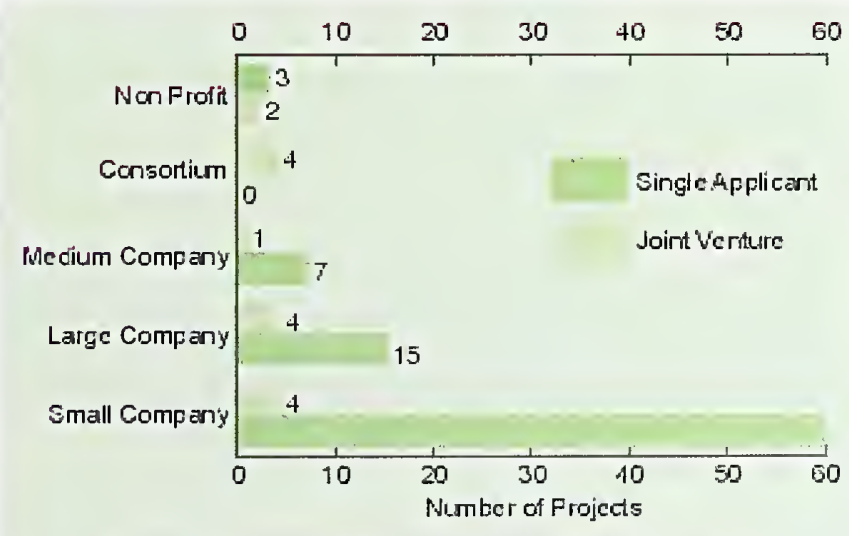

Soure: Achaned Technobgy Program Fret iú Status hepors

\footnotetext{
${ }^{1}$ From the 1991 competition, when nonprofits were eligible to
} lead ATP projects. 


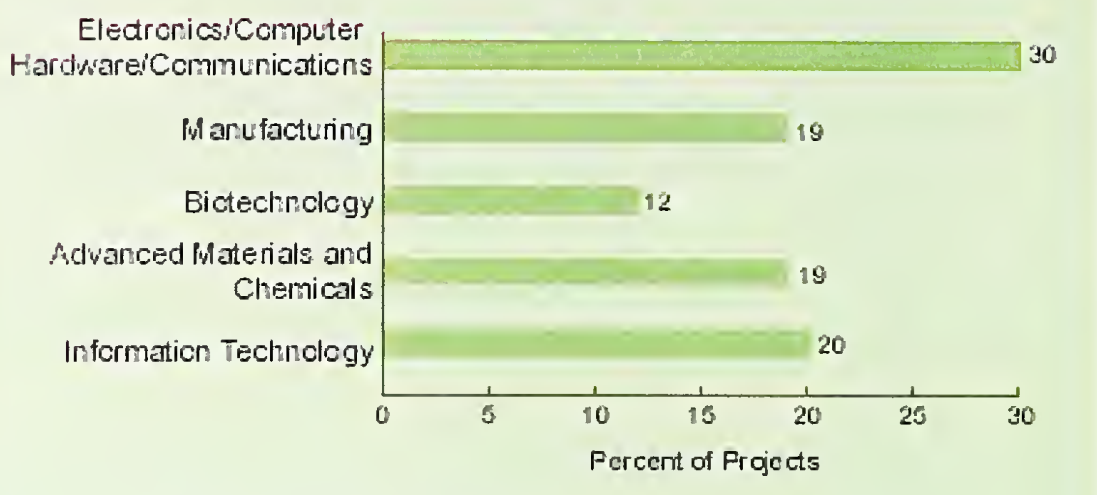

Scurce:Actanced Technolgcy Program Flak 100 status Repons

Figure 1.2 shows the percentages of completed projects by technology area. The highest concentration, accounting for 30 projects, or 30 percent of the total, is in "Electronics, Computer Hardware, or Communications." This category includes microelectromechanical technology, microelectronic fabrication technology, optics and photonics, and other electronics projects.

"Manufacturing," "Advanced Materials and Chemicals," and "Information Technology" account for similar shares, 19 to 20 percent each, of the 100 projects. The Manufacturing category includes areas such as energy conversion and energy generation and distribution, in addition to machine tools, materials handling, intelligent control, and other discrete manufacturing. The Advanced Materials and Chemicals category includes the subcategories of energy resources/petroleum, energy storage/fuel cell, battery, environmental technologies, separation technology, catalysis/biocatalysis, and other continuous manufacturing technologies, as well as metals and alloys, polymers, building/construction materials, and other materials.

The lowest concentration of projects is in the area of Biotechnology, which accounts for 12 percent of the 100 projects. The category of biotechnology includes areas such as bioinformatics, diagnostic and therapeutic, and animal and plant biotechnology.

The technology make-up of these 100 projects differs from that of the larger ATP portfolio of projects in part because the composition of ATP applicants and awardees over time may change. Of the first 100 completed projects, 77 percent come from ATP's General Competitions that were open to all technologies, while 23 percent come from ATP's focused program competitions, which were held from 1994 through 1998. These competitions funded technologies in selected areas of focus, such as in Motor Vehicle Manufacturing Technology and Digital Video in Information Networks. It should be noted that while the five major technology areas are used to classify the projects, most of the projects are not easy to classify. Most ATP projects involve a mix of technologies and interdisciplinary knowhow.

\section{Collaborative Activity}

Although only 16 percent of the 100 projects were joint ventures, 82 percent of all projects had collaborative arrangements. As shown in Table 1.1, 42 percent of the projects involved close research and development (R\&D) ties with universities. Fifty-one percent reported collaborating on R\&D with companies or other nonuniversity organizations. Slightly more than half the projects formed collaborative relationships with other organizations for commercial pursuit of their ATP-funded technologies. Twenty-six percent of projects had collaborative relationships with both universities and nonuniversities for either R\&D or commercial purposes.

For more detail, Figure 1.3 illustrates the types of collaboration undertaken by projects with different forms of project leadership. It highlights the fact that under all forms of project leadership, projects were highly likely to involve collaboration with other companies. About 35 percent of the projects led by small and large companies involved university collaboration, while the share rose to 62 percent for projects led by medium-sized companies, and 75 percent for consortium-led projects.

\section{Costs of the Projects}

As shown in Table 1.2, ATP and industry together invested in excess of $\$ 400$ million on the 100 projects. Overall, they shared almost equally in project costs, with ATP providing a slightly larger share. ATP spent an 


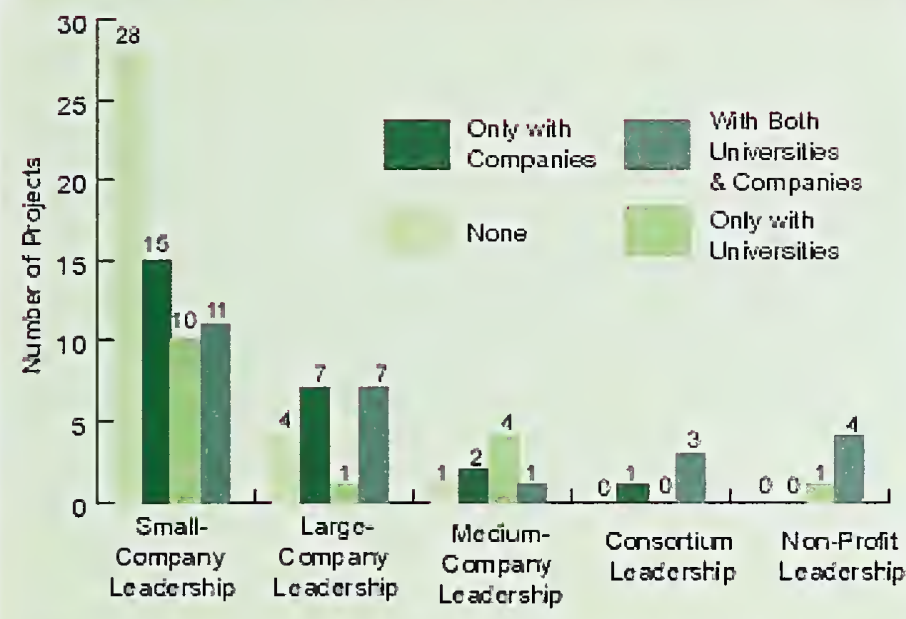

Source:Actance Techolcgy Program Firs ico Stadus Feports

average of $\$ 1.78$ million per single-applicant project and an average of $\$ 3.53$ million per joint-venture project. Across the 100 projects, the average total cost (ATP plus industry) per project was $\$ 4.09$ million. Estimated benefits attributed to ATP from just a few of the 100 projects for which quantitative economic benefits have been provided exceed ATP's funding for all of the 100 projects. In addition, there is considerable evidence of large project benefits that have not yet been quantified.

Approximately two-thirds of single-applicant projects had total research costs under $\$ 3$ million. These projects had an ATP share that ranged from a little more than $\$ .5$ million to $\$ 2$ million. Over 50 percent of the joint-venture projects had total research costs greater than $\$ 3$ million and just under 50 percent were below $\$ 3$ million. Onethird of them had total research costs greater than $\$ 5$ million, and one project had total research costs greater than $\$ 30$ million. ATP's share of these costs were $\$ 2$ million or more for 60 percent of the projects and were $\$ 5$ million or higher for 25 percent. For one of the projects, ATP's share exceeded $\$ 10$ million. Joint ventures, which made up only 16 percent of the total number of projects, accounted for 27 percent of total ATP funding.
Table 1.1 Collaborative Activity

Type of Collaboration

Percentage

Collaborating on R\&D with other companies or nonuniversity $51 \%$ organizations

Close R\&D ties with universities

$42 \%$

Collaborating on R\&D with other companies or nonuniversity organizations OR close R\&D ties $67 \%$ with universities

Collaborating with both universities and nonuniversity organizations

Collaborating on commercialization with other organizations

Collaborating in one or more of the ways identified above

$82 \%$

Note: This assessment of collaborative relationships likely understates the number because it focused on the project's lead organization and probably missed some of the informal collaborative relationships of other participants.

Source: Advanced Technology Program First 100 Reports 
Table 1.2 ATP Funding, Industry Cost Share, and Total Costs of 100 Completed Projects

Single Applicant

Projects

ATP Funding ( $\$$ millions)

Industry Cost Share (\$ millions)

Total Project Costs $(\$$ millions)

ATP Share of Costs

Industry Share of Costs

Average Project Funding

Provided by ATP ( $\$$ millions)

Average Project Cost-Share

Provided by Industry (\$ millions)

Average Project Funding

Provided Overall (\$ millions)
149.6

146.8

296.4

$50 \%$

$50 \%$

1.78

1.75

3.53
Joint Venture Projects

56.4

55.8

112.2

$50 \%$

$50 \%$

3.53

3.49

Source: Advanced Technology Program First 100 Status Reports
2.06

2.03

Total Projects

206.0

202.6

408.6

$50 \%$

$50 \%$

4.09 


\section{PAR T 2}

\section{Gains in Technical Knowledge}

One of ATP's major goals is to build the nation's scientific and technical knowledge base. Each of the first 100 completed ATP projects targeted a number of specific technical goals designed to achieve a new or better way of doing things. The knowledge created by each project is the source of its future economic benefit, both for the innovator and for others who acquire the knowledge. It is a good starting place for assessing completed projects.

\section{New Technologies and Knowledge Gains}

Knowledge gains by the 100 projects are diverse and encompass, within their wide range, the following: mathematical algorithms underlying new software tools; the science of growing human tissue; new techniques for fabricating high-temperature superconducting devices; optical technology for increasing brightness and clarity of miniaturized and projected displays; and new chemical formulations. Advances were made in each of the five major technology areas.

The technologies developed in the 100 projects are listed in column B in Tables A.1-A.5 in Appendix A. The set of tables provides the reader with a convenient, quick reference to the entire range of technologies. The entries are arranged alphabetically, using the five technology areas shown in Figure 1.2. As was mentioned earlier, most of these projects are interdisciplinary, involving a mixture of technologies and generating knowledge in multiple fields.

Even those projects that were not fully successful in achieving all of their research goals, or those that have not been followed by strong progress in commercialization, have achieved knowledge gains. Moreover, some of the projects carried out by companies that have since ceased operations or stopped work in the technology area yielded knowledge, as indicated primarily by the presence of publications and patents. In these cases the direct market routes of diffusion of knowledge gains through commercialization by the innovators are likely lost. However, the indirect routes-whereby others acquire and use the knowledge-remain.

\section{Of What Significance Are the Technical Advances?}

Measuring the significance of technical advances is challenging. One factor that challenges measurement is the length of elapsed time that typically separates an R\&D investment and its resulting long-term outcomes. In the interim period, various short-run metrics may serve as indicators that project results appear to be on track toward achieving long-term goals. One metric that has been used to signal the significance of a project's technical achievements is formal recognition in the form of an award from a third-party organization.

Twenty awards for technical accomplishments were made to participants for achievements related to ATPfunded projects. Participants in 13 of the 100 projects received awards for their technical achievements. Participants in five of the projects received multiple technical awards. Table 2.1 lists the awards made to these projects by third-party organizations in recognition of their technical accomplishments. 
Table 2.1 Outside Recognition of Technical Achievements of the First 100 Completed Projects

Project Awardee
American
Superconductor
American
Superconductor
Communication
Intelligence \#1

DuPont

Ebert Composites

Engineering Animation

Engineering Animation

Engineering Animation

Engineering Animation

HelpMate Robotics

HelpMate Robotics

Illinois Superconductor

Illinois Superconductor

Integra Life Sciences

Molecular Simulations

NCMS

Perceptron (formerly

Autospect, Inc.)

Strongwell Corporation

X-Ray Optical Systems

(XOS)

X-Ray Optical Systems

(XOS)
Year Awarding Organization

1996

1996

1997

1993

1999

1994

1995

1995

1996

1997

1997

1996

1997

1999

1996

1994

1998

1998

1995

1996

$R \& D$ Magazine

Industry Week Magazine

Arthritis Foundation

Microwave \& Rf Magazine

Civil Engineering Research Foundation

Computerworld Magazine

Association of Medical Illustrators

International ANNIE Awards

Industry Week Magazine

Discover Magazine

Science Technology

Foundation of Japan

\section{Microwave \& Rf Magazine}

American Ceramic Society

New Jersey Research and Development Council

\section{Computerworld Magazine}

Institute for Interconnecting \&

Packaging Electronics Circuits International Body Engineering Conference Composite Fabricators Association Conference

$$
R \& D \text { Magazine }
$$

Photonics Spectra Magazine
Award

One of the 100 most important innovations of the year.

Technology of the Year award.

"Ease-of-Use Seal of Commendation" for the development of natural handwriting technology for use by disable people who have trouble with keyboard entry. One of the Top Products of 1993, for high-temperature superconductivity component technology.

Charles Pankow Award for Innovation in Civil Engineering.

Smithsonian Award for the use of information technology in the field of medicine.

Association of Medical Illustrators Award of Excellence in Animation.

Finalist, received jointly with Walt Disney, for best animations in the film industry.

One of the 25 Technologies of the Year

for interactive $3 D$ visualization and dynamics software used for product development.

One of 36 finalists for Technology of the Year for the HelpMate robot used in hospitals.

Japan Prize to CEO Joseph Engelberger for "systems engineering for an artifactual environment."

One of the Top Products of 1996 for cellular phone site filters and superconducting ceramics.

Corporate Technical Achievement Award.

Thomas Alvin Edison Award to Dr. Kohn of Rutgers University for his collaborative work with Integra on the project.

Finalist for Smithsonian Award, the 1996 Innovator Medal.

Best Paper of Conference Awards.

Best Paper Award.

Best of Show Award.

R\&D top 100.

Photonics Circle of Excellence Award.

Source: Advanced Technology Program First 100 Status Reports 


\title{
Dissemination of Knowledge
}

\author{
If knowiedge from the projects is disseminated-either through products and processes \\ commercialized by the innovators or through publications, patents, and other modes of knowledge \\ transfer-it may benefit other producers in the economy and, subsequently, consumers. The resulting \\ national benefits may go far beyond the returns to the innovating firms and the benefits to their \\ customers.
}

\section{Multiple Ways of Disseminating Knowledge}

New knowledge developed in a project can be diffused in a variety of ways. This section discusses two principal means: through patents filed and granted by the U.S. Patent and Trademark Office (USPTO) and cited by others, and through preparation of technical papers that are published or are presented at conferences.

Collaborative activity among research and commercial partners, treated in Part 1, is another way by which knowledge is disseminated. Another way is through the observation and reverse engineering of the new goods or services produced directly by the innovators and their partners, discussed in Part 4. Among the other important ways - not explicitly covered here-in which knowledge developed in a project can be diffused are informal interactions among researchers, suppliers, customers, and others; movement of project staff to other organizations; distribution of nonproprietary project descriptions by government funding agencies; and project-related workshops and meetings.

Pathways of knowledge dissemination allow others to obtain the benefits of R\&D without having to pay its full cost. When the technology is particularly enabling-in the sense of providing radically new ways of doing things, improving the technical bases for entire industry sectors, or being useful in many diverse areas of application-the spillover benefits to others are likely to be particularly large. ${ }^{2}$

\footnotetext{
${ }^{2}$ The generation of spillover benefits, or positive externalities, from technological advancement is an important argument for public support of enabling technologies.
}

\section{Balancing Intellectual Property Protection and Knowledge Dissemination}

ATP encourages broad dissemination of knowledge produced in ATP-funded projects because it increases the number of potential users of the knowledge and, therefore, may increase national benefits. At the same time, ATP does not force innovating companies to compromise their ability and willingness to pursue early commercial applications of the technology by giving away all of their intellectual property. After all, these companies, which contribute a substantial share of the costs, have agreed to tackle difficult research barriers and to take the technology to the marketplace as rapidly as possible.

Thus, it is not surprising that the amount of knowledge dissemination varies among the projects. Most of the projects pursue some forms of deliberate knowledge dissemination, such as publishing scientific papers, giving presentations, and forming collaborative relationships. Most projects also engage in considerable unintended knowledge dissemination; for example, as a company's scientists move and work among other companies and universities; as myriad formal and informal discussions occur; as others reverse-engineer their products; and through mergers and acquisitions of the innovating companies.

\section{Public Disclosure of Patent Filing Information}

When applying for a patent to protect intellectual property, an inventor must explicitly describe the invention. Because patent law requires that the invention is both novel and useful, the inventor must demonstrate that the invention is essentially different from any other invention and must describe how it can be used. When the USPTO grants a patent, the full application text 
Figure 3.1 Distribution of Projects by Number of Patents Filed

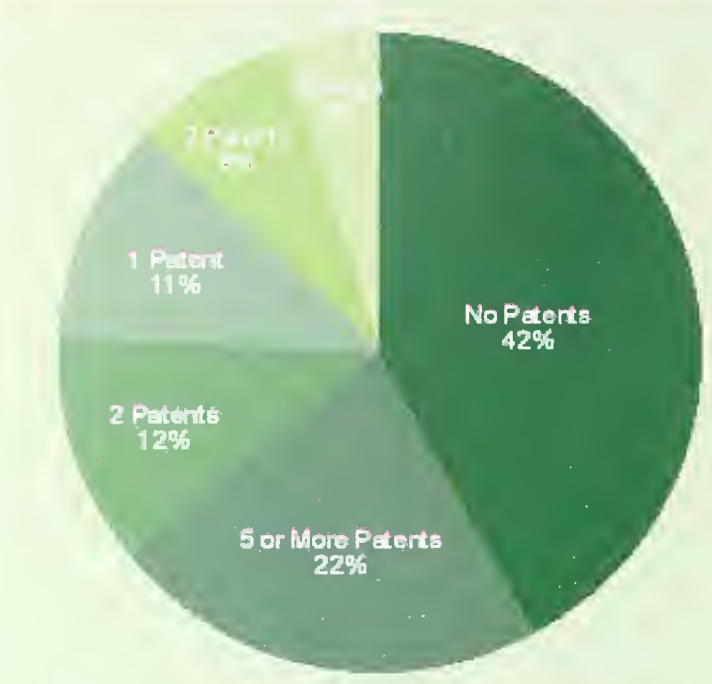

Sourc: Advanced Technalogy Frogram Firs 100 Status Recorts

describing how the invention may be used and how it is related to other technologies is put into the public record and becomes a medium through which knowledge is transferred to others. Hence, patents serve to disseminate knowledge.

At the same time, patent data are not perfect signals of knowledge creation and dissemination. Despite the limitations, patent statistics serve as useful indicators of knowledge creation and dissemination, and they are widely used by researchers. The decision to seek patent protection for intellectual property is influenced by many factors, including the ease with which others can copy the property's intellectual content and the difficulty of defending the patent position from infringement. Some companies may decide that patent protection is not worth its expense or that a strategy of trade secrets and speed-to-market is more effective. Conversely, patents may be filed as the basic ideas are forming, and trade secrets used in later stages. Furthermore, the importance of patents as a strategy varies among technology areas; for example, patents figure more strongly in electronics and manufacturing than in computer software. The absence of a patent does not mean that intellectual property was not created. But the presence of a patent is a signal that it was created.

Of the 100 completed projects, 58 had filed 326 patents at the time the study data were collected. ${ }^{3}$ Fifty-one of

\footnotetext{
${ }^{3}$ Patents filed and not yet granted are included here, in addition to those filed and granted, despite the fact that there is no public disclosure until patents are actually granted. The reason for including patents filed and not yet granted is to help offset the problem that there are substantial differences across industries in the lag time between patent filing and granting.
}

the projects had among them a total of 202 patents granted, or 60 percent of the total filed. Twenty-two of the projects had filed a total of 124 patents for which a final decision on granting was still pending.

Figure 3.1 displays the distribution of the 100 projects by the number of patents filed, whether granted or not yet granted. More than half the projects have filed one or more patents. Participants in 11 percent of projects had filed a single patent, 25 percent had filed 2 to 4 patents each, and 22 percent had filed 5 or more patents. Fortytwo percent of the projects had yet to file a patent.

\section{Knowledge Disseminated by Patents as Revealed by Patent Trees}

Each published patent contains a list of previous patents and scholarly papers that establish the prior art as it relates to the invention. The citations provide a way to track the spread of technical knowledge through patents granted to ATP-funded projects. By following the trail of the patent referenced, it is possible to construct what looks much like a horizontal genealogy tree.

Once the pool of ATP-related patents was identified, computerized tools made available by the USPTO were used to track subsequent patents that refer to each of the ATP-related patents as prior art and the links recorded. ${ }^{4}$ The process is then repeated in turn for each of these patents, until the chain of references is complete. Next, the information is converted into a graphic format that illustrates the diffusion of knowledge along the path from ATP project patents in the tree.

With the passage of additional time, new branches may emerge as outgrowths of earlier patents. To the extent that later patents are dependent on the earlier ones, the patents in the tree represent developments in knowledge that would not have occurred, or at least not in the same timeframe, had ATP not stimulated the creation and dissemination of that platform knowledge.

\section{Patent Tree Illustrating International Knowledge Dissemination}

Figure $3.2^{5}$ is a patent tree for 1 of the 100 completed projects, a project to develop liquid solder-jetting carried out by MicroFab Technologies, Inc., a small company based in Plano, Texas.

\footnotetext{
${ }^{4}$ The references to prior patents contained in a published patent are based on information supplied by the applicant and on research by USPTO researchers. There is no way to distinguish between the two sources and no indication that one tends to dominate the other. (USPTO telephone interview with ATP staff, February 11, 2000.)

${ }^{5}$ Patents highlighted in pink are assigned to foreign companies.
} 
Figure 3.2 Patent Tree for MicroFab Technologies, Inc. Patent 5,772,106

Project Impact through Knowledge Dissemination

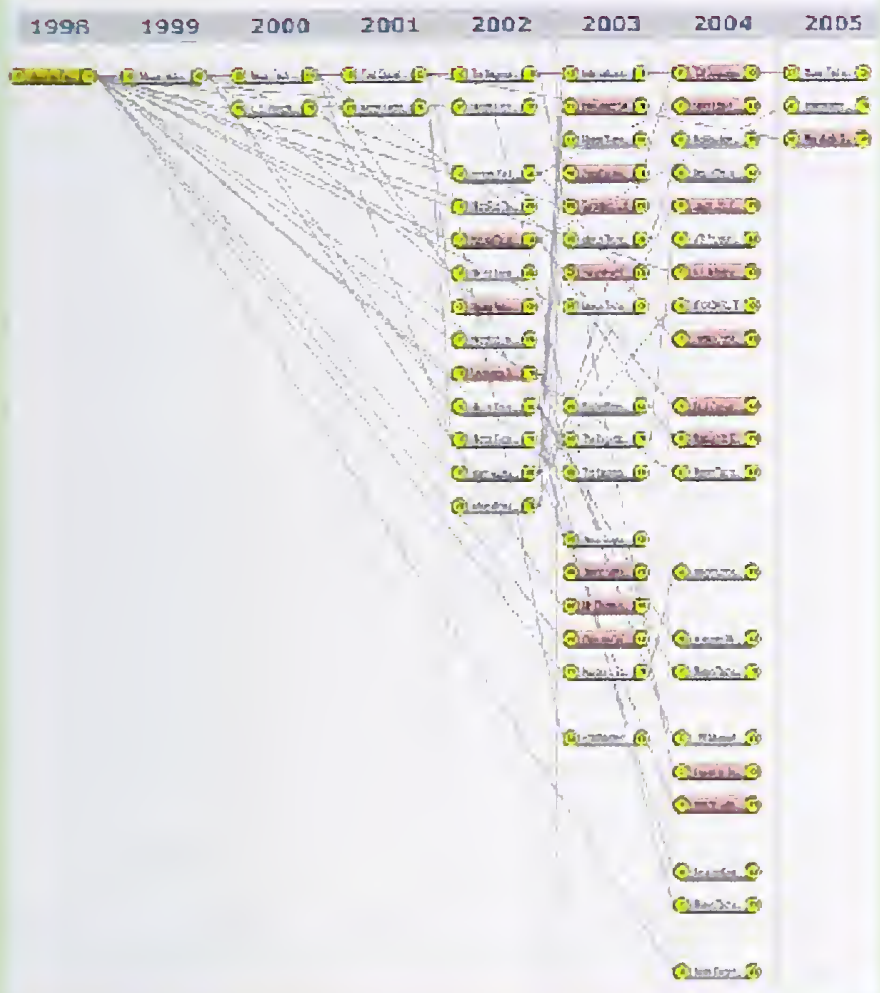

The company received five patents for technologies resulting from its ATP-funded project. Patent number $5,772,106$, granted in 1998 and entitled "Printhead for liquid metals and method of use," involved a printhead assembly used for depositing molten solder droplets, without the need for fluxes and without conducting the operation in a confined chamber, into a semiconductor substrate. In the following 6 years, 19 patents that directly cited the MicroFab patent were granted to 13 companies. Some of the companies that benefited from the knowledge were Hewlett Packard Company, Micron Technology, Inc., and Ferro Corporation from the United States, as well as Unimicron Technology Corporation, Ltd. from Taiwan, Kuroda Techno Corporation and Olympus Optical Company Ltd. from Japan, and Luk. Automobiltechnik $\mathrm{GmbH}$ \& Company from Germany. At the end of 2004, a total of 56 patents, which directly or indirectly cite the MicroFab patent, were granted to companies from 8 countries, including France, Sweden, Korea, and the Netherlands.
As explained in the project status report for MicroFab Technologies, Inc., the ATP award was instrumental in allowing the company to collaborate with and attract additional funding from a consortium of five major electronics manufacturers (Motorola, Delco, Texas Instruments, Kodak, and AMP) to further develop its technology. These relationships also had the potential to improve the ultimate diffusion of the technology.

The patent tree in Figure 3.3 shows citations of a patent that came out of an ATP-funded project led by TopicalNet, Inc. (formerly Continuum Software) during which they developed MultiPly ${ }^{\mathrm{TM}}$, a technology allowing business programmers to develop scalable business applications without having to learn parallel programming. Though TopicalNet achieved technical success, at the time the project was completed, venture capital was not available because the computer industry was focused on $\mathrm{Y} 2 \mathrm{~K}$ compliance. This situation made it difficult for the small start-up company to market its innovative software application. For this and other reasons, TopicalNet did not market MultiPly ${ }^{\mathrm{TM}}$.

The patent tree illustrates how an ATP-funded project whose direct path appears to have slowed or has come to a standstill nevertheless has the potential to remain influential along an indirect path of knowledge utilized and cited in subsequent patents. As the patent tree illustrates, a number of other companies are referencing the TopicalNet patent, and the potential for beneficial impact from the research continues. (See http://statusreports-atp.nist.gov/reports/94-06-0034.htm.)

Figure 3.4 shows citations by other companies of a patent resulting from a project led by Ingersoll Milling Company. Though the company went bankrupt, the patent tree illustrates how knowledge can outlive its creator and continue to be disseminated. An observer who equates business success of the innovator, one-toone, with ATP project success may be mistaken, because the indirect path may nevertheless produce important benefits.

Figure 3.3 Patent Tree for TopicalNet (formerly Continuum Software) - Patent 5,999,729

Project Impact After Innovator Reduced Activity
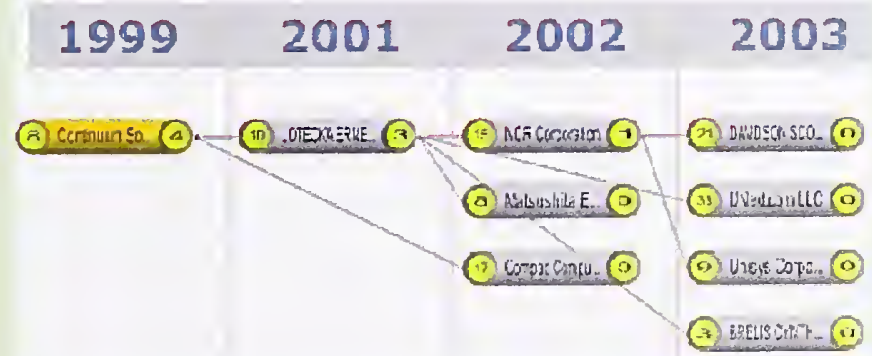
Figure 3.4 Patent Tree for Ingersoll Milling Company - Patent 5,392,663

Project Impact Where Innovator Went Bankrupt

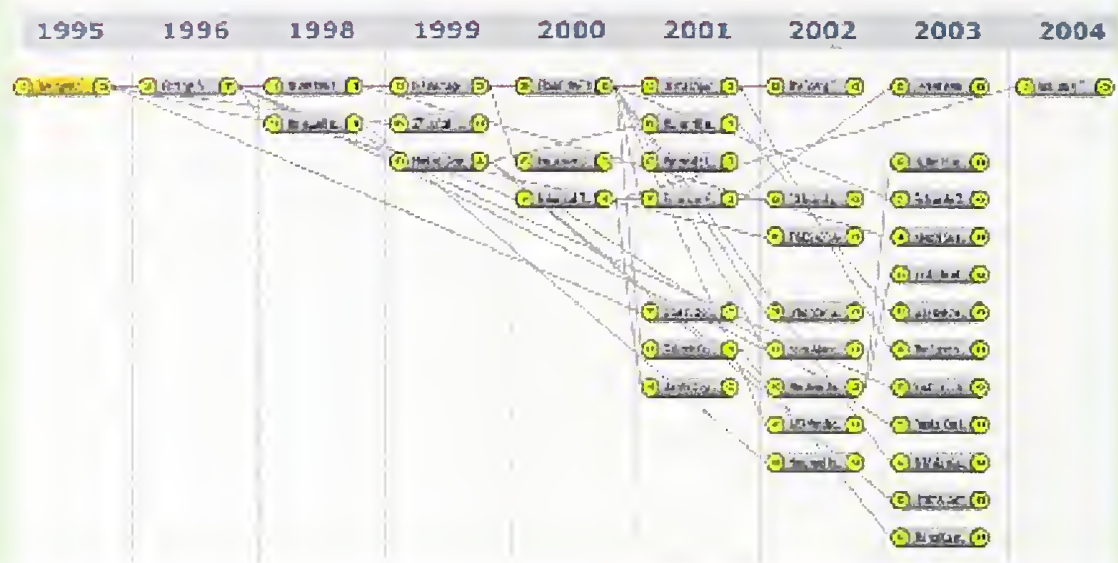

Figure 3.5 Patent Tree for Hynomics (formerly Sagent Corporation) - Patent 5,963,447

Example of Extensive Knowledge Flows

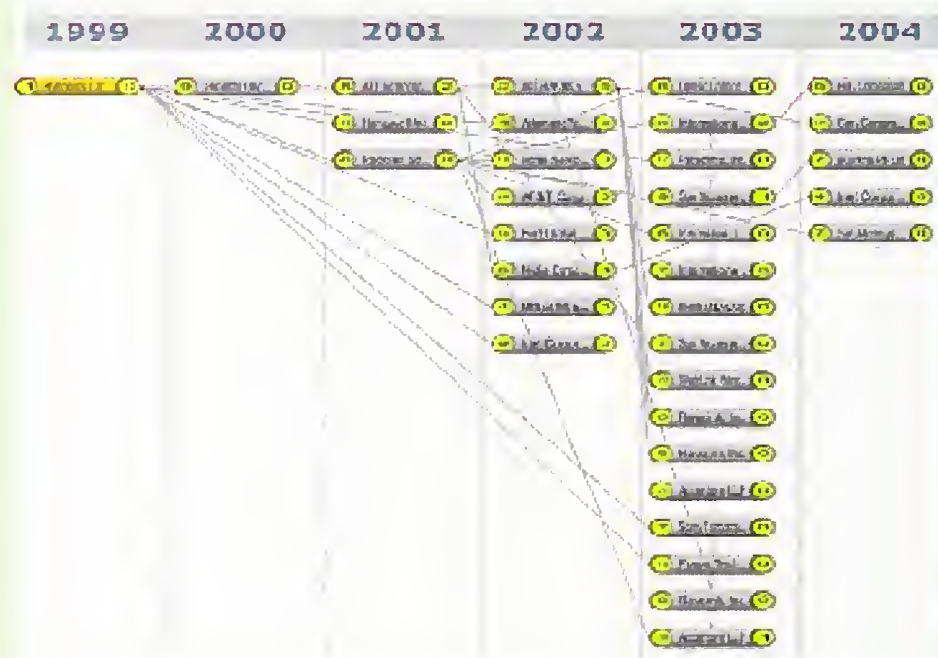

Patent Tree Illustrating Extensive Knowledge Flows

Figure 3.5 illustrates just how complex knowledge dissemination through patent citations can become. The path shown is for a patent resulting from an ATP-funded project led by Hynomics (formerly Sagent Corporation). The project developed a workforce optimizer and people scheduler using hybrid systems, automata, and control theory. Hynomics has entered into a number of partnerships involved with commercializing their technology. As shown in the patent tree, the work has generated substantial interest as demonstrated by the number of citations of their patent.

For projects that have received a patent or patents, access to patent trees is available through the individual status reports on the NIST ATP website (http://statusreports-atp.nist.gov/basic_form.asp). All patent trees for the first 100 status reports were updated as of June 2004. Although representing only one aspect 
of knowledge dissemination, the patent trees extend awareness of the influence of the new knowledge.

\section{Knowledge Dissemination through Publications and Presentations}

Participants in almost 60 percent of the 100 projects had published or had presented papers in technical and professional journals or in public forums. Participants in about half of all projects had published, and the number of publications totaled at least 393 papers. Participants in nearly 40 percent of the projects had given projectrelated presentations, and the number of presentations totaled at least 443. Overall, publications and presentations for these 100 projects equaled or exceeded 836.

Figure 3.6 gives the distribution of projects by their numbers of publications and presentations. Thirty-five percent of the projects each had between one and five papers published or presented. Seven percent had between 6 and 10 papers published or presented, and another 7 percent had between 11 and 20. At the high end, 10 percent of projects each had more than 20 papers published or presented. Forty-one percent had no known presentations or publications.

\section{Knowledge Dissemination through Other Means}

Aside from publishing, presenting, and patenting, ATPfunded projects have a high rate of collaborative activities. Eighty-two percent of the projects showed some type of collaboration (see Table 1.1). With so many partners, collaborators, and subcontractors involved, it would be difficult to secure the information. The involvement of so many participants in the projects

Figure 3.6 Distribution of Projects by Number of Publications and Presentations

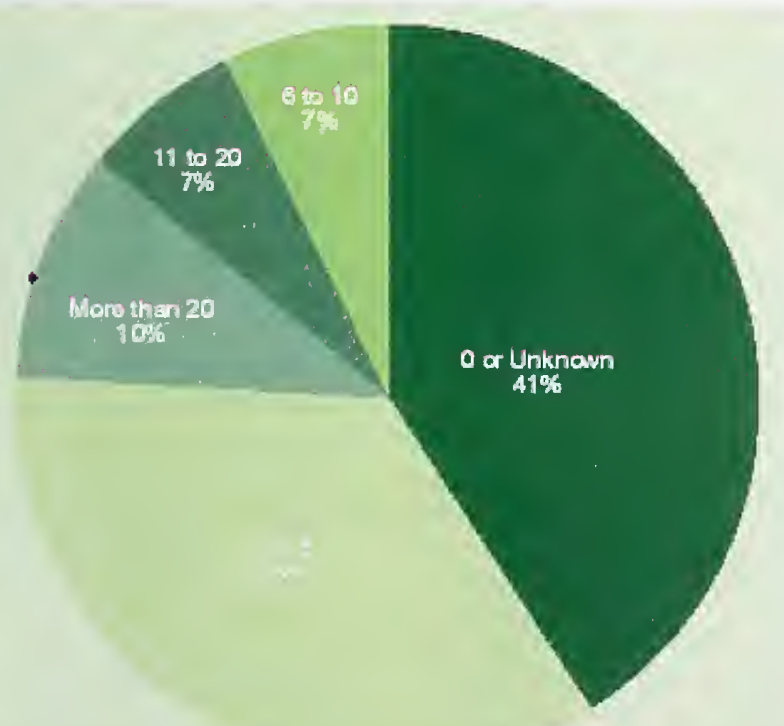

provides rich avenues of further interaction, and those interactions in turn may increase knowledge flows through personal and professional contacts.

When the government enters into an agreement with an organization, certain information about the agreement is generally made public. Such is the case with ATP and company cost-sharing partnerships. Nonproprietary information has been disclosed to the public for each of the 768 projects funded by ATP in 44 competitions held from 1990 through September 2004 (project information is available on the ATP website ${ }^{6}$ ). Further, new nonproprietary project descriptions are added to the site as new awards are made. Evaluation reports, such as this one, are also available at ATP's website and provide information to the public.

ATP organizes and sponsors public workshops, where companies present non-confidential aspects of their ATP-funded research and engage in open discussions. These workshops facilitate information flow among ATP award recipients and from the recipients to other companies, ATP project managers, other government program managers, the press, potential investors, and universities. Public meetings, presentations by ATP staff, and other events are posted at ATP's website.

When a product or service incorporating new technology reaches the marketplace, a buyer can learn a great deal about the technology. The mere functioning of a new product reveals some information. Intentional investigation, including reverse engineering, reveals even more. More than 60 percent of the 100 projects reviewed for this study had some commercial products or processes based on ATP-funded technology already on the market. Therefore, product use and examination are providing others with information about the new technologies.

\footnotetext{
${ }^{6}$ http://jazz.nist.gov/atpcf/prjbriefs/listmaker.cfm or http://atp.nist.gov (go to Funded Projects Database).
} 


\section{PART 4}

\section{Commercialization of the New Technology}

New technical knowledge must be used if economic benefits are going to accrue to the nation. This generally means that a new product or process is introduced into the market by the innovating firm, its collaborators, or other companies that acquire the knowledge. In competitive markets, the producer is typically unable to capture all the benefits of a new product or process, and the consumer reaps part of the benefits. The higher up the supply chain the innovation occurs, the more value-added steps there are before final consumption, and the more intermediate firms in the supply chain may benefit, in addition to the final consumer. ${ }^{7}$ It is through commercialization that society reaps the benefits of new technology, such as reduced product costs, improved efficiency, enhancments to health and welfare, and economic growth.

Commercialization of Products and Processes-A Critical Step Toward National Benefits

Sixty-four of the projects had already spawned or expected to bring to market 143 new products or processes when the data for this report were collected. Companies in 13 additional projects expected to achieve their first commercialized results shortly ${ }^{8}$, and companies in 14 projects that had already commercialized their technology expected to add new products and processes soon. Thus, 77 percent of the projects had spawned one or more products or processes in the market or were expected to do so shortly, for a total of 161 products or processes either on the market or expected shortly after the time the data were collected. Table 4.1 summarizes the commercialization results.

A number of additional years have passed since the data for the first 50 projects were collected. Since that time, further developments have doubtless occurred with these projects, which have changed their commercialization results. This overview reports commercial progress of the first 100 projects, all at approximately comparable times following their completion.

\section{A Quick Glance at the New Products}

A variety of new products and processes resulted from the projects. For a convenient, quick reference, brief descriptions of the new products or processes for each project are listed in column C in Tables A.1-A.5 in Appendix A. For each new product or process, the new technology on which it is based is also listed in the tables, in column B.

\section{Commercialization: A Critical Step, but Not the Final Word}

Commercializing a technology is necessary to achieve economic benefit, but it does not ensure that the project is a full success from the perspective of either the company or ATP. Widespread diffusion of the technology may or may not ultimately follow the initial commercialization. Nevertheless, it is significant that these products and processes are actually on the market.

\footnotetext{
${ }^{7}$ For a detailed treatment of the relationship between spillover benefits (knowledge, market, and network spillovers) and commercialization, see Adam B. Jaffe, Economic Analyses of Research Spillovers: Implications for the Advanced Technology Program, GCR 96-708, (Gaithersburg, MD: National Institute of Standards and Technology, December 1996). He notes: "Market spillovers will not be realized unless the innovation is commercialized successfully. Market spillovers accrue to the customers that use the innovative product; they will not come to pass if a technically successful effort does not lead to successful commercialization" (p. 12). In commenting on spillovers that occur because new knowledge is disseminated to others outside the inventing firm, he observes: "Note that even in the case of knowledge spillovers, the social return is created by the commercial use of a new process or product, and the profits and consumer benefits thereby created" (p. 15).

8 "Shortly" refers to the time when the question is asked. Since Status Reports are written about 5 years after ATP funding ends, the perspective is the same for all status reports. So, when a company answers that they expect a product or process on the market soon or shortly, they are referring to new product commercialization in the next 3 to 12 months.
} 
Table 4.1 Progress of Participating Companies in Commercializing the New Technologies

Degree of Progress

$$
\begin{gathered}
\begin{array}{c}
\text { Number } \\
\text { of } \\
\text { Projects }
\end{array} \\
\text {. }
\end{gathered}
$$

Number of

Products/

Processes

Products/Processes On

the Market and Expected

Soon

Products/Processes On

the Market with None

Expected Soon

No Products/ Processes

On the Market with At

Least One Expected Soon

Total Products/Processes

On the Market or Expected

Soon

14

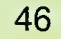

50

Source: Advanced Technology Program First 100 Status Reports

\section{Rapidly Growing Companies}

Rapid growth often signals that a small innovating company is on the path to taking its technology into the market, and one dimension of company growth typically is its employment gains. ${ }^{9}$

Figure 4.1 shows employment changes at the 60 smallcompany, single-applicant ATP award recipients. ${ }^{10}$ Twenty-eight percent of these companies experienced job growth in excess of 500 percent from the beginning of the project until several years after the project had completed. Thirty-six percent-the largest shareexperienced job growth in excess of 100 percent, ranging up to 500 percent.

Not all the small companies grew. A little less than onefifth of them experienced no change or a decrease in staff. Several of the companies that were small when they applied to ATP grew so rapidly they moved out of

\footnotetext{
${ }^{9}$ Employment within the small companies is considered here as an indicator of commercial progress. Assessing macroeconomic employment gains from the technological progress stimulated by the 100 projects is beyond the scope of this report.

${ }^{10}$ Employment changes in joint ventures, larger companies, and nonprofit organizations are less closely tied to the success of individual research projects, and, therefore, are not included in the employment data in Figure 4.1.
}

the small-size category. As a group, of the 60 small single-applicant companies, 39 companies at least doubled in size; 12 of them grew more than 1,000 percent. ATP helped these companies develop advanced capabilities, which they subsequently leveraged into major businesses.

For example, Vitesse had approximately 200 employees when it applied to ATP, but had nearly 800 at the time it was profiled for inclusion in the 2001 report of ATP's first 50 completed projects. Now the company has more than 900 employees. ${ }^{11}$ Another, Cree Research, Inc., had 41 employees at the project start, 210 when it was included in the 2001 report of the first 50 completed projects, and now it has more than 1,000 employees. ${ }^{12}$ Yet another, Integra LifeSciences, grew from 32 employees at the beginning of the project to 129 at the time the data were collected for the second 50 completed projects, to 760 as currently reported. ${ }^{13}$ At least one of the companies that was quite small at the time it applied to ATPGelTex Pharmaceuticals, Inc. - has since changed size categories as a result of being acquired by a large company, Genzyme.

The following examples illustrate the potential impact of ATP funding on the technological and commercial prospects of funded companies.

Digital Optics: In the late 1990s, as the labor-intensive integration and packaging of optoelectronic components was causing customer costs to rise, Digital Optics faced the prospect of a loss of business to inexpensive overseas competition. Supported by $\$ 1.7$ million in ATP funding, Digital Optics achieved its goal of developing an integrated micro-optical systems (IMOS) R\&D initiative that resulted in its commercial launch of the patented Photonic Chip ${ }^{\mathrm{TM}}$.

The company, which grew from a staff of 35 at the project's start to 130 employees as of December 2001, has applied for 42 patents since the project launch and has become the leader in integrated optical modules. Well respected in the marketplace, its technology is positioned to become the primary production method for integrated optical subassemblies (OSAs). Moreover, with the financial resources necessary to anticipate market trends and act on emerging opportunities, the company has taken the steps necessary to pursue new opportunities in the data storage, telecommunications, and data communications markets.

\footnotetext{
${ }^{11}$ Current employment data were obtained from Market Guide, Inc. (2003), an on-line database of descriptive and financial information on publicly traded companies.

${ }^{12}$ Market Guide, Inc. (2003).

${ }^{13}$ Ibid.
} 
Figure 4.1 Employment Change at Small Companies that Received a Single-Applicant Award

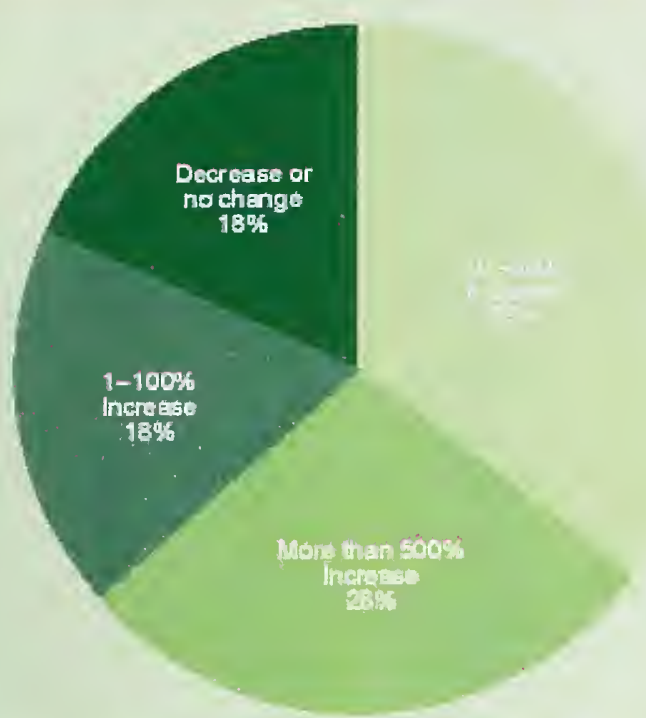

Source: Advanced Technolog Frogram Firt 100 Stafus Reports

Although the telecommunications market contraction since 2001 has created a less than optimal environment in which to market new technologies, the company has experienced continued growth and has outperformed its competitors. Once current adverse market conditions begin to subside, the Photonic Chip ${ }^{\mathrm{TM}}$ and its IMOS technology will position Digital Optics to compete successfully for new customers and play a leading role in further advances in optical integration.

Displaytech, Inc.: Continued, rapid advancements in emerging large- and small-screen display applications (as well as consumer expectations of these products and their prices) created a need for technology to replace traditional Liquid Crystal Displays (LCDs). The nextgeneration solution had to be smaller, faster, and deliver more power while using less power. Displaytech invented and demonstrated just such a solution in Ferroelectric Liquid Crystal (FLC) technology. However, it had to overcome significant capital obstacles to put its new manufacturing process strategy in practice. To meet that challenge, the company proposed a new process that could reduce the net cost per unit by 99 percent and increase the daily yield from 4 to 500 units per operator. A two-year ATP award of $\$ 1.7$ million made the successful launch of this manufacturing process possible and led to the commercialization of a new line of devices. Without this funding, the best-case scenario was a cost reduction of 80 percent.

The company's success extended beyond development of the technology required to mass-produce FLC display chips to significant process improvements that generated a 600-percent increase in image quality, a 100-percent extension of product lifetime, and a 97.4percent reduction of cost per unit (from $\$ 6,000$ to $\$ 160$ ). These achievements increased the number of potential applications for FLCs, both within and beyond the electronics industry, and created an opening for U.S. firms in the Japanese-dominated display market. Displaytech, which grew from 20 employees at the start of the project to a staff of 150 , realized production capabilities of 100,000 displays per month as of early 2000.

Ebert Composites Corporation: When market demand for electricity skyrocketed in the early 1990s, options for increasing supply seemed limited to those that were economically burdensome and/or environmentally unacceptable. Ebert Composites Corporation proposed and successfully created prototypes of corrosion-resistant, lightweight, nonconductive structures. Bar-coded for quick snaptogether construction, they were nearly 50 percent lighter than steel; their advantages also included lower life cycle and installation costs and reduced environmental risks in comparison with steel towers or wooden poles.

Now a joint venture, Strongwell-Ebert, LLC has commercialized the composite structures for electric power poles and lattice towers that are sold and used throughout the United States within the electric power industry and may have market applications in other industries, as well. The company, which had 12 employees at the start of the project, had grown through the joint venture to nearly 865 by September 2004 and had established sales sufficient to fund operations as well as future $R \& D$ projects.

\section{Capital Attraction}

Attraction of additional capital is another signal that a company is positioned to make further progress. Of the 100 projects, 69 had attracted additional capital to further pursue development of their technologies. Additional funding came variously from collaborative partners, venture capitalists, public offerings of stock, other governmental departments including state government programs, and other sources. 


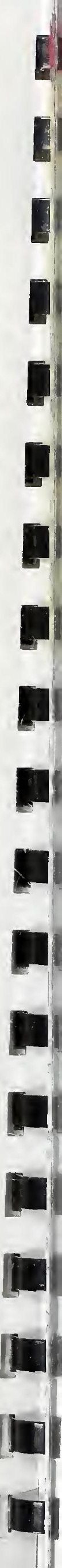




\section{Overall Project Performance}

The individual performance of the 100 completed projects has varied, as, measured by the creation and dissemination of knowledge and the accelerated use of that knowledge for commercial purposes. Some of the award-recipient companies grew by leaps and bounds as they translated their knowledge gains from ATP-funded research into profitable and beneficial products, services, and production processes. Some continued to strive toward hard-to-achieve goals, while others showed little outward signs of further progress. A few that achieved impressive research accomplishments later failed in the commercialization phase. However, the achievements of the more successful projects, with their impressive new performance capabilities resulting in lower costs and higher quality products and processes, appear to have much more than compensated for the less successful projects. There is considerable evidence that the benefits attributable to ATP from the 100 completed projects substantially exceed their costs.

\section{Composite Performance Scores}

During the intermediate period covered by this analysis - after project completion but before long-term benefits have had time to be realized-ATP uses a Composite Performance Rating System (CPRS) to help gain a sense of how projects in the portfolio have performed overall thus far against ATP's mission-driven multiple goals. ${ }^{14}$ In this intermediate period of project life cycles, the focus is on progress toward the goals of 1 ) knowledge creation, 2) knowledge dissemination, and 3) commercialization. The CPRS uses a weighted composite of output data systematically collected for each of the 100 projects-some of which have been presented in aggregate form in the preceding sections of this overview - to assess overall performance of the portfolio of completed projects in this intermediate period.

The output data serve as indicator metrics of progress toward achieving goals. Examples of available indicator metrics signaling progress toward the creation and dissemination of knowledge are a) awards for technical excellence bestowed by third-party organizations, b) patent filings, c) publications and presentations, d) knowledge dissemination from potential reverse engineering of new and improved products/processes on

\footnotetext{
${ }^{14}$ For an in-depth treatment of the CPRS, which was developed in prototype for ATP's use, see Rosalie Ruegg, Bridging from Project Case Study to Portfolio Analysis in a Public R\&D Program, NIST GCR 03-851 (Gaithersburg, MD: National Institute of Standards and Technology, forthcoming).
}

the market or expected soon, and e) collaborative activity. Available indicator metrics signaling progress toward commercialization of the new technology include a) attraction of additional capital, b) employment gains, c) project-related company awards for business success, d) moving products and processes into the market, and e) analysts' outlooks for future progress by the awardrecipient companies.

Weights are assigned to the indicator data, which are combined to produce a composite numerical score that is then converted to a zero- to four-star rating for each project. A score of one star or less signals poor overall performance; two stars, moderate performance; three stars, strong performance; and four stars, outstanding performance. The distribution of CPRS scores computed for each project in a portfolio of projects is then examined, and the results taken as indicative of overall portfolio performance.

The resulting CPRS ratings provide an easy-to-grasp highlighting of portfolio performance in the intermediate period. They call out those projects that have exhibited outstanding or strong outward signs of progress towards long-run program goals during the years covered and those that have exhibited moderate or few signs of progress. However, the ratings are imperfect and should be viewed as only roughly indicative of overall performance.

The performance metrics are consistent with the view of varying degrees of success-with knowledge creation 
and dissemination constituting partial success, and a continuation into commercialization constituting a fuller degree of success in terms of project progress. Some companies carried out their proposed research with a degree of success during the time of ATP funding, but then did not continue pursuit of their project's larger goals after ATP funding ended. At this stage of evaluation, ATP considers such projects only partial successes, because the direct path for achieving project goals is truncated. Such projects are not among the higher scorers in this report. It is possible, however, that developments along the indirect path (diffusion of knowledge from the project through publications, presentations, patents, and licensing) may nevertheless occur-particularly if a project produced effective knowledge transmitters, such as patents and publications. It is also possible that a company may work in secrecy for a long period of time with no visible outputs and then suddenly explode on the scene with a single output that will yield large societal benefits.

Limiting factors include the extent to which not all relevant effects are captured; moreover, the use of indicator metrics is constrained by data availability, the development of the weighting system is empirically driven rather than theoretically based, and the ratings do not directly measure national benefits. The degree of correlation between a project's performance score and its long-run societal benefits is impossible to know at this time. Projects with the same scores are not necessarily equal in their potential benefits. They are, however, somewhat comparable in terms of the robustness of their progress to date.

\section{Scoring the First 100 Completed Projects}

The distribution of CPRS scores for ATP's first 100 completed projects is shown in Figure 5.1. The largest group of projects, 33 percent, fell in the three-star categoryshowing strong progress. Combining these with the 12 percent rated "outstanding," shows an impressive 45 percent of projects performing at a high level.

Twenty-seven percent fell into the two-star category-moderate progress, but not particularly robust overall. Twenty-eight percent of the projects scored one star or less, indicating poor performance overallperhaps not surprising for companies taking on difficult goals.

The 12 top-scoring projects overall include 11 single-applicant projects led by small companies and 1 joint venture led by a consortium. Leaders of these top-scoring projects were Engineering Animation, Inc., Integra LifeSciences, Third Wave

Technologies, X-Ray Optical Systems,
Nanophase Technology Corporation, Cree Research, Inc., Aastrom Biosciences, Inc., Tissue Engineering, Inc., ColorLink, Torrent Systems, Inc., American Superconductor Corporation, and the National Center for Manufacturing Science.

The next tier of 33 strong projects included 28 singleapplicant projects and 5 joint-venture projects. Of the single-applicant projects, 22 were led by small companies, 2 by medium companies, and 4 by large companies. Of the joint ventures, two were led by small companies, one by an industry consortium, one by a large company, and one by a nonprofit organization.

A few projects with low CPRS ratings had impressive technical achievements as indicated by the receipt of a third-party technical award, though most of the technical awards went to those with the highest overall ratings. In contrast, all of the awards for business acumen went to the projects with CPRS ratings of three or four stars.

\section{Performance by Technology Areas}

Overall project performance in the intermediate period covered by the study varied by technology area, as illustrated in Figure 5.2. Of the 12 biotechnology projects, 8 were 3 - or 4-star projects. Of the 30 electronics projects, half scored high. Of the 20 manufacturing projects, close to half scored high, but 45 percent scored low. The 19 projects in the materials group were more evenly divided into high, low, and moderate scorers. The 19 information technology projects had 7 projects that were both moderate and high-scoring projects and 5 low-scoring projects.

Differences in life cycles among the technology areas may account for part of the performance differences, but

Figure 5.1 Distribution of Projects by Star Rating

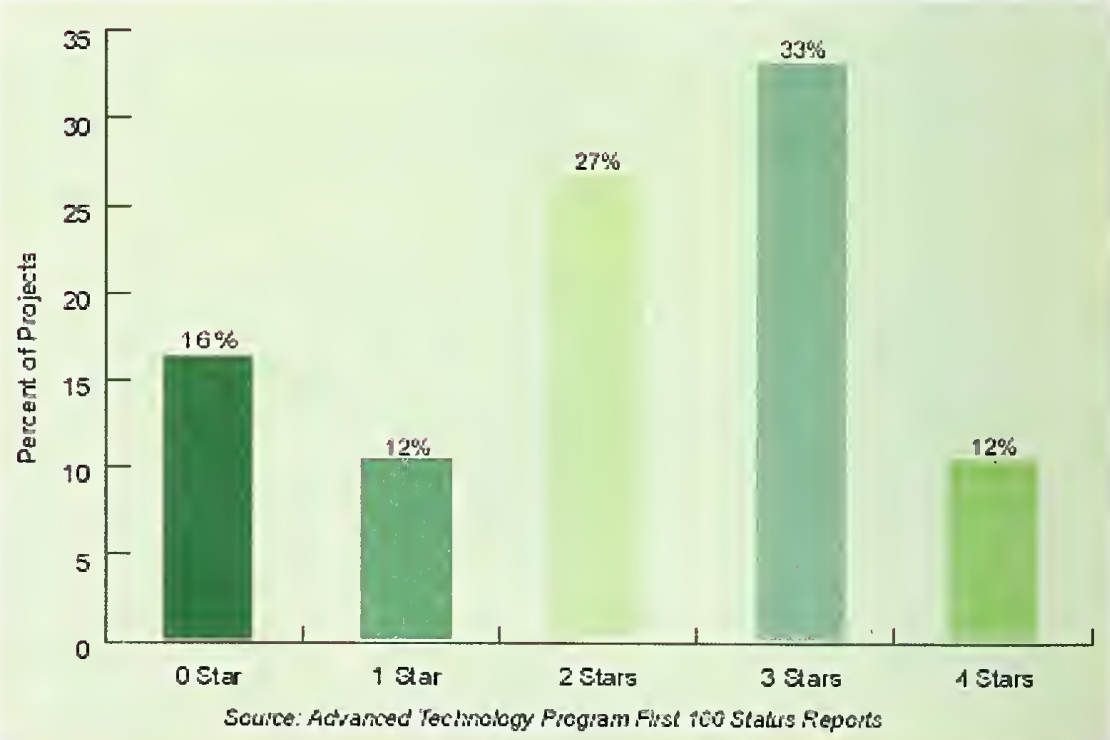


Figure 5.2 Distribution of Star Ratings by Technology Area

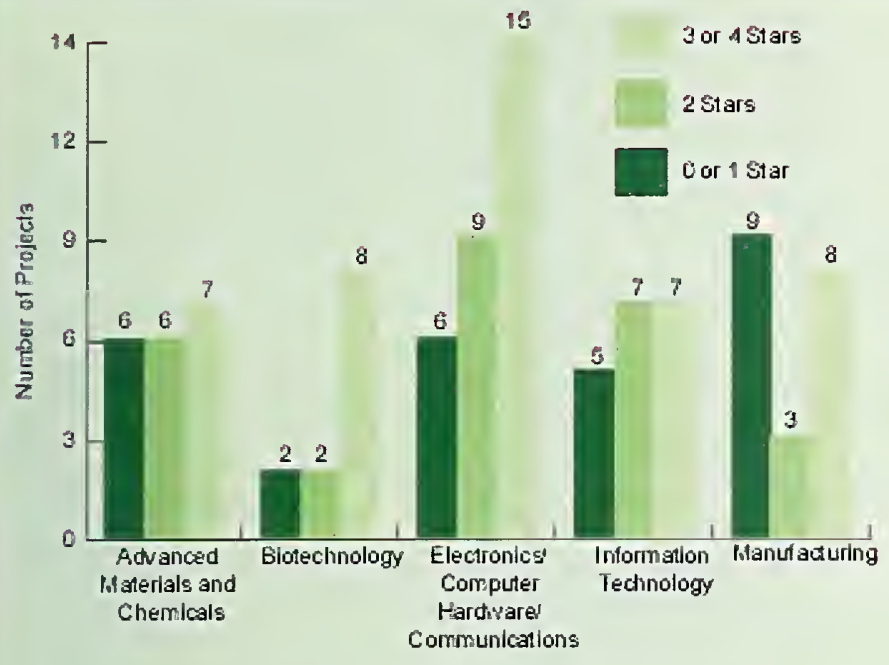

Source: Adraned Technctegy Prcgram First îo Stalis Repcrts

the relatively small number of projects in each category does not support the drawing of robust conclusions about how projects in the different technology areas will perform.

\section{Project Performance Translated into Economic and National Security Benefits}

For a few of the 100 projects, in-depth evaluation studies have been conducted to estimate at least part of their expected economic impacts. One such study conducted by economists at the Research Triangle Institute (RTI), a consulting firm in North Carolina, included three medical technologies that are among the first 100 completed. ${ }^{15}$ $\mathrm{RTI}$ economists provided early estimates of the value of a new biopolymer to repair fractures, developed by Integra LifeSciences; a system for replicating stem cells, developed by Aastrom Biosciences, Inc. ${ }^{16}$ and a new prosthesis material-animal-derived extracellular matrix, or ADMAT-developed by Tissue Engineering, Inc. Professor Karen Polenske and Nicolas Rockler from the Massachusetts Institute of Technology (MIT) completed

\footnotetext{
${ }^{15}$ Martin, Sheila A., Daniel L. Winfield, Anne E. Kenyon, John R. Farris, Mohan V. Bala, and Tayler H. Bingham, $A$ Framework for Estimating the National Economic Benefits of ATP Funding of Medical Technologies, NIST GCR 97-737 (Gaithersburg, MD: National Institute of Standards and Technology, April 1998).

${ }^{16}$ Aastrom Biosciences, Inc. utilized human hematopoetic stem cells derived from blood or bone marrow for its ATP-supported research and continues to use bone marrow and umbilical cord blood in its development efforts. The bone marrow and cord blood utilized by Aastrom during its research complied with the regulations for the protection of human subjects as codified by the Department of Commerce at 15 CFR Part 27.
}

a retrospective study of the Auto Body Consortium's dimensional control project. ${ }^{17}$ More recently, RTI conducted an economic study of ATP's investment in a portfolio of 24 component-based software projects, 3 of which are among the first 100 completed studies examined here. ${ }^{18}$

The following examples draw on the economic evaluation studies mentioned above to provide a rough notion of quantified net benefits. In addition, it supplements the results of the economic studies with several examples of projects/companies that also appear to be generating significant economic benefits.

Biocompatible Polymers for Cartilage Repair: The RTI study estimated the medical cost savings from the project led by Integra LifeSciences, in terms of avoiding second surgeries to remove implants, such as pins and screws, when trouble arises. Integra has shown continued robust progress since the RTI study was completed several years ago. At the time the project analysis for this mini-study was completed in late 1999, company employment, which was 32 at the project's start, had increased fourfold. A recent check showed nearly a 24-fold increase in the company's employment to 760 , in part through internal growth and in part through acquisitions. The company's sales revenue was reported at $\$ 118$ million in 2002, and a recent Standard and Poor's stock report estimated a 44-percent increase in revenue in 2003 , pointing to the company's participation in an expanding number of markets. ${ }^{19}$ Through its commercial partners, Integra's technology is utilized in surgical fixation devices for attaching soft tissue to bone in the knee and shoulder. These products are currently in clinical trials. Patient benefits include avoidance of medical complications and further surgeries associated with utilizing existing technologies, as well as lower surgical costs.

Stem Cell Replication: Because of the difficulty of estimating the value of patient pain reduction and improved health outcomes, the RTI study also based the benefits estimates for Aastrom's stem cell expansion technology only on the reduction in procedure costs, although it is the patient pain avoidance and improved outcome effects that were the main expected benefit of this technology. By allowing a small amount of stem cells to be multiplied into a larger quantity, the technology reduces donor clinic visits to collect the stem cells;

\footnotetext{
${ }^{17}$ Polenske, Karen, and Nicolas Rockler, Closing The Competitive Gap: An Analysis of the ATP 2mm Project, NIST GCR 03-856 (Gaithersburg, MD: National Institute of Standards and Technology, July 2004).

${ }^{18}$ White, William J. and Michael P. Gallaher, Benefits and Costs of ATP Investments in Component-Based Software, NIST GCR 02-834 (Gaithersburg, MD: National Institute of Standards and Technology, November 2002).

${ }^{19}$ Standard and Poor's stock report.
} 
reduces procedure hours; is easier for medical staff to perform; reduces treatment costs; substantially reduces patient pain and negative side effects; and has been shown to result in better treatment outcomes.

$\mathrm{RTI}$ economists estimated that once it was implemented, Aastrom's replication system (commercialized as the AastromReplicell ${ }^{\mathrm{TM}}$ System), would save several million dollars in the costs of providing bone-marrow transplants for cancer treatment

Aastrom has since continued unabated pursuit of the commercialization of its AastromReplicell ${ }^{\mathrm{TM}}$ System. According to a Standard and Poor's stock report, the company over time has made a strategic shift in its business model from that originally centered on the bone marrow transplantation market, to a model focused on multiple paths to using human cell-based therapies for stem cell repair and regeneration, cancer treatments, and infectious disease treatments. Core to the original and the new business models is its ability to grow stem cells outside the body, the ATP-funded technology.

The edition of this report that covered the first 50 completed projects described how a recent clinical trial had demonstrated success in using the cell replication system to enable cancer patients-for which there were otherwise no donors-to receive stem cell transplants by expanding tiny amounts of cord blood samples that matched the patients. ${ }^{20}$ According to the director of medical oncology at Hackensack University Medical Center, "These results suggest that we may have found a new treatment approach that will enable more patients to receive treatment for this very serious and often fatal disease [leukemia]."21 According to the American Cancer Society, 2,800 new cases of leukemia will be found in children in 2005, making new, more effective treatments of great value to society. ${ }^{22}$

An investigation of developments revealed that in September 2003, Aastrom received a National Institutes of Health grant-one of several grants-to demonstrate

\footnotetext{
${ }^{20}$ Cord blood, the blood in the umbilical cord and placenta after the birth of a child, has been found to offer an alternative source of stem cells for transplantation that provides an acceptable transplant even with a higher degree of tissue mismatching. As a result, a cord-blood banking infrastructure is being established, but the small amount of cells available from this source restricts its use. In recent clinical studies, several adult cancer patients needed very high-dose chemotherapy to be followed by a stem cell transplant, but no suitable bone marrow donors could be found. In the cord blood bank, small samples were found that provided a match, but the amounts were too small to be used. In the clinical trials, the AastromReplicell ${ }^{\mathrm{TM}}$ System was used to replicate the number of matching cord blood cells, allowing the patients (for which there were otherwise no donors) to receive stem cell transplants.

${ }^{21}$ Company press release, April 19, 2000.

${ }^{22} \mathrm{http}$ ://www.cancer.org/docroot/home/index.asp
}

the feasibility of using the cell replication system for the production of completed dendritic cell-based vaccines for immunotherapy against ovarian cancer, the leading cause of gynecological cancer-related deaths in women. Recent studies reportedly have shown that dendritic cells produced and exposed to cancer molecules have resulted in immune responses. But there are difficulties in producing the quantities of antigen-loaded dendritic cells needed to perform a complete immunotherapy treatment in patients with cancer, which is why the AastromReplicell ${ }^{\mathrm{TM}}$ System is needed. ${ }^{23}$

There have been news releases about the company's commercial activities. In activities related to the immunotherapy approach reported above, the company is reportedly preparing to begin clinical studies of its approach in collaboration with Stanford University for multiple myeloma cancer and with Duke University for colorectal cancer. ${ }^{24}$ Other reports describe an agreement with Astro Instrumentation, L.L.C. to manufacture the subassemblies and parts of the instrumentation platform of the AastromReplicell ${ }^{\mathrm{TM}}$ System. ${ }^{25}$

Biomaterials for Prostheses: RTI predicted expected benefits from the first application of Tissue Engineering's (now TEI Biosciences) ADMAT technology, namely, the repair of damaged knee ligaments (specifically, anterior cruciate ligaments, or ACLs). RTI was able to estimate benefits expected to result from improvements in the quality of life for patients receiving the treatment by using a "quality adjusted-life-years" index value. ${ }^{26}$ As of 2004, TEl has sales exceeding \$2 million from three products on the market, and has strategic collaborations with Medtronic, Stryker Orthopedics, and other U.S. medical device companies. The products are used by more than 450 surgeons and have benefited more than 1,200 patients.

Auto Body Manufacturing Assembly: One project, led by the Auto Body Consortium (ABC), has generated documented production cost savings, has improved automobile quality, and has demonstrated the potential for extending these same kinds of benefits to the manufacturing assembly of other products. A retrospective study on this project by researchers at MIT found that the project reduced variation of critical body dimensions to meet the 2-millimeter objective (with $+/$ $1 \mathrm{~mm}$ variance) and was the key driving force in changing the manufacturing quality control technology

\footnotetext{
${ }^{23}$ CBS MarketWatch, September 15, 2003.

${ }^{24}$ Ibid.

${ }^{25}$ CBS MarketWatch, August 26, 2003.

${ }^{26}$ For a description of the use of Quality Adjusted Life Years

(QALY) in evaluating patient benefits in evaluation studies, see Andrew Wang, "Key Concepts in Evaluating Outcomes of ATP Funding of Medical Technologies," Journal of Technology Transfer, Vol. 23 (2), 1998, pp. 61-66.
} 
used to improve quality, reduce cost, and shorten timeto-market by domestically owned vehicle manufacturers. The implementation of 2-millimeter technology helped domestic producers slow the loss of market share to offshore and transplant manufacturers, created no fewer than 1,400 new jobs, and generated, by conservative estimate, an increase of $\$ 186$ million in gross domestic product (measured over a 10-year period following the start of the ATP-funded project). ${ }^{27}$

Component-Based Software (CBS): Developing the capacity to build large software systems from assemblies of smaller, reusable, independent components is an important strategy to reduce software system costs, increase system reliability, and enable lower cost upgrades. Three projects included among the first 100 Status Reports were part of a portfolio of 24 projects that was included in an in-depth economic case study conducted by RTI. ${ }^{28}$ These projects were led by Reasoning Inc., TopicalNet, Inc. (formerly Continuum Software), and HyBrithms (formerly Hynomics Corp.).

Across the entire CBS portfolio, RTI's economic study estimated $\$ 840$ million in net-present-value benefits and a benefit-to-cost ratio at 10.5 , suggesting that the investment in the portfolio of projects as a whole was worthwhile. The net-benefits estimate is based on the cost of all 24 projects, but the estimated benefits of only 8 were the subject of the detailed case study. In addition, the study found other benefits that were presented qualitatively, namely, enhancing the credibility of the mostly small software firms that were funded and assisting firms in strengthening their planning and management functions.

Reasoning Inc., TopicalNet Inc. (formerly Continuum Software), and HyBrithms (formerly Hynomics Corp.) had commercialization activities underway when RTI conducted its study. Their costs, but not their benefits, were included in RTl's aggregate portfolio net-benefit measure, because they were not among the eight projects selected by RTI for the portfolio benefits assessment. Thus, the RTI study results, at best, suggest that the three projects are part of a portfolio of projects found to be valuable. Of the three projects, two are rated as three-star performers, and one is a two-star performer.

It is also informative to look at how some of the other projects that were rated as top performers have progressed since the original data were compiled and the CPRS ratings calculated. Six additional projects are profiled below.

Scalable Parallel Programming: One of the topperforming projects among the first 50 completed

\footnotetext{
${ }^{27}$ Polenske and Rockler, July 2004.

${ }^{28}$ White and Gallaher, November 2002.
}

projects, originally profiled in Volume 1, was a project led by Torrent Systems, Inc. Although Torrent had fewer knowledge-dissemination outputs than the other topperforming projects, its exceptional commercialization efforts boosted it into the four-star group. The project developed a component software system that insulates programmers from the complexities of parallel programming while allowing them to use it productively in scalable applications. Torrent delivered this new capability in its software product, Orchestrate ${ }^{\mathrm{TM}}$. An early user of the new software, United Airlines, was able to increase its revenue by $\$ 100$ million per year as a direct result of using Orchestrate ${ }^{\mathrm{TM}} .^{29}$

When revisited in Status Reports, Volume 2, Torrent's technology was reported to be enabling e-businesses and other companies to process and analyze unlimited volumes of data. Torrent was listed in Computerworld's "100 Hot Emerging Companies" in 1998 and received a number of other awards recognizing both its software technology and business acumen.

Since that time, Torrent, which had only two employees when it received its ATP award, has been acquired for a purchase price of $\$ 46$ million by Ascential Software Corp., a global company with a market capitalization of $\$ 1.1$ billion, headquartered in Westboro, Massachusetts. ${ }^{30}$ According to Ascential's Chairman and CEO, Peter Gyenes, "Torrent's patented and proven parallel processing technology is a perfect complement to the rich feature set within our data integration solution, DataStage." ${ }^{31}$ According to additional public statements by the company, Ascential has integrated Orchestrate ${ }^{\mathrm{TM}}$ into its DataStage XE product family, with the result that customers will be able to integrate data of virtually any volume and complexity, with infinite scalability, and turn growing amounts of data into valuable information assets.

United Airlines, first a Torrent customer and then an Ascential customer, is using Orchestrate ${ }^{T M}$ and an IBM parallel-processing computer to design a system for managing airplane seat assignments. A statement by Bob Bongirno, managing director of applications development for United Airlines, that is posted at the Ascential Software Corp. website provides a user's perspective of the importance of the product:

\section{At United, we analyze 'astronomical' amounts of data every day through our Orion system to determine the optimum seat availability and price across tens of millions of passenger itineraries," he}

\footnotetext{
${ }^{29}$ Information from Hoover's Online company search and Torrent's website, current August 31, 2000.

${ }^{30}$ Standard and Poor's stock report on Ascential Software Corp.

${ }^{31}$ Press Release, November 28, 2001, available on-line at wnw.ascentialsoftware.com, Press Center.
} 
said. "For Orion and our other data-intensive applications, we demand a parallel processing technology that is robust and reliable enough to process massive data volumes on very large systems and will provide a state-of-the-art data integration foundation that helps us manage all our disparate data sources and accelerates the development of new applications. The combination of technologies from Torrent and Ascential holds great promise for meeting the data processing needs of customer-centric organizations like United.

Thus the commercialization path has grown more complex for this ATP-funded technology as the technology has been combined with other software elements. At the same time, the impact potential of the technology appears strong. According to Doug Laney, META Group Vice President, the worldwide market for data integration was projected to grow from $\$ 900$ million in 2001 to $\$ 1.3$ billion in $2004,{ }^{32}$ and the technology platform funded in part by ATP appears well positioned to play a role in serving this growing market.

High-Temperature Superconducting (HTS) Wire: The project led by American Superconductor Corporation (AMSC) is another of the top-rated 100 completed projects profiled originally in Status Report Volume 1. At the time Volume 1 was being written, the company was beginning to launch its commercialization effort. Since then, the company has reportedly continued making impressive advances, building the world's first highvolume HTS wire manufacturing plant with a capacity to manufacture 20,000 kilometers of wire per year when it is fully equipped. This new manufacturing capacity is said to give potential customers the ability to accelerate their schedules for launching commercial products incorporating HTS wire by making the product available to them in commercial quantities, at commercial prices. ${ }^{33}$ AMSC's products and services listing now shows a vertically integrated portfolio that includes HTS wire, motors, generators, synchronous condensers, industrial power quality solutions, power conversion, and transmission grid solutions.

A press release issued October 1,2003 , announced that AMSC had received additional funding from the Department of Defense (DOD) and Department of Energy (DOE) to support further manufacturing scale-up for second-generation HTS wire. According to Dr. Paul Barnes, U.S. Air Force Superconductivity Team Leader, ensuring that the United States will have a reliable supply of the second-generation HTS wire is expected to be central to the development of many future military systems, including lightweight high-power generators

\footnotetext{
32 Ibid.

${ }^{33}$ Information provided by the company at its website, www.amsuper.com.
}

and advanced weapon systems. According to James Daley, manager of the Superconductivity program at DOE, the technology is also expected to play an important future role in upgrading the nation's power grid. ${ }^{34}$

Visualization Software: As in the preceding examples, Engineering Animation, Inc. (EAI), leader of another of the top-performing projects and originally profiled in Status Report Volume 1, continued to aggressively and successfully pursue applications of its award-winning imaging software capabilities developed in the ATPfunded project. Founded by two professors and two graduate students in 1990, EAl had 20 employees at the time ATP made the award. According to company officials, the ATP award allowed it to significantly extend its capabilities in computer visualization and computations dynamics and to form important collaborative relationships that enabled it to leverage the technology in many different directions. The company used its ATP-funded technology to improve the training of doctors as well as to guide medical procedures. Furthermore, patients reportedly had better outcomes when the visualization software was used during their surgical procedures.

In 1999, the company employed approximately 1,000 staff members and had sales of $\$ 71$ million. At that time, EAl had extended and deployed its award-winning visualization capabilities to develop a virtual factory technology implemented at Ford Motor Company. This application of the software enabled faster design and analysis of factory models.

On October 23, 2000, EAI was acquired by Unigraphics Solutions Inc. for $\$ 178$ million. Subsequently, through acquisition and merger, Unigraphics and another software services company, SDRC, became a combined subsidiary of Electronic Data Systems Corporation (EDS), the world's largest information technology outsourcing services company, which has a worldwide infrastructure and 138,000 employees. ${ }^{35}$ Unigraphics and SDRC were combined to form EDS's fifth line of business, Product Lifecycle Management (PLM) Solutions. This union provided, through Unigraphics NX software, a unified approach to extended enterprise collaborations enabling the modeling and validation of products and their production processes digitally from initial concept to finished parts. Thus, EAl followed the business model for growth of merging with a much larger company. ${ }^{36}$ An online search revealed that previously developed EAl products and books remain on the market.

\footnotetext{
${ }^{34}$ Company press release, October 1, 2003.

${ }^{35}$ Prior to the acquisition of Unigraphics, EDS was the major company stockholder. Information found at www.eds.com. ${ }^{36}$ Ibid.
} 
Examples of strong projects from among the three-star group are described below. These, too, appear to be delivering important economic benefits.

Composite Piping Systems: An example from the three-star group is a project led by EDO Specialty Plastics. The company developed an improved method to join composite pipe segments and more efficient, less costly processes for manufacturing the pipe fittings. The reliable joining methods that Specialty Plastics developed during this ATP-funded project have led to an increased use of composite piping systems on offshore tension leg platforms (TLPs) by the oil industry with significant cost savings.

DNA Sequencing System: Another three-star project was led by Amersham Pharmacia Biotech, which is credited with accelerating development of an enzyme important to the speed of the human genome projectwhere timing is of enormous importance.

Highly Integrated Digital Circuits: A project with continued strong commercialization was led by Vitesse Semiconductor Corporation. Vitesse successfully applied gallium arsenide (GaAs) material in the volume production of highly integrated and very complex digital circuits. Most of the world's telecommunications companies now use Vitesse chips; virtually every long-distance call passes through its integrated circuits. The project's main avenue for knowledge dissemination was through

commercialization, rather than patents and publications.

To these examples, other promising technologies may be added-technologies that improve productivity, facilitate better weather forecasts, improve communications, enable new drug discovery, reduce energy costs, and improve health and safety.

\section{What Difference Did ATP Make?}

ATP aims to improve the international competitiveness of U.S. firms by funding projects that would not take place in the same timeframe, on the same scale, or with the same goals without ATP's support. A project may be successful in terms of achieving its goals, but if the same accomplishments would have occurred in the same timeframe without ATP, then the program has not had the intended effect. For this reason, evaluation studies of ATP_-as well as other government programs—should apply the principle of "additionality" to correctly distinguish between benefits that would likely have occurred anyway and those benefits that are reasonably attributable to ATP.

In preparing the 100 individual mini-case studies in this report, analysts asked project leaders about the role ATP funding played in their projects. Throughout the project selection process, beginning with the application, ATP presses the questions of why the project requires
ATP funding, why funding is appropriate, what will happen if ATP funding is not provided, and how the expected outcome will differ with and without ATP involvement. During the evaluation process, these questions are again pursued retrospectively, i.e., what happened that was different as a result of ATP? Applied prospectively, the results are hypothetical. In evaluation studies, the results may be based on counterfactual survey and interview questions, such as those posed in the status report case studies. Evaluation studies have also used control group techniques, which provide more reliable evidence of the additionality impacts of ATP. ${ }^{37}$

Fifty-five percent of the respondents indicated their projects would not have happened at all without ATP funding. Indeed, some participants said their companies would have gone out of business had the ATP award not been made.

Forty-five percent of the respondents said they would have aitempted the project at some later date or at a slower pace and that ATP funding enabled them to accelerate the technology. Table 5.1 shows the project time savings attributed to ATP for those projects that reported they would have proceeded without ATP funding. With ATP, the projects avoided delays ranging from six months to five years and more. The acceleration of some of the projects may seem short; however, the value of even a small acceleration can be substantial. For example, the six-month lead in developing ThermoSequenase, a DNA polymerase that is both thermostable and accurate, was significant to DNA sequencing. Speed in developing and commercializing a technology can also mean increased global market share for U.S. producers. A number of companies also reported other effects of their ATP awards. Some reported that receiving their award enhanced their ability to raise additional capital. Some reported that their award helped them form collaborative relationships for research and commercial activities. Others reported that receipt of their ATP award had enabled them to gain in international competitiveness.

\section{What Constitutes Success and Failure for ATP?}

Because individual project failure must be allowed and tolerated in a program that focuses on overcoming challenging technical barriers to innovation, it is essential to take a portfolio approach to assessing ATP. Moreover, success should be assessed against the legislated mission of the program.

\footnotetext{
${ }^{37}$ See Survey of Applicants 2000, NIST GCR 03-847, (Gaithersburg, MD: National Institute of Standards and Technology, June 2003) and Maryann P. Feldman and Maryellen R. Kelly, Winning an Award from the Advanced Technology Program: Pursuing R\&D Strategies in the Public Interest and Benefiting from a Halo Effect, NISTIR 6577 (Gaithersburg, MD: National Institute of Standards and Technology, March 2001).
} 
Table 5.1 Effect of ATP Funding on Expected Timing of Research

Effect on Project

Number

of Projects

Would not have conducted Project without

ATP funding

Would have proceeded without ATP funding, but with delay*

$\begin{array}{lc}\text { Length of Delay } & \\ 6 \text { months } & 1 \\ 18 \text { months } & 4 \\ 21 \text { months } & 3 \\ 24 \text { months or more }{ }^{\star \star} & 8 \\ \text { Some other specified } & 2 \\ \text { number of months } & \\ 5 \text { years or more } & 10 \\ \text { Delay, but time unspecified } & 12\end{array}$

Total Respondents

Source: Advanced Technology Program First 100 Status Reports

*Another factor potentially influenced by ATP funding (the scope and scale of the project) was not explicitly covered).

**The Printed Wiring Board Joint Venture project had a split response: half the tasks would not have been done at all and half would have been delayed by at least a year. This result is recorded conservatively in Table 5.1 as a two-year delay.

Four general tests, and several additional specific tests-all derived from ATP's mission-if applied after sufficient passage of time, should reveal the extent to which ATP has successfully met its mission, as described below.

Test 1: Has the portfolio of ATP-funded projects overall produced large net social benefits for the nation?

Test 2: Has a substantial share of net social benefits accrued to citizens and organizations beyond ATP direct award recipients?

Test 3: Did ATP make a substantial positive difference in the size and timing of the benefits?

Test 4: Has the portfolio of ATP-funded projects enhanced United States' economic and technological competitiveness?

Additional specific tests of success include the following: Did the projects produce new scientific and technical knowledge? Did ATP increase collaboration? Were small businesses able to participate? Were manufacturing capabilities improved?

While the ultimate answers to these success "test questions" depend on the long-run impacts of the entire portfolio of ATP projects, the performance-to-date of the sub-portfolio of 100 projects provides emerging answers.

There is mounting evidence that the tests for program success are being met. First, there is strong evidence that social benefits of the portfolio are large and exceed program costs. Second, there are benefits extending well beyond those captured by the direct award recipients: there is substantial evidence of knowledge and market spillovers as others cite the project patents and use the products. Third, there is evidence that ATP has made a significant difference in the amount and timing of benefits, as well as having other beneficial impacts on the companies. Fourth, there is some evidence of improvements in the competitiveness of U.S. companies.

The performance ratings show that the majority of the projects continued to make progress in the several years after ATP funding ended. Moreover, the portfolio has been shown to contain a core group of highly active and productive projects that are successfully accomplishing their high-risk project goals.

ATP awarded a total of $\$ 206$ million to the 100 completed projects. Questions of keen interest are what is the public investment producing in the way of benefits, and are the tests for program success being met? Estimated benefits attributed to ATP from just a few of the 100 projects for which quantitative economic benefits have been provided exceed ATP's funding for all of the 100 projects. In addition, there is considerable evidence of large project benefits that have not yet been quantified.

This completes the portfolio view of ATP. Appendix A that follows provides an overview of the 100 individual projects that make up the portfolio. Appendix $B$ describes reasons that some ATP-funded projects did not proceed to completion. Appendix C lists the first 100 completed projects along with their CPRS star ratings. 


\section{Calmac Manufacturing Corporation}

\section{New Refrigeration Cycle To Improve 100-Year-Old Technology}

Refrigeration is one of the leading uses of electric power in the United States. The term "refrigeration" refers to air-conditioning for homes, businesses, and industry and the operation of refrigerators, freezers, and heat pumps. The technology most often used in refrigeration, the vapor compression cycle, is 100 years old, inefficient, and environmentally unsound. Since the 1980s, the refrigeration industry has faced pressure to improve efficiency and reduce emissions of the chloroflurocarbon (CFC) compounds used in vapor compression cooling. Attempts to decrease CFC emissions by using alternate compounds have typically made refrigeration devices less efficient.

Calmac Manufacturing, Inc., proposed a new, efficiency-enhancing twist on the old paradigm. It proposed an ejector expansion refrigeration cycle (EERC) to increase the efficiency of the cycle by recovering some of the unused energy in the compressed fluid. Calmac targeted a 10-percent reduction in energy used for air-conditioning and up to a 20-percent improvement for other, lower temperature applications over standard vapor compression refrigeration systems. Because Calmac lacked the internal funding resources to support such an ambitious, but risky, project, it turned to the Advanced Technology Program (ATP). In March 1993, ATP awarded $\$ 729,000$ to Calmac to pursue the development of EERC technology. Unfortunately, scientific and technical failures prevented Calmac from successfully developing the EERC technology and, by the project's end in February 1996, the company had abandoned its efforts. Calmac did, however, advance the refrigeration industry's body of knowledge for modernizing the vapor compression process, and future industry efforts may potentially expand on the inroads made by Calmac.

\section{COMPOSITE PERFORMANCE SCORE \\ (based on a four star rating) \\ No Stars}

Research and data for Status Report 92-01-0007 were collected during October-December 2001.

100-Year-Old Refrigeration Techniques Are Obsolete

Vapor compression refrigeration systems use 23 percent of all electric energy in the United States. Add the millions of gallons of gasoline burned to power automobile air conditioners, and it is clear that any increase in efficiency could lead to tremendous societal benefits. Unfortunately, decades of attempts to improve the vapor compression refrigeration system by reducing chloroflurocarbon (CFC) emissions have not resulted in increased efficiency or reduced the environmental impact of the system. Typically, reductions in CFC emissions lead to decreased efficiency, requiring the use of more electric power as well as the emission of more environmental toxins from the electric-powergeneration process.

\section{Efficient, Cleaner Refrigeration Through EERC}

Calmac developed an ejector expansion refrigeration cycle (EERC) process to improve the efficiency of vapor compression refrigeration by recovering energy typically lost during the process. Specifically, the EERC process uses the energy normally lost in the expansion process to help compress the gas entering the compressor. The 
EERC expands the liquid refrigerant in two steps. The first step is through a specifically designed nozzle where the liquid is used to increase the pressure of the gas returning to the compressor. After this stage, the liquid refrigerant is collected in a receiver where it is metered into the evaporator by conventional methods.

\section{Prior Success Indicates Goals Are Possible}

Before applying for ATP funding, Calmac had expended significant internal resources to overcome prior EERC failures in the industry. For example, industry efforts to achieve EERC had not generated sufficient pressure within the ejector nozzle to enhance refrigeration efficiency. Calmac, however, had developed techniques to achieve a six-percent improvement in energy expended for refrigeration through the use of the EERC. That level of improvement was not high enough to make the technology cost effective, but, with further research and refinement, Calmac expected a 10percent improvement for air-conditioning and up to a 20-percent improvement for other, lower temperature applications. Moreover, more efficient refrigeration would reduce both the size of the equipment needed in the process and the potential release of CFCs into the environment. When improvements reached the 10percent threshold, cost savings would then be high enough to encourage original equipment manufacturers (OEMs) to use the EERC process. At that point, economic and environmental spillover could be achieved.

Limited internal funds had hindered efforts, however, to reach the commercially viable 10 -percent improvement stage. Furthermore, given the previous failures to develop EERC technology within the industry, external funds through the private market were not available to Calmac.

\section{Improved Refrigeration Efficiency Has Potential Spillover Benefits}

Because refrigeration is used in almost every residential and commercial structure, and because it accounts for such a high percentage of the nation's consumption of electric power, improvements in refrigeration efficiency could result in lower overhead costs across many industries. In the commercial setting, cost savings could then be invested back into product development. In the residential setting, the decrease in money spent each month on electricity could free up spending for a host of consumer items or for personal savings. The potential spillover benefits supported Calmac's proposal to receive cost-shared funds from ATP. Therefore, in 1993, ATP awarded the company $\$ 729,000$ to pursue further development of the EERC technology.

\section{Unforeseen Obstacles Block Increased Efficiency and Commercialization}

In the first 18 months of the project, Calmac engineers researched materials and engineering advances that had the potential to push the EERC above the 10percent efficiency improvement threshold. The following six months were spent integrating these innovations into the EERC technology. At the start of the third year of the project, however, Calmac encountered unforeseen instability in the ejector's operation. Three sources of the instability were examined, but Calmac was unable to completely pinpoint and solve the problem. The specific operating parameters needed in the ejector for the EERC operation introduced inherent instabilities to the system outside this design window.

Calmac conducted research into the cause of the instability and generated extensive documentation of its findings. However, the company could not make the EERC operate efficiently for the equipment's complete range of operation.

\section{Calmac enconntered unforeseen instability in the ejector's operation.}

Consequently, Calmac could not commercialize a component package for retrofitting older machines or for installation by OEMs because the costs were still prohibitive. When the ATP project concluded in 1996, Calmac decided not to continue its work on EERC.

\section{Conclusion}

ATP funded Calmac's effort to develop more efficient, more environmentally friendly refrigeration technology based on recovering the energy lost during the process. 
However, scientific and technical failures prevented the company from achieving the performance goal needed to make the EERC technology financially viable.

Scientific and technical failures prevented the company' froun achieving the performance goal needed to make the EERC technology financially viable.

Nevertheless, Calmac's research did add to the body of knowledge of engineering processes related to refrigeration. In the future, that knowledge may save engineers time and money as they continue to search for more efficient refrigeration methods. 


\section{PROJECT HIGHLIGHTS \\ Calmac Manufacturing Corporation}

Project Title: New Refrigeration Cycle To Improve 100-Year-Old Technology

(Ejector Expansion Refrigeration Cycle (EERC))

Project: To improve the efficiency of refrigeration through an ejector expansion refrigeration cycle (EERC) that recycles energy normally lost during the process. If successful, this technology would benefit every consumer of electric power by making refrigerators, air conditioners, and freezers substantially more efficient and cost effective.

Duration: 3/1/1993-2/29/1996

ATP Number: 92-01-0007

Funding (in thousands):

$\begin{array}{lrr}\text { ATP Final Cost } & \$ 729 & 62 \% \\ \text { Participant Final Cost } & \underline{448} & 38 \% \\ \text { Total } & \$ 1,177 & \end{array}$

Accomplishments: Although Calmac made some progress in developing more efficient, more environmentally friendly refrigeration technology based on recovering the energy lost during the process, technical problems prevented the company from achieving the performance goal needed to make it cost effective. Despite this failure, however, Calmac advanced the refrigeration industry's body of knowledge for modernizing the vapor compression process by identifying for the industry those EERC methods that would not work.

Commercialization Status: Calmac was unable to commercialize the EERC technology it worked to develop in this ATP-funded project due to scientific and technical failures.

Outlook: Calmac has abandoned further work on the EERC project, and there are no plans for commercialization at this time. In 2003, the outlook for this particular project is poor.

Composite Performance Score: No Stars

Number of Employees: 16 at project start, 65 as of December 2001

\section{Company:}

Calmac Manufacturing Corporation (formerly Inc.) 101 West Sheffield Avenue

Englewood, NJ 07631

Contact: Calvin D. MacCracken

Phone: (201) 569-0420 


\section{Corning Tropel (formerly Tropel Corporation)}

\section{Improving Measurement Accuracy and Speed Using Optical, Noncontact Technology}

Many precision fabrication industries, such as fuel-injector and bearing manufacturing, rely on precise measurement techniques to sustain dimensional accuracy. During the early to mid-1990s, the primary technologies used to measure surface forms, particularly complex surface forms, failed to keep pace with the growing need to improve speed and accuracy through in-process measurement of these surfaces. Accordingly, Tropel Corporation, one of the world's leading small optics companies, sought to meet this need by developing its unique noncontact, optical interferometric measurement technology. In 1995, the company applied for and received funding through the Advanced Technology Program (ATP) to develop this new technology. By project conclusion in 1998, Tropel had developed a laser interferometry measuring system for complex shapes that increased measurement speed by a factor of 10 to 20 times and improved dimensional measurement accuracy by 2 to 5 times more than the mechanical measurement. Through these research and development accomplishments, Tropel was able to commercialize its CylinderMaster ${ }^{\mathrm{TM}}$ machine. Since the project ended, Tropel has sold more than a dozen machines worldwide.

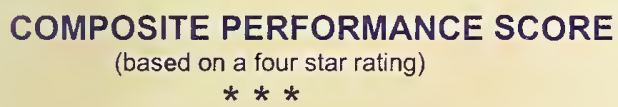

Research and data for Status Report 95-01-0022 were collected during July - September 2001.

Existing Measurement Instruments Were Slow and Costly

Precision manufacturing has always required a great deal of dimensional accuracy. It relies on performing exact measurements of component surfaces during the manufacturing process. Methods used for this type of measurement before the mid-1990s were reliable, but painstakingly slow and costly, causing major bottlenecks that affected the productivity of industries such as automotive and bearing manufacturing. During this time, coordinate measuring machines (CMMs) and precision roundness gauges were the backbone of general-purpose shape measurement; however, these machines had several limitations.

When a large number of points are needed to characterize a surface, the data-acquisition time becomes prohibitive, and the accuracy of the data often deteriorates because of thermal and other drifts. Data acquisition was limited to a few points per second with CMMs. Moreover, these machines did not permit inprocess measurement of surfaces, which would let machine operators measure a surface before a process and make any necessary changes before completing the entire manufacturing loop. The need for greater inprocess testing to improve the quality of manufacturing processes drove the evolving industry's need to measure machined part dimensions at higher speeds, with greater accuracy, and at lower costs.

Particularly challenging to the precision manufacturing industry was the need to measure complex shapes, such as cylinders and cones, which had to be measured by physical contact. At the time, most manufacturers used $\mathrm{CMMs}$ to perform these measurements. CMMs move tiny contact probes around the surface and build up a set of measurement 
points that are used to ensure that the object measured is within certain dimensional tolerances. The process was slow, however, and could not be used for real-time control.

\section{Measuring Complex Shapes Requires New} Technology

Even companies that had mastered methods for measuring simple, flat surfaces struggled to develop new methods for measuring complex shapes. Tropel Corporation, one of the world's leading small optics companies, teamed with Cummins Engine to develop a new approach for measuring complex surfaces using optical, noncontact methods.

Particnlarly challenging to the precision wannfactnring industry was the need to measnre coniplex shapes, snch as cylinders and cones, which had to be neasnred by physical contact.

Tropel proposed to investigate advanced optical interferometric methods for measuring complex machined surfaces that would allow in-process characterization of these surfaces. Interferometry had been used successfully for many years to accurately and rapidly measure simple shapes such as spheres and flat surfaces. Common optical systems, such as laser interferometry, worked well for simple surfaces because they were able to accurately create the optical wavefronts that conform to and, therefore, permit the measurement of such surfaces. However, more complex surface forms, such as cylinders and cones, could not be easily measured by these common optical components, because the components were unable to create the complex wavefronts (conical or axiconical) required to test such surfaces. Therefore, accomplishing accurate yet rapid measurements of complex surface forms was challenging. The complexity of the technology and the failures of other CMM manufacturers to develop new methods caused Tropel to seek support for its technology development efforts. In 1995, the company applied for and received ATP funding.

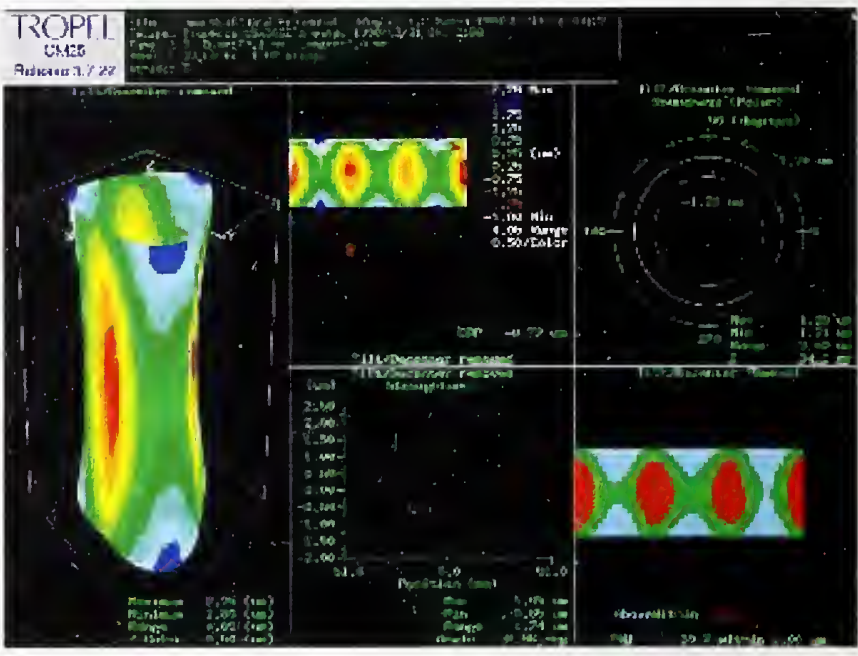

An example of the imaging capabilities that were possible using the CylinderMaster ${ }^{\mathrm{TM}}$ machine.

Tropel's unique approach used diffractive optics (DOs) to apply the multiplexing and noncontact advantages of laser interferometry to more complex shapes. The company planned to use DOs to produce complex wavefronts by applying the same lithography techniques that were common in the semiconductor industry for processing silicon wafers. DOs allow wavefronts to be designed or engineered with a nearly arbitrary shape from a software description. Thus, with DOs, interferometry could be used with a much broader class of surfaces, limited only by the ability to mathematically describe the desired wavefront or surface. It was predicted that replacing mechanical measurement systems with laser interferometry systems would improve the speed and accuracy of complex surface measurements.

\section{Tropel Faces Technical and Business Barriers}

The project's technical and business risks were particularly daunting for a company as small as Tropel. For example, major technical risks included the use of DOs for this type of measurement, since this technology was in its infancy at the time; the self-alignment and automatic operation elements of the proposed technology; and the fact that completing the dimensional measurements required analyzing large amounts of data. 
Assuming technical success, the major business risk was that the techniques proposed were radically different from the existing ones, and no other equivalent technology existed. Tropel knew that there would be a long acceptance period before manufacturers and other end users would readily adopt these technologies.

The uew technology increased measurement speed by a factor of 10 to 20 tines and improved dinensional measurenent accuracy by a factor of 2 to 5 times.

By project conclusion in 1998, Tropel had successfully improved measurement accuracies to the submicron level and had reduced measuring time to less than one minute. Tropel was able to develop a prototype, the CylinderMaster ${ }^{\mathrm{TM}}$, which measures shape and form, and Cummins performed tests on this prototype machine. However, as discussed earlier, the measuring machine used techniques that were very different from the techniques normally used at that time. Cummins was dissatisfied with the results of the new technology because the company had difficulty correlating measurements by the prototype machine with data obtained from existing instruments. Consequently, Cummins ended its participation in the ATP project at the testing stage.

Despite losing its strategic partner, Tropel continued developing the technology and was able to perform inplant demonstrations. Additionally, the company disseminated its knowledge to others, allowing the University of North Carolina at Charlotte to use the machine for research purposes.

CylinderMaster ${ }^{\mathrm{TM}}$ Improvements in Speed and Accuracy Lead to Success

The new technology increased measurement speed by a factor of 10 to 20 times and improved dimensional measurement accuracy by a factor of 2 to 5 times.
These improvements allowed Tropel to find enough support for its technology to commercialize the CylinderMaster ${ }^{\text {TM }}$ in 1998, shortly after the ATP project concluded.

Through this project, the conpany successfully developed the basis for its CylinderMaster ${ }^{\mathrm{TM}}$ product, which is now being used throughont the world.

Since then, Tropel (now Corning Tropel) has sold more than a dozen machines for $\$ 200,000$ each. This success has allowed the company to establish a worldwide, three-year sales agreement with Carl Zeiss IMT for Tropel's metrology instruments business.

\section{Conclusion}

Manufacturing industries are constantly striving to improve the speed and accuracy of their processes. One major aspect involved in the process is the measurement system that is used to ensure that the parts produced are within the required dimensional tolerances.

Measurement techniques used during the time of this ATP project were fairly accurate, but painstakingly slow. To meet the need for a more precise and quicker method, Tropel sought ATP's assistance in developing its unique optical interferometric measurement technology based on diffractive optics. Through this project, the company successfully developed the basis for its CylinderMaster ${ }^{\mathrm{TM}}$ product, which is now being used throughout the world to improve the accuracy and speed with which complex shapes are measured in precision manufacturing plants. 


\section{PROJECT HIGHLIGHTS \\ Corning Tropel (formerly Tropel Corporation)}

Project Title: Improving Measurement Accuracy and Speed Using Optical, Noncontact Technology

(Noncontact Optical Metrology of Complex Surface Forms for

Precision Industrial Manufacturing)

Project: To develop a unique optical interferometric measurement technology based on diffractive optics to enable high-speed, in-process, noncontact measurement of complex shapes, such as cylinders and cones, in a manufacturing environment.

Duration: 8/1/1995-3/31/1998

ATP Number: 95-01-0022

\section{Funding (in thousands):}

$\begin{array}{lrr}\text { ATP Final Cost } & \$ 924 & 45 \% \\ \text { Participant Final Cost } & \underline{1.115} & 55 \% \\ \text { Total } & \$ 2,039 & \end{array}$

Accomplishments: Through this project, Tropel accelerated the development of its optical measurement technology and achieved important milestones leading to its technological successes. The company improved dimensional measurement accuracies to the submicron level and reduced measuring time to less than one minute. The project's accomplishments also enhanced the company's reputation as an innovative optical metrology company, and they experienced a 10to 15 -percent increase in revenue and employment.

Tropel received the following five patents as a result of technology related to the ATP project:

- "Diffraction management for grazing incidence interferometer"

(No. 5,719,676: filed Aprit 12, 1996; granted February 17, 1998)

- "Object fixturing in interferometer" (No. 5,684,594: filed April 18, 1996; granted November $4,1997)$

- $\quad$ "Fringe pattern discriminator for interferometer using diffraction gratings"

(No. 5,724,137: filed June 27, 1996; granted March 3, 1998)
- Interferometric measurement of toric surfaces at grazing incidence"

(No. 5,889,591: filed October 17,1996; granted March $30,1999)$

- "Interferometric measurement of absolute dimensions of cylindrical surfaces at grazing incidence" (No. 5,777,738: filed March 17, 1997; granted July 7, 1998)

The developers of the technology made several presentations and wrote numerous papers explaining the technology. The following presentations and papers are a sampling:

- Kulawiec, A.W. and J.H. Bruning, "Applications of Diffractive Optics to Three-Dimensional Surface Form Measurements," 1990 Annual Meeting of the Optical Society of America, Paper TuH3, Rochester, NY, October 20-24, 1996.

- Kulawiec, A.W., J.F. Fleig, and J.H. Bruning, "Interferometric Measurements of Absolute Dimensions of Cylindrical Surfaces," 1997 Annual Meeting of the American Society of Precision Engineering, Norfolk, VA, October 5-10, 1997.

Commercialization Status: Before this ATP project, Tropel conceived of a cylinder-measuring instrument and had established a proof of concept. Through the ATP-funded project, the company was able to develop a prototype of the metrology instrument. In 1998, after the conclusion of the ATP project, Tropel successfully commercialized its CylinderMaster ${ }^{\mathrm{TM}}$ product. They have sold two to three CylinderMasters ${ }^{T M}$ ( $\$ 200,000$ each) per year over the past five years and have established a worldwide, threeyear sales and marketing agreement with Carl Zeiss IMT for Tropel's metrology instruments business.

Outlook: Currently, the technology is aimed at a specific, highend, precision manufacturing segment. Tropel (now Corning Tropel) expects its CylinderMaster ${ }^{7 \prime}$ to experience limited growth over the next couple of years as the firm continues to develop an increased market for the instrument. Coming Tropel is seeking to expand the development of this technology by adding new capabilities that would be useful for process manufacturing, such as the ability to measure size and diameter, in addition to 
measuring shape and form. The company is exploring additional applications for its technology, such as fiber-optics packaging for the telecommunications industry.

\section{Composite Performance Score: * *}

Number of Employees: 120 employees at project start,

260 as of September 2001

\section{Company:}

Corning Tropel

60 O'Connor Road

Fairport, NY 14450

Contact: Andrew Kulawiec

Phone: (716) 388-3410

\section{Subcontractors and Strategic Partners:}

INTI Electronics

Cummins Engine 


\title{
Magnetic Pulse Welding Process To Decrease Vehicle Weight and Increase Fuel Efficiency
}

\begin{abstract}
Looking forward in 1995, automobile manufacturers identified a potential shift in customer preferences to lighter weight, fuel-efficient automobiles; fuel-cell powered cars; and hybrid gas/electric vehicles. To make existing cars more fuel efficient and to meet the coming needs of alternatively powered vehicles, automobile original equipment manufacturers (OEMs) needed lighter components. These same OEMs, however, recognized that the 1995 generation of automobile components was manufactured as light as they could be using the existing technology. Therefore, improved efficiency could only be gained by using new, lighter weight materials, such as aluminum, and new manufacturing processes that reduced the use (and therefore the weight) of steel in welding. The Advanced Technology Program's (ATP) Focused Program, Motor Vehicle Manufacturing Technology, provided Dana Corporation with the necessary funding to develop technology to bond aluminum to steel without depositing additional metal at the weld site. Dana Corporation developed a functional magnetic pulse welding machine prototype to manufacture automobile parts that are twothirds lighter. Once installed into vehicles, these lighter parts would result in increased fuel efficiency of 8 to 10 percent. Since the project ended in 1998, automakers have contacted Dana Corporation about using magnetic pulse welded materials in their vehicles.
\end{abstract}

\section{COMPOSITE PERFORMANCE SCORE \\ (based on a four star rating) \\ $* * *$}

Research and data for Status Report 95-02-0055 were collected during October - December 2001.

\section{Current Welding Technology Increases Component Weight}

The challenge that the industry faced was how to join different metals together so that the assembled components had the desired stiffness, strength, and dimensional quality. Current manufacturing technologies that provided multi-metallic joints, such as the use of fasteners or adhesives, require additional implementation expense, such as processes and special design features, and may not achieve acceptable levels of strength and dimensional quality. Attachment processes are critical to performance in weight-reduction initiatives involving rotating assemblies, such as driveshafts. Minimizing forcing functions related to both the shaft's mass and dimensional quality necessitated a new assembly approach, especially when using large-diameter, thinwalled tubular components.
The welding method commonly used before this ATPfunded project deposited substantial amounts of additional metal onto the joint. This additional metal was critical to the integrity of the weld because it flowed into the materials to be joined, hardened, and formed into an intermolecular bond. While this bond was extremely strong, the added metal from each weld could increase the part's weight by up to 10 percent, thereby decreasing fuel efficiency.

\section{ATP Funds Development of Magnetic Pulse Welding Process}

In 1995, Dana Corporation submitted a proposal to ATP's Focused Program, Motor Vehicle Manufacturing Technology, to develop a novel technology for bonding aluminum to steel without depositing additional metal at the weld site. ATP awarded the company $\$ 2.0$ million for a three-year research program. The company's 
proposed magnetic pulse welding process begins by subjecting preshaped aluminum and steel tubular stock to high pressure within precision die cavities machined directly from computer-aided design files. This process, called hydroforming, leads to more precisely fitting structural components, which require little overlap or fill material for the subsequent welding steps.

The welding method connmonly used before this ATP-funded project deposited substantial anounts of additional metal onto the joint.

These hydroformed parts are then fitted loosely together. An inductor is utilized either internally or externally to create a rapidly switching magnetic field that causes one of the metallic components to form quickly and finally impact the other "stationary" metallic part with sufficient velocity and force to create a metallurgical bond. Implementation of this process would require new machinery capable of generating proper welds in complex geometric arrangements. Because of these project risks, automobile parts manufacturers had only studied the technology, but had not taken steps to develop it.

New Welding Process Promises Wide-Ranging Benefits

Dana Corporation envisioned that its new process would enhance manufacturing productivity through a simplified welding process that offered a reduction in manufacturing steps, materials, equipment, and personnel expenses. One predicted benefit to the original equipment manufacturers (OEMs) and automobile purchasers was a vehicle frame that was two-thirds lighter, which would result in an 8- to 10percent improvement in vehicle fuel efficiency. Increased fuel efficiency, in turn, would reduce air pollution. Moreover, Dana Corporation's process could potentially reduce the energy consumed in joining components and eliminate the shielding gases associated with conventional welding, benefits that would further decrease air pollution.

If U.S.-manufactured vehicles became less expensive to manufacture, operate, and recycle, U.S. competitiveness could be enhanced, and domestic

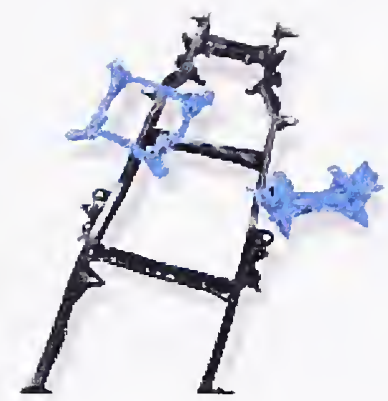

Frames, side rails, cradles, stampings, space frames, and bumper reinforcements are a few examples of automobile products produced more efficiently due to the magnetic pulse welding process.

automobile companies would realize a higher market share. Moreover, the new technology could benefit other industries that need to efficiently join dissimilar metals. Combining hydroforming with magnetic pulse welding could result in nearly limitless possibilities to improve any industry that requires machined metal or welding. New lighter, stronger, and potentially more efficient structures could be created, and costs could be reduced. The strong potential for economic spillover made the project more attractive to ATP.

\section{Dana Corporation Overcomes Project Roadblocks}

During the project, Dana Corporation's team faced daunting technical roadblocks that threatened to derail the project. The prototype magnetic pulse welder, as originally designed, forged a new path for shop floor assembly power distribution and required a substantial risk assessment that took many months of the initial installation. The welding process utilized a rapidly changing magnetic field derived from the rapid release of high-voltage and high-current electricity through the welding circuitry. Concerns and design revisions addressed changes to the power distribution and insulation of the elements to prevent the potential of electrical arc-off that could compromise components of the equipment. The Dana Corporation team took nearly a year to resolve these safety problems, and, by October 1996, the machine was operating safely and more efficiently.

A second technical challenge was to determine the proper geometric relationship between the mating components to be welded. The weld angle, for example, ultimately determines a shape configuration that 
influences the design for hydroformed tube ends. The shape factor is important because precisely formed tubes allow strong, smooth bonds without the need to deposit additional metal on top of deformities. A challenge throughout the project was to understand the relationship between weld angle, part size, and power distributed to the weld surface. After much effort, Dana Corporation determined the appropriate parameters for particular tubes, created prototypes, and sent the prototypes to automobile OEMs for testing. A third technical challenge was to develop consistent metallurgical bonds.

\section{OEMs are rethinking their antomobiles'} structures and powertrains to find cost savings and fuel efficiencies that were not thought possible before this project.

The goal was to create bonds strong enough that, even under extreme torque, the tube warped before the bond failed. The team achieved this goal; moreover, there was virtually no gross distortion associated with this welding process once the company refined the process. It could be used to join combinations of low-carbon steel, aluminum, and stainless steel in a variety of geometries.

\section{ATP-Funded Technique Applies to Other Industrial Applications}

Despite delays, Dana Corporation's advanced welding method has the potential to change entire industries. Dana Corporation engineers continue to work on production technology transfer in this post-project phase and, as of mid-2001, imminent commercialization was anticipated with a machine expected on the production floor by fourth quarter of 2002. Technical issues have been solved, a proof of concept has been developed, and automobile OEMs now recognize the value of magnetic pulse welding. When commercialization is achieved, the new welding process promises to deliver driveshafts that are straighter and lighter, experience less vibration, and enable new geometries that could change the configuration of automobile transmissions and undercarriages.

Dana Corporation's process is the most advanced of its kind in the industry. Automotive industry news indicates that BMW attempted to use friction welding to accomplish a similar result, but could not forge strong enough bonds in their bimetallic driveshafts. According to Dana Corporation executives, because of ATP's funding and the company's innovation, major automobile manufacturers are conducting studies on how to incorporate magnetic pulse welding into their production. Since the ATP project disproved the old paradigm that dissimilar metals could not be structurally welded, OEMs are rethinking their automobiles' structures and powertrains to find cost savings and fuel efficiencies that were not thought possible before this project.

While clearly important to the automobile industry, magnetic pulse welding has wider applicability. Bimetallic welding enables lighter structures in new shapes and allows for cost savings in a way that could revolutionize the design and manufacture of many kinds of metal-based products.

\section{Conclusion}

ATP funded the development of a new welding method to join dissimilar metals (something never before accomplished for productive structural shapes). Dana Corporation developed magnetic pulse welding and is poised to begin selling components into automotive production. Moreover, the company received four patents as a result of the ATP-funded project. The company had also filed several other patents that had not yet been granted when this project case study was compiled. Magnetic pulse welding has the potential to change the way many kinds of metal items are manufactured by making them lighter, assembled with greater dimensional accuracy, less expensive, and easier to assemble. 


\section{PROJECT HIGHLIGHTS \\ Dana Corporation}

Project Title: Magnetic Pulse Welding Process To Decrease Vehicle Weight and Increase Fuel Efficiency (Advanced Welding Technology-A Phase Shift for Metallurgical Manufacturing)

Project: To develop a versatile manufacturing process (implemented by a new machine that combines a precision metalforming step with an unconventional welding method that is capable of joining dissimilar metals) to build lower cost, lower weight aluminum and steel load-bearing structures, such as car and truck frames. The process requires precisely crafted and machined tubes of metal bonded by heat generated by a rapidly shifting magnetic field.

Duration: 9/10/95-9/9/98

ATP Number: 95-02-0055

\section{Funding ${ }^{\star *}$ (in thousands):}

$\begin{array}{lrr}\text { ATP Final Cost } & \$ 2,000 & 47 \% \\ \text { Participant Final Cost } & \mathbf{2 , 2 2 1} & 53 \% \\ \text { Total } & \$ 4,221 & \end{array}$

Accomplishments: Through ATP funding of this technology, Dana Corporation created a process for welding tubular steel to aluminum without depositing additional metal, overcame technical barriers to join dissimilar metals, enabled new geometries for automobile undercarriages, and maintained the potential to increase fuel efficiency and create a phase shift in automobile manufacturing.

Dana Corporation holds four U.S. patents as a result of this ATP-funded technology and has filed for several others still in the approval process. The patents granted are:

- "Molecular bonding of vehicle frame components using magnetic impulse welding techniques" (No. 6,104,012: filed June 14, 1996, granted August $15,2000)$

- "Method of magnetic pulse welding an end fitting to a driveshaft tube of a vehicular driveshaft" (No. 5,981,921: filed June 20, 1997, granted November 9, 1999)

** As of December 9, 1997, large single applicant firms are required to pay $60 \%$ of all ATP project costs. Prior to this date, single applicant firms, regardless of size, were required to pay indirect costs.
- "Method for joining vehicular frame components" (No. 5,966,813: filed December 13, 1997, granted October 19 1999)

- "Molecular bonding of vehicle frame components using magnetic impulse welding techniques"

(No. 6,234,375: filed August 22, 1998, granted May 22, 2001)

Commercialization Status: Despite delays, Dana Corporation views commercialization of the technology as imminent. The only remaining barrier is to complete extensive durability testing at original equipment manufacturer (OEM) sites, something Dana Corporation expects will occur by the end of 2002. The big U.S. automakers, as well as European companies, have contacted Dana Corporation about using magnetic pulse welded materials in their vehicles. Moreover, the company is ready to provide component parts for fuel-cell or hybrid-electric cars, if and when they are produced in larger volume.

Outlook: The outlook for this technology is good. Safety-related concerns and other manufacturing difficulties delayed commercialization of this manufacturing process, but Dana Corporation has overcome these difficulties. If commercialization occurs as planned, the benefits to automobile manufacturers, automobile purchasers, other industries requiring metal components, and the U.S. economy as a whole could be substantial.

\section{Composite Performance Score: ***}

Focused Program: Motor Vehicle Manufacturing Technology, 1995

\section{Company:}

Dana Corporation

Robeson \& Weiser Streets

P.O. Box 13459

Reading, PA 19612

Contact: Bob Durand

Phone: (610) 371-7111 


\title{
General Electric Corporate Research \& Development
}

\section{Mercury-Free Lighting Could Provide Environmental and Economic Benefits}

\begin{abstract}
In 1994, William Woodburn, then vice president of worldwide marketing for General Electric (GE) Lighting, made the following statement regarding the lighting industry: "What was a relatively stable industry dating back to Thomas Edison's invention, with innovations coming at an evolutionary pace, has accelerated into a revolutionary outpouring of new technology and new products." During the early 1990s, many companies engaged in research and development to create technologies that would lead to further innovation in this field. One impetus behind these initiatives was the need to create lighting systems that are friendlier to the environment, a goal that led companies to focus on developing mercury-free lighting technologies. Many of these efforts centered on an earlier innovation-fluorescent lighting. GE focused on developing mercury-free fluorescent lighting because it recognized the technology's potential economic and environmental benefits. Because the technical risks were too high for internal funding, given the required rates of return when compared with less environmentally friendly products, GE submitted a project proposal in 1993 to seek cofunding from the Advanced Technology Program (ATP). Although the company did not achieve its goal of developing mercury-free fluorescent lighting for existing sockets, it did advance the state of the art of mercury-free fluorescent lighting. GE also used the technologies developed during this three-year project to improve conventional fluorescent lighting. Moreover, the company published papers and gave presentations on the subject and received three patents for technologies related to this ATP project.
\end{abstract}

\section{COMPOSITE PERFORMANCE SCORE \\ (based on a four star rating) \\ *}

Research and data for Status Report 92-01-0132 were collected during October - December 2001.

Mercury-Filled Products Burden the Lighting Industry

For more than 62 years, fluorescent lighting has been used in offices and homes as a low-cost, energy-saving power source. Fluorescent bulbs last longer, are more energy efficient than incandescent bulbs, and have reduced the load on power plants. But there is a downside, fluorescent tubes contain mercury vapor, a substance that is toxic. In the early 1990 s, it cost $\$ 275$ million annually to dispose of fluorescent tubes in an environmentally sound manner, greatly burdening the industry and its end users. In fact, during this period, several states enacted legislation to ban or limit the disposal of any products containing mercury.
Fluorescent tubes contain mercury vapor, a substance that is toxic. In the early 1990s, it cost $\$ 275$ million anunally to dispose of flnorescent tubes, greatly burdening the industry and its end users.

Two essential elements are involved in fluorescent lighting: plasma and phosphors. In a fluorescent tube, electrical energy is used to excite electrons in conducting plasma, which emits ultraviolet photons that then strike a phosphorescent layer on the inner surface of the tube, emitting visible light. Mercury is used in plasma because it converts electrical energy into 
relatively low-energy ultraviolet photons with a high level of efficiency.

\section{Phosphor and Plasma Technology To Replace Mercury-Filled Systems}

In 1992, GE proposed to use ATP co-funding to develop a lighting source that was more environmentally safe and as cost efficient as the original fluorescent bulb. GE pursued research to develop a low-pressure xenon-positive column discharge, which would excite the phosphor to create white light.

\section{GE proposed to use ATP co-funding to develop a lighting source that was more environunentally safe and as cost efficient as the original fluorescent bulb.}

This discharge would replace the mercury gas discharge used in existing fluorescent lamps. GE's plan was to develop the two essential parts of the lamp: 1) the mercury-free discharge to produce the ultraviolet light and 2) the quantum-splitting phosphor that would convert the ultraviolet light into acceptable visible light. To replace the mercury, it was necessary to find a lowpressure plasma source that was comparable to the high efficiency level of mercury (roughly 65 percent) and was compatible with existing phosphors.

The difficulty was to create a mercury-free product that could be used immediately in current socket structures, since GE anticipated there would be low market penetration for a product that used new socket structures. Therefore, the company decided to concentrate its efforts on developing commercial phosphors and on lowering the amount of mercury in its current fluorescent lights, rather than creating a new mercury-free product. The technical risks for this project were too high to allow GE to use internal funds because other, less environmentally friendly products could produce a higher rate of return. The potential broad benefits to the economy and the environment from this project, however, could be significant.

\section{Partnerships Contribute to Technical Success}

GE's alliance with ATP gave the company access to rich resources throughout the life of the project and allowed G드 to gain the support of valuable university subcontractors to perform some of the research. For example, the California Institute of Technology studied circuit topologies in an effort to develop a ballast prototype to contain the mercury-free light. (The ballast starts the lamp and then regulates the electric current that flows into it.) The University of Wisconsin helped in assessing plasmas as ultraviolet light sources. Access to the expertise at these universities proved invaluable to the research.

\section{GE achieved spin-off benefits related to the development of quantum-splitting phosphors. The completed work on quantum-splitting phosphors led to an increased interest anong universities.}

Through ATP, GE met another ATP award recipient, Photonics Imaging, which manufactures plasma flat panel displays (PFPDs). A technology overlap existed between GE's primary path in this project and Photonics Imaging's primary path in developing PFPDs. GE's path involved low-pressure xenon-positive column discharge and an efficient phosphor used to create white light. Photonics Imaging's path was aimed at an intermittent atmospheric-pressure discharge in a gas mixture containing xenon, which excites phosphors to create red, green, and blue pixels. Through discussions regarding similar uses of phosphor technology, the companies shared knowledge that proved valuable to both efforts.

\section{GE Encounters Technical Difficulties, but Realizes} Spin-Off Opportunities

GE was able to achieve operating conditions under which a direct-current xenon discharge reached approximately two-thirds of the efficiency and output of a conventional fluorescent lamp. Unfortunately, the research team was not able to achieve its goal of a candidate discharge (low-pressure xenon-positive column) that was highly efficient at a high-discharge power density.

However, GE achieved spin-off benefits related to the development of quantum-splitting phosphors as well as technologies that can be used in any type of fluorescent 
lighting. The completed work on quantum-splitting phosphors led to an increased interest among universities and within GE to further develop such phosphors. GE is currently pursuing additional research and development efforts in this area.

The following technologies developed through this ATP project can be used in any type of fluorescent lighting:

- Lifelong, low-pressure cathodes, which led to higher lamp efficiency, lower ballast costs, and better performance from lamps that are frequently switched. These cathodes are used in a range of applications, from basic lighting to electron microscopes and plasma cathode electron guns.

- Electronic ballasts, which have advantages over conventional electromagnetic ballasts, including smaller size, lower weight, higher efficiency, and faster starting and dimming capability. This cheaper, more efficient method of applying power electronics to improve traditional fluorescent lighting eliminates flickering and reduces the acoustic noise associated with fluorescent bulbs.

- Electromagnetic shielding of ballast, lamp, and phosphors, which led to higher efficiencies by protecting the power system from spikes in energy and from the heat of the lamp.

\section{Conclusion}

Through the research performed during this project, GE made advances in the design and production of quantum-splitting phosphors. Although GE was not able to develop a mercury-free fluorescent light that is as efficient as mercury filled lights, the technologies developed have been used to improve conventional fluorescent lighting. For example, oxide quantumsplitting phosphors are being used generically in conventional fluorescent lights and in the development of miniature lamps. 


\section{PROJECT HIGHLIGHTS \\ General Electric Corporate Research \& Development}

Project Title: Mercury-Free Lighting Could Provide Environmental and Economic Benefits (Mercury-Free Fluorescent Lighting)

Project: To demonstrate the feasibility of developing an environmentally safe, cost-competitive fluorescent lamp source that is as efficient as the currently used mercury-filled fluorescent lamps.

\section{Duration: 5/10/1993-5/9/1996}

ATP Number: 92-01-0132

Funding ${ }^{* *}$ (in thousands):

$\begin{array}{lrr}\text { ATP Final Cost } & \$ 1,336 & 40 \% \\ \text { Participant Final Cost } & \underline{2,044} & 60 \% \\ \text { Total } & \$ 3,380 & \end{array}$

Accomplishments: Through the ATP funded project, GE made improvements in the design and production of quantum-splitting phosphors. Although the company did not develop efficient mercury-free fluorescent light, the technologies developed have been used to improve conventional fluorescent lighting. GE also accomplished the following:

- Achieved a breakthrough in getting quantum-splitting phosphors to work in everyday chemicals (oxidebased) that are regularly used in manufacturing

- Published several technical papers and gave presentations regarding the mercury-free fluorescent lamp program and research that was conducted during the project

- Received the following patents for technologies related to the ATP project:

- "Quantum splitting oxide phosphor and method of making"

(No. 5,57 1,451: filed January 3, 1995, granted November 5,1996 )

- "Determination process for determining if quantum splitting phosphors are obtained and novel compositions"

(No. 5,788,883: filed February 28, 1997, granted August 4, 1998)

- "Mercury-free ultraviolet discharge source" (No. 5,866,984: filed November 6, 1997, granted February 2, 1999)
Commercialization Status: GE was not able to commercialize the technologies that were developed under this project. The company is continuing to work to develop a commercial phosphor, however, and is concentrating its efforts on lowering the amount of mercury in existing fluorescent lights.

Outlook: While a clear path does not seem to exist for replacing mercury-filled fluorescent lighting with a mercury-free product, the research and development conducted during this project has led to further development in fluorescent technology. GE continues to improve its ability to measure phosphorquantum efficiencies and to assess new candidate phosphor material, working toward its goal of developing a quantumsplitting phosphor that can be manufactured.

\section{Composite Performance Score:}

\section{Company:}

General Electric Corporate Research \& Development One Research Circle

Niskayuna, NY 12309

Contact: Dr. Timothy Sommerer

Phone: (518) 387-6440

\section{Subcontractors:}

California Institute of Technology University of Wisconsin

"As of December 9, 1997, large single applicant firms are required to pay $60 \%$ of all ATP project costs

Prior to this date, single applicant firms, regardless of size, were required to pay indirect costs. 


\title{
Octahedral Hexapod Design Promises Enhanced Machine Performance
}

\begin{abstract}
In the field of advanced machine tools, enhanced performance is seldom achieved without greater design complexity, reduced operational flexibility, and higher costs. These drawbacks have stalled innovation in the U.S. machine tool industry, where most research and development (R\&D) efforts focus on incremental improvements to conventional machines. Ingersoll Milling Machine Company developed its octahedral hexapod prototype, which promised superior accuracy, stiffness, and speed, as well as lower prices, shorter delivery times, simpler assembly, and greater accessibility. Further development of the octahedral hexapod tool concept had the potential to boost U.S. status in a competitive international market and to bolster smaller manufacturing companies by meeting their need for highprecision machine tools at an affordable price. However, because the industry viewed Ingersoll's prototype as a radical design and its continued development as too high risk to fund, the company sought and received funding from the Advanced Technology Program (ATP).
\end{abstract}

Since 1996, when the project ended, sales of the octahedral hexapod machine have been limited to three laboratories. However, Ingersoll's R\&D during the ATP project laid the foundation for eventually bringing the octahedral hexapod to maturity. Moreover, the company's efforts have resulted in additional research by two-dozen machine companies that are currently investigating this machine tool.

\section{COMPOSITE PERFORMANCE SCORE \\ (based on a four star rating)

Research and data for Status Report 92-01-0034 were collected during October - December 2001.

\section{Manufacturing Industry Needs More Precise Tools}

The machine tool industry depends heavily on stackedaxis computer-numerical-control (CNC) machines, which achieve a specified position and orientation of the spindle by controlling individually as many as six positioning axes ( $X, Y, Z$, roll, pitch, and yaw). The CNC commands up to six separate movements, each performed independently, whose combined effects produce a target position. However, the stacked-axis machine architecture generates cumulative error. This occurs because inexact positioning on one axis dislocates the positioning of the spindle on the next axis, which multiplies the imprecision with each subsequent adjustment. In addition to this design shortcoming, the traditional stacked-axis machine requires a massive granite foundation for stability. This results in a cumbersome unit that takes up considerable factory floor space and is difficult to transport.
The manufacturing industry desired a more precise tool. The development of a high-precision, low-cost machine tool became imperative for small companies' ability to enhance the quality of U.S. products. Moreover, innovation was vital for the United States to improve its position in the machine tool industry (the nation lagged behind Japan and Germany in a competitive market, with domestic manufacturing companies importing $\$ 1.6$ billion in machine tools in 1991).

\section{The Octahedral Hexapod Offers Promise}

In 1987, a radical concept caught the attention of engineers at Ingersoll. Eventually called the octahedral hexapod, this novel design creatively employs the Stewart platform concept, most commonly known for its application in flight simulators. The Stewart platform, a floating base supported or suspended by six actuators, is familiar to several generations of pilots (it was the basis for the design of the Link flight simulator). 
The octahedron, a regular geometric shape of eight equilateral triangles, is built on an octahedral frame and a Stewart platform actuation, the hexapod. Machining operations take place within the octahedral frame, and the struts, or the pods of the hexapod, directly translate the force generated during the machining operation to the six vertices of the octahedral frame. The shape has such stiffness that when a load is applied, the frame responds by distributing the weight of the load evenly throughout the shape, eliminating much of the bending because of the shape's stiffness. Furthermore, the six axes are in simultaneous movements rather than the independent sequential movements experienced with the CNC machine. Hence, the shape of the octahedral hexapod tool would offer six times the machine stiffness and five times the position accuracy of the traditional $\mathrm{CNC}$ machines.

Under the ATP award, Ingersoll planned to use a laboratory prototype octahedral hexapod machine (which they had constructed prior to the ATP project with their own funding) to develop detailed baseline data on the performance of the design. Then they would try various enhancements to improve and measure machine precision. The results would be used to design a future class of commercial machines based on the octahedral hexapod concept.

\section{ATP Provides Early Catalyst for R\&D Proliferation}

As indicated by the numerous predicted uses of the octahedral hexapod, this technology has the potential to substantially impact a wide range of manufacturing industries across the supply chain. However, the risk of funding research for such a radical design was too high for either machine tool companies or their manufacturing clients. Moreover, if Ingersoll absorbed the cost of the extensive R\&D required to fully develop the octahedral hexapod, it would have to subsequently increase the cost of its machine tools by at least 20 percent. This cost escalation would put their products in a range that would be prohibitive for many smaller companies, such as those who provided parts for the automobile industry.

The concept demonstrated the potential to evolve into a machine tool that offered double the accuracy at a selling price and life cycle cost that was 30 percent less than that of the best existing technology. Therefore, ATP awarded cost-shared funding to Ingersoll.

\section{Project Slowly Overcomes Technical Obstacles}

With a prototype of the octahedral hexapod as a starting point, Ingersoll set out to design and develop several applications to achieve the machine tool's maximum potential for improved accuracy and precision. Though the design concept itself was in place, other components essential to achieving these performance objectives needed to be developed.

This teclmology has the potential to substantially impact a wide range of mannfactming ind nstries.

A key step of this process was the development of a computer control system and accompanying software that were capable of processing the complex algorithmic calculations necessary to command the parallel movement of the hexapod's six struts. To direct these complicated six-axis moves in real time, the processor requires a calculation power equivalent to that of several fast PCs combined. Additionally, the software needs to compute error as well as offset data, thermal deviations, and compensation formulas. During the project, Ingersoll worked with software suppliers GE Fanuc and Siemens to incorporate software algorithms into a central control system, taking important strides toward the full computerized alignment envisioned for ideal accommodation of the octahedral hexapod. Ingersoll was able to begin the development of the system during the ATP project. However, the development and programming of such a system proved to be extensive and time-consuming, demanding R\&D beyond the timeframe of the ATP project.

Ingersoll also faced the challenge to develop a calibration system that would guarantee high-level accuracy, enabling the machine tool to manufacture parts repeatedly within specified tolerances. Because of its design, the octahedral hexapod concept did not lend itself to conventional inspection techniques. Therefore, before it could be commercialized, Ingersoll needed to develop a turnkey calibration method that could be performed more quickly and efficiently than the existing labor-intensive procedure. To this end, the company worked to implement a self-calibration system that would allow machines to check their own performance and correct any detected inaccuracies. 
In addition to these tasks to install control and calibration systems, Ingersoll encountered obstacles in developing the supporting electronic and mechanical components of the octahedral hexapod machine tool. However, the company maintained steady and productive R\&D efforts throughout the ATP project, continuing to demonstrate promise for eventual commercialization and revealing more and more possible applications.

\section{Sustained R\&D Points to Commercialization on the Horizon}

At the conclusion of the project in 1996, the technology components of the octahedral hexapod were well understood; however, six years later, the machine tool was still in development. While several fully functional hexapods exist, researchers must improve their accuracy, streamline the production process, develop standards, and solve small but important mechanical problems before pursuing full-fledged commercialization. Based on the interest generated by Ingersoll's original prototype, there are currently about two-dozen companies that have invested R\&D funds in hopes of bringing the Ingersoll hexapod to market.

\section{The connany maintained steady and prodnctive $R \& D$ efforts thronghont the ATP project, however, six years later, the machine tool was still in developnent.}

Ingersoll has sold three octahedral hexapods, one each to the National Institute of Standards and Technology (NIST), Lockheed-Martin's research facility, and Aachen University. Because Ingersoll's current goal is the evaluation of production techniques rather than sales, only a national laboratory, a large corporate research facility, and a university have purchased hexapods. Octahedral hexapods are custom-made because Ingersoll has not developed a protocol for high-volume, quick, and affordable manufacturing. Future research will address production problem areas, such as computer control systems and struts, which together account for 75 percent of the machine tool's cost. Other research will focus on simplifying the hexapod's design, since reducing the number of machine parts could lower costs by an estimated 40 percent.
Calibration, control, and thermal compensation issues persist as roadblocks to commercialization, reducing the octahedral hexapod's ability to repeatedly manufacture parts within specified tolerances. Using an octahedral hexapod purchased from Ingersoll, a project at NIST's Manufacturing Engineering Laboratory, supported in part by ATP intramural funds, is addressing these problems by setting common performance-evaluation procedures and developing measurement methods to achieve high positioning accuracy.

Scientists at NIST have focused on implementing a built-in metrology system and an enhanced machine controller that simplifies performance-enhancing modifications in software or hardware. Ingersoll has improved thermal compensation techniques by using laser feedback that senses and eliminates deviant length changes of the hexapod's struts. Additional postproject research will determine the optimal machine configuration and the most advantageous strut length given a particular working envelope size (the work area).

\section{Researchers Identify Multiple Uses for the} Octahedral Hexapod

As researchers assessed the mechanical and electronic specifications for the octahedral hexapod, they discovered the versatility and flexibility of this machine tool. Engineers at Ingersoll predict that the hexapod could become a general manipulator for various tasks or a universal carrier for several end effectors, such as milling heads, coordinate measuring machine probes, and turning tools. These engineers anticipate that current R\&D efforts will lead to the octahedral hexapod's role in numerous applications, including the following:

- Mold and die industry uses, such as contouring large surfaces and machining dies for precision sheet-metal forming

- The machining of high-value, low-volume, high-complexity components, such as titanium for use in military aircrafts

$\circ$ The machining of lighter metals and materials 
- Precision assembly technology; for example, delicate welding in an automotive assembly line and in aerospace and aircraft production

\section{Conclusion}

Dennis Bray, vice president of engineering at Ingersoll, reports that the current configuration of the octahedral hexapod would not have been designed without ATP funding. The ATP project allowed Ingersoll to tackle a number of the deficiencies identified in the original prototype and to bring the hexapod closer to full-scale development. Additionally, ATP funding helped to validate the unconventional concept and design of the octahedral hexapod, convincing other machine tool companies of its worth and generating further investment in its $R \& D$. Although commercialization of the octahedral hexapod machine tool has stalled, Ingersoll continues to research methods to improve accuracy, streamline the production process, and develop the ability to manufacture parts repeatedly within specified tolerances, with reasonable production costs. 


\section{PROJECT HIGHLIGHTS \\ Ingersoll Milling Machine Company}

Project Title: Octahedral Hexapod Design Promises

Enhanced Machine Performance (Octahedral Hexapod Machine

Development Program)

Project: To demonstrate a revolutionary new design for highprecision, multi-axis machine tools based on an octahedron frame and a Stewart platform actuator.

Duration: 3/1/1993-2/28/1996

ATP Number: 92-01-0034

Funding (in thousands):

\begin{tabular}{lrr} 
ATP Final Cost & $\$ 1,864$ & $53 \%$ \\
Participant Final Cost & 1,635 & $47 \%$ \\
\cline { 2 - 2 } & $\$ 3,499$ &
\end{tabular}

Accomplishments: Ingersoll has sold three octahedral hexapod machine tools, one each to NIST, Aachen University, and Lockheed-Martin's research facility, to be used for further R\&D. The company performed several demonstrations of its prototypes to potential clients such as Boeing Corporation and the U.S. Air Force. These demonstrations created interest and generated constructive feedback.

Ingersoll received the following patent for its work:

- "Octahedral machine tool frame"

(No. 5,392,663: filed November 9, 1993, granted

February 28, 1995)
Commercialization Status: Due to the need for additional research, Ingersoll has not been able to fully commercialize the octahedral hexapod. However, the company has sold three of these machine tools, generating $\$ 6$ million in revenue.

Outlook: The outlook for the octahedral hexapod is clouded. At this point, researchers at Ingersoll have been unable to combine accuracy and the ability to manufacture parts repeatedly within specified tolerances with reasonable production costs. This has stalled the commercialization of the octahedral hexapod machine tool. However, several companies continue to research the octahedral hexapod tool concept.

\section{Composite Performance Score:}

\section{Company:}

Ingersoll Milling Machine Company

707 Fulton Avenue

Rockford, IL 61103

Contact: Dr. Dennis Bray

Phone: (815) 987-6891 


\section{M\&M Precision Systems Corporation}

\section{World's Most Accurate Gear-Measurement Machine}

Automobile transmissions, submarine screws, and helicopter rotors can all be made quieter, smoother running, and more efficient with enhanced gear precision. By the 1980s, American gear-measurement instruments were beginning to lag behind the accuracy of gearmanufacturing technology, and the gear-measurement market shifted toward foreign-made instruments that had a higher level of accuracy. In 1994, M\&M Precision Systems Corporation, in collaboration with Pennsylvania State University, submitted a proposal to the Advanced Technology Program (ATP) to develop a highly accurate gear-measurement machine. ATP awarded co-funding for a three-year project, and M\&M subsequently successfully developed gear-measurement technology that was more than five times more accurate than existing U.S. gear-measurement tools. The technology was later commercialized, which increased the U.S. share of the global gear-measurement machines market to 50 percent and led to a resurgence of confidence in the accuracy of American gears.

\section{COMPOSITE PERFORMANCE SCORE \\ (based on a four star rating) \\ **}

Research and data for Status Report 93-01-0191 were collected during October-December 2001.

Gear Precision Inaccuracy Harms U.S. Gear Industry

Gears have been used for centuries and are critical mechanical elements in the operation of a device that requires a transfer of motion and power to enable rotation. A mainstay of civil and military engineering, gears are in virtually all motor vehicles, aircraft, machine tools, and military combat vehicles. One of the constants of the industry is that as gears become more exact, their operation becomes smoother, quieter, and more efficient As gear-manufacturing technology became more complex, however, it was more difficult to perform gear measurements with the degree of accuracy required; thus, precision in gear manufacturing began to suffer. Partly as a result of this declining precision, the U.S. gear industry began to suffer, and German firms began taking more dominant control of the world market.

\section{M\&M Proposes World's Most Accurate Gear- Measurement Machine}

No single company or organization had the capabilities or could afford the investigation required to research and identify the problems with gear-measurement machines. Therefore, M\&M teamed with Pennsylvania State University to study current gear-measurement technology, to identify and eliminate weaknesses, and to create the world's most accurate gear-measurement machine.

\section{ATP Funds Development of New Technology}

Recognizing that the future of both the U.S. gear and gear-measurement industries depended on improvements, ATP funded the research and development of new gear-measurement technology.

M\&M teaned with Penusylvania State University to create the world's most accurate gearnueasurement machine.

Awarded in 1994, the ATP grant provided a fresh start to the industry-an opportunity to reassess the technology, correct existing problems, and develop breakthrough technologies to enhance the precision of gear measurement. Moreover, the potential for 


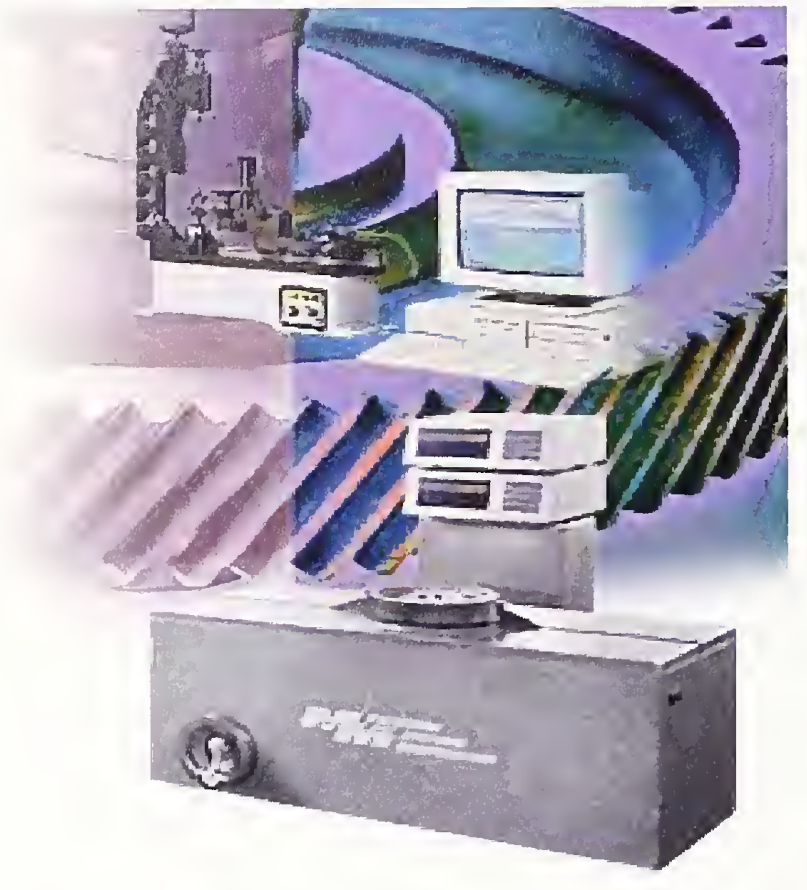

M\&M's 3500-series machine has automatic software-driven correction, rotary axis motion, and new control technology.

far-reaching economic spillover was high. The technology would impact the nation's 350 gear and gear-related component manufacturers.

\section{M\&M Addresses Technical Issues}

First, M\&M engineers had to correct errors inherent in the operation of gear-measurement machines. Gearmeasurement machines typically rotate the gear and compare the specimen with precise measurements taken from the appropriate gear mold. Gearmeasurement machines cannot hold a specimen perfectly still, which causes errors in the final measurement. To solve this problem, M\&M developed algorithms for the computer correction software that adjusts measurements for errors caused by the gearmeasurement machine itself. Second, M\&M tried to incorporate a linear motor into the gear-measurement machine to enable "on-the-fly" operation. Typically, gear-measurement devices set the gear in one place, take a measurement, move the gear to another fixed spot, and take another measurement. This is a timeconsuming process, and M\&M sought to improve the speed of gear-measurement machines by taking laser measurements as the gear rotated. Unfortunately, linear motors did not run smoothly enough to allow accurate measurements, and the gear-measurement machines resulting from the project did not have the desired on- the-fly measurement capability. In the years following the ATP project's completion, however, linear-motor technology advanced to the point where the second generation of M\&M gear-measurement machines now has this capability.

\section{ATP Project Leads to Technology and Knowledge Spillover}

What began as a partnership with Pennsylvania State University evolved into a coalition of several universities. After the ATP project, M\&M entered into cooperative research agreements with professors and laboratories at the University of North Carolina, Ohio State University, and the University of Toledo. Not only do these alliances generate new innovations from the academic labs, but they also train students to enter industry fully prepared to operate in, and improve upon, cutting-edge technology. According to Dean Hawk, M\&M's ATP principal investigator, gear-measurement software technicians typically are not productive for the first four to six months of their tenure in the industry because they must climb a steep learning curve. Recently hired graduates of the collaborating universities, however, are capable of stepping in and being productive from day one.

\section{Conclusion}

As a result of this ATP project, M\&M brought its 3500series machine to market in 1998. The machine's most important innovations were automatic software-driven correction, rotary axis motion, and new control technology. The 3500-series machine measures spaces between gear teeth to within 0.22 uncertainty microns and provides an entire tooth profile to within 1.3 microns. This represents improvements over prior capabilities of 78 percent and 74 percent, respectively. The 3500-series machines developed through this project helped M\&M to gain approximately 50 percent of the world's market share for gear-measurement machines and to increase its U.S. market share to 70 percent in the years after the project concluded.

According to an M\&M executive, more accurate gears enabled the U.S. automobile industry to increase the quality of its transmissions. Moreover, in the defense industry, U.S. submarines and aircraft are now the quietest in the world, in part because of their more precise gear operation. 


\section{PROJECT HIGHLIGHTS \\ M\&M Precisions Systems Corporation}

Project Title: World's Most Accurate GearMeasurement Machine(Advanced Gear-Measurement Technologies to Achieve Submicron-Level Accuracies)

Project: To create a new generation of gearmeasurement machines, which were necessary to enhance the accuracy of American-made gears, to create smoother running transmissions, and to maintain market share for gear-measurement machines within the United States

Duration: 4/1/1994-3/31/1997

ATP Number: 93-01-0191

\section{Funding (in thousands):}

$\begin{array}{lrr}\text { ATP Final Cost } & \$ 1,950 & 64 \% \\ \text { Participant Final Cost } & 1,093 & 36 \% \\ \text { Total } & \$ 3,043 & \end{array}$

Accomplishments: This ATP project led to a revolution in gear-measurement technology and innovations in motor-powered transportation transmissions that were not possible before the project. By starting over and aiming to design the perfect gearmeasurement machine, M\&M achieved submicron-level accuracy in gear measurement. This ATP-funded project generated the following new technologies and process improvements:

- Automatic computer-controlled errorcorrection software

- Rotary-axis technology, enabling smoother and faster gear measurements

- New control technology, enabling a smoother, more precise gear motion during measurements

Commercialization Status: Before this ATP project, no U.S.-based company had the ability to measure gears to less than one-micron accuracy. Because this measurement inability created uncertainty about the precision of U.S.-manufactured gears, U.S industrial customers turned to foreign companies for both gears and gear-measurement systems.
The error-correction software and control mechanisms developed by M\&M during this ATP project were later commercialized into the 3500 -series measurement machine. The 3500 -series machine measures spaces between gear teeth to within 0.22 uncertainty microns and provides an entire tooth profile to within 1.3 microns, an improvement over previous capabilities of 78 percent and 74 percent, respectively.

The 3500-series machines helped M\&M gain approximately 50 percent of the world's market share for gear-measurement machines and to increase its U.S market share to 70 percent. Additionally, the technology had an immediate impact on the 350 gear and gearrelated component manufacturers within the United States. The many improvements developed during M\&M's ATP project have been incorporated extensively into automobile transmissions, submarinescrews, and nelicopter rotors.

Outlook: The prototype machine developed through this ATP project continues to be the gear-measurement industry's "gold standard." The newest generation, which made its debut at gear shows in Detroit and Germany in late 2001, includes linear motors for on-the-fly measurement, in addition to the improvements already made through the ATP-funded project. These machines should continue to dominate the gear-measurement industry, allowing quieter, smoother running transmissions and gear assemblies for the foreseeable future.

\section{Composite Performance Score: * *}

Number of Employees: Seventy-seven employees at project start, 70 upon completion of status reports.

\section{Company:}

M\&M Precision Systems Corporation 300 Progress Road

West Carrollton, $\mathrm{OH} 45449$

Contact: Dean Hawk

Phone: (937) 859-8273 


\section{Perceptron (formerly Autospect, Inc.)}

\section{Laser Ultrasonics to Improve Automotive Painting Process}

Whether the hue is sports-car red, school-bus yellow, or sleek black, the automotive painting process has frustrated manufacturers for years. Of all automotive manufacturing processes, painting has historically been the most costly (\$345 per vehicle in 1995) and arguably the most painstaking, involving 13 discrete steps. Moreover, the slightest inaccuracy can cause corrosion, adhesion, and poor finish, requiring that the auto body undergo a costly repair process. Existing paint-thickness-measurement systems could only measure dry paint, so by the time controllers detected errors and made proper adjustments, paint-booth operators had often coated up to 100 more units. To remain competitive, U.S. automotive manufacturers needed an accurate and reliable non-contact method for online paint-thickness measurement, and in 1995, Autospect proposed to develop a new wet-paint-thickness measurement system using its existing laser ultrasonics $(L U)$ method.

Autospect suggested that three significant benefits would accrue to the industry: savings of $\$ 683$ million annually for the Big 3 auto manufacturers (Ford, General Motors, and DaimlerChrysler), improved vehicle quality, and lower volatile organic chemical emissions. Due to the technical risk, direct funding from the Big 3 was unavailable; they did, however, commit to participating in the project's process integration stage. In 1995, Autospect was awarded \$1.8 million in cost-shared funding from the Advanced Technology Program (ATP) to develop a wet-film-measurement (WFM) system. By the end of the ATP project in 1998, Perceptron had successfully produced a prototype LU WFM system for a DaimlerChrysler test site. Though the prototype WFM system has proven its value and technical viability, Autospect (now Perceptron, which acquired Autospect in 1997) encountered severe financial difficulties in 1998 that have forestalled its ability to commercialize the technology.

\section{COMPOSITE PERFORMANCE SCORE \\ (based on a four star rating)}

*

Research and data for Status Report 95-02-0005 were collected during October - December 2001.

Measurement Techniques Fail to Simplify

Painstaking Painting Process

In the early 1990s, the painting process represented a disproportionate amount of the total automobile manufacturing costs and labor requirements, requiring several expensive materials and 13 discrete steps to coat a bare-metal auto body with a high-quality finish. Additionally, painting errors were frequent and costly, and the paints and solvents used posed a threat to the environment. Consequently, there was increased pressure from both consumers and environmentalists to produce high-quality finishes through efficient methods.
For example, a 1994 Delphi study indicated that 50 percent of consumer appeal and satisfaction derives from factors directly or indirectly related to the automobile's paint job, such as appearance, durability, and resistance to scratching. Further, amendments to the 1989 Clean Air Act limited the discharge of volatile organic chemicals (VOCs), thereby requiring automotive manufacturers to consider the environment by more efficiently using paints and solvents.

Before the ATP project, existing paint-thicknessmeasurement methods failed to help automotive manufacturers address these concerns or to reduce the 
high cost of painting each vehicle. At the time, noncontact-measurement techniques were not reliable outside the laboratory, so magnetic-inductance methods, including the Elcometer and the Fischer Scope, were the only available paint-measurement technologies. Both of these methods were extremely time-consuming. After each coat (i.e., the electrocoat, primer, base coat, and clear coat), manufacturers had to wait for the coat to dry and then had to remove the test vehicle from the assembly line for inspection of the coat at 60 to 80 points on the car's surface.

Fifty percent of consumer appeal and satisfaction derives from factors related to the antomobile's paint job.

With these costs, manufacturers could only afford sampled quality control, measuring approximately 1 to 3 cars per day, or about 1 out of every 500 vehicles. Moreover, the slowness of the quality control contributed to poor feedback response time. By the time quality control detected a problem and made proper adjustments, up to 100 vehicles had passed through the defective painting production line. Manufacturers had to repair all vehicles with defective paint coatings by using one or both of the low bake repair (LBR) and high bake repair (HBR) processes, at a cost of $\$ 600$ to $\$ 1,200$ per vehicle in 1995. In some extreme cases, the manufacturer had to completely scrap the vehicle. At the time of the ATP project, 15 percent of all vehicles required $\mathrm{HBR}$, putting a massive strain on overall automotive production budgets.

\section{Autospect Proposes a More Efficient Coating Process}

To address the problems that riddled the automotive painting process, Autospect proposed to develop a wetfilm-measurement (WFM) system that would provide non-contact inspection and online measurement. This process would eliminate the need for an operator and would allow manufacturers to measure every vehicle, thus reducing the time it took them to detect and respond to problems in the coating process. Thickness and distribution information would feed back immediately to logic controllers that controlled paint flow to sprayers, reducing the number of vehicles that passed through the process after error detection from up to 100 units to just 1 to 2 units. With accumulated feedback data, manufacturers could correlate wet-filmbuild measurements with flow-control methods so they could predict future behavior and develop more precise systems.

\section{Rednced paint use and rednced defects wonld save \$683 million annually for the Big 3 unannfacturers and wonld lower costs and improve quality for consunters.}

Autospect envisioned a non-contact WFM system that included a precise and reliable instrument for the online measurement of paint thickness and that provided closed-loop feedback in real time for the painting process. The proposed system would function in the hostile environment of the factory paint booth, withstanding paint splatter, temperature and humidity fluctuations, and exposure to evaporated solvents, without performance degradation.

\section{Broad-Based Benefits Extend to the Environment and Consumers}

The proposed WFM system also promised broad-based economic benefits. The automotive industry would reap significant advantages, as demonstrated in Autospect's cost-benefit analysis. Before the ATP project, 106 of the 168 paint production lines in North America used Autospect's existing QMS-I and QMS-BP products. Thus, the company's equipment assisted in the production of nine million vehicles annually. The average cost of paint required to coat a vehicle was $\$ 345$. Unfortunately, up to 60 percent of the paint was wasted due to inefficient production processes.

Therefore, a measurement system that reduced excess paint could lead to savings of up to $\$ 200$ per vehicle. Conservatively estimating that its WFM system would save $\$ 50$ in paint per vehicle, Autospect projected an annual savings of $\$ 360$ million for its existing customer base. Because figures indicated that 15 percent of all vehicles required HBR at a cost of at least $\$ 600$ per vehicle, a system that prevented painting defects could save Autospect's customers another $\$ 323$ million 
annually. Thus, reduced paint use and reduced defects resulting from the company's WFM system would save $\$ 683$ million annually for the Big 3 manufacturers and would lower costs and improve quality for consumers.

Autospect also expected that consumers would benefit from improved vehicle appearance as well as from reduced repair costs related to low-quality paint coats that easily scratch and corrode. Autospect identified the environment as another beneficiary, since a more efficient painting process would lead to lower VOC emissions. Further development of a WFM system could provide advantages to other industries in which the painting of large surfaces is expensive and environmentally hazardous, such as the aerospace and coil-coating industries. Finally, Autospect itself would benefit by tapping into a potential market of $\$ 500$ to $\$ 750$ million, increasing its engineering leadership by 5 to 10 employees, and strengthening its position to provide best-in-class measurement and control for the U.S. automotive industry.

\section{WFM Technology Supported by Industry But} Lacks Funding

Despite the many potential benefits, Autospect recognized the high risk involved in developing a breakthrough product. Measurement systems that appear promising from a theoretical standpoint often fail to realize the flexibility and ruggedness required for the factory floor. Thus, as a small company with about 10 employees and limited internal research funds, Autospect could not single-handedly undertake such a project. Without additional funding, Autospect would need to scale back its goals and focus on small, incremental development.

Although unable to find private funding, Autospect secured the support of the entire industry for cooperative development and feedback. The Big 3 auto companies committed to participating in the project's process integration stage. Painting-robot manufacturer Fanuc, paint shop manufacturer Haden, and automotive paint suppliers PPG and BASF agreed to help, and PPG also offered the use of its Flint Applications Facility for product testing. Confident of the importance of WFM technology to the automotive industry, Autospect applied for and was selected to receive $\$ 1.8$ million in cost-shared funding from ATP's 1995 motor vehicle manufacturing technology-focused program competition.

\section{Laser Ultrasonics Can Improve Efficiency and Reduce Costs}

In accordance with its plan, Autospect explored three potential measurement techniques. After eliminating other non-contact methods, such as an alternating current impedance method and a method using microstrip microwave resonators, Autospect turned to laser technology to develop the ideal technique for wet-film measurement. Extensive research indicated that laser ultrasonics (LU), a non-contact ultrasound technique, was most promising in terms of repeatability, measurement sensitivity, practicality, and cost.

Autospect valued the LU method for its simplicity. It requires only three square feet of paint booth space and three main components: two lasers and an interferometer. To measure wet-paint thickness, the first laser produces a very short pulse to generate ultrasound on the painted surface. The absorption of this light causes a temperature rise in the paint film, inducing a density gradient in the material and thereby producing an ultrasonic acoustic signal. Thus, the short laser pulse is analogous to a quick hammer strike to a bell. The second laser detects the minute ultrasonically induced motions (about 0.1 nanometers) on the paint surface. This detecting laser light is reflected off the surface and coupled into the interferometer, which strips away and measures the surface vibrations. The resulting spectra provide raw data for analysis, as film thickness has an inverse relationship to resonant frequency.

In addition to saving paint booth space, which costs about $\$ 100,000$ per square foot, the LU method has many other advantages. The system can measure all automotive body coatings, both wet and dry. Its measurement is extremely fast and does not require calibration, even for new paint materials. Since laser light can be fiber-optically coupled to the paint booth, a manufacturer can place sensitive equipment far away from the spray area, thereby eliminating splatter disturbance and vibration problems. The LU method also provides advantages on the factory floor because the measured parametric frequency of the ultrasound is 
not affected by changes in intensity of the signal, which is a parameter susceptible to many environmental conditions. Finally, and perhaps most importantly, the LU system can be multiplexed; that is, 250 or more sensors in multiple locations can make measurements that feed to one set of equipment, allowing for the measurement of every vehicle in a plant by a single system.

\section{Successful Prototype Proves System's} Technical Feasibility

By the end of the ATP project in 1998, Autospect (hereafter referred to as Perceptron, which acquired Autospect in 1997) had successfully developed a WFM system and had achieved positive results from in-plant testing at PPG's Flint facility. Perceptron engineers Jeffrey White, Frederick LaPlant, and John Dixon coauthored a paper with PPG engineers Donald Emch and Vince Datillo that discussed the LU WFM technology. The paper, titled "Non-Contact Real Time Film Thickness Gauge," won the Best Paper Award at the 1998 International Body Engineering Conference.

Shortly after the close of the project, Perceptron sold a prototype system to DaimlerChrysler and installed it at the company's Windsor Assembly Plant, creating an alpha test site. Tests at the Windsor facility continued to prove the system's technical feasibility. Perceptron initiated its eight-stage product development process and planned its next step to pursue sales of the WFM system to each of DaimlerChrysler's eight plants. In 1998, Perceptron set target sales at 4 systems by 2000 and another 8 in 2001, with the hope of ramping up sales to 12 annually by 2002 .

Financial Difficulty Halts Perceptron's Commercialization Effort

Equipped with a clear-cut business plan, Perceptron aimed to move forward to commercialize the LU WFM technology. However, the company began to experience the effects of the automotive industry's 1991 to 1993 slump and its stagnant sales from 1994 to 1997. The company's stock, which had peaked at just under $\$ 40$ a share and had held steady there during 1996 and 1997, dropped to about $\$ 20$ per share in the second half of 1998. Since then, Perceptron has not been able to recover, with its stock continuing to fall to around $\$ 5$ per share between 1999 and 2000. In 2001, its shares decreased further and as of fall 2001 were valued at $\$ .03$

Because of these severe financial difficulties, Perceptron has focused on survival strategies, and product development of the new WFM technology has become a low priority. Perceptron has managed to invest more than $\$ 1$ million of its internal funds since the close of the ATP project, working with DaimlerChrysler to fine-tune the prototype and to convert raw thickness and distribution data into useful feedback information. Perceptron estimates that the system will require three years of product development before full-scale commercial release becomes feasible. At this time, the company is unable to pursue that development due to its financial position. Perceptron engineer Mr. White confirmed that the company is open to the possibility of a transfer of the technology to another company, but expressed doubt that any other automotive suppliers are in a position to take on the risk or the investment.

The WFM system has also sparked interest from the aerospace industry and coil-coating manufacturers, who are currently considering investments in the development of the WFM technology for their applications.

\section{Industry Resistance Presents Another Barrier to Commercialization}

In addition to the lack of available funds to commercialize the WFM system, industry resistance has presented another unforeseen challenge. Mr. White explained that because automotive painting is such a fragile and expensive process, manufacturers worry that constant adjustments to spray flow and other parameters will only compound the problems. Even though the existing process is error-laden, manufacturers hesitate to alter it until a new system demonstrates proven quality control elsewhere. While the DaimlerChrysler prototype exhibits superior measurement, researchers need to perform further testing and complete research to convert raw data into useful feedback before proving the WFM system's capability for total closed-loop feedback control. 


\section{Conclusion}

As a result of the ATP project, Perceptron successfully developed a WFM (wet-film-measurement) system based on its LU (laser ultrasonics) technology. The company affirms that this advance would not have occurred without ATP's support. Despite the system's excellent technical outlook, however, Perceptron has not been able to fund commercial development because of severe financial difficulties and industry resistance. If Perceptron regains financial strength, it plans to resume commercialization efforts. In consideration of its present situation, the company expresses its willingness to negotiate a technology transfer to another company. 


\section{PROJECT HIGHLIGHTS \\ Perceptron (formerly Autospect, Inc.)}

Project Title: Laser Ultrasonics To Improve Automotive Painting Process (Wet Paint Thickness Measurement System)

Project: To develop a non-contact method for online measurement of wet-paint thickness to enable a high-quality, time-efficient, and cost-effective painting process for the automotive industry.

\section{Duration: 9/15/1995-9/14/1998 \\ ATP Number: 95-02-0005}

\section{Funding (in thousands):}

$\begin{array}{lrr}\text { ATP Final Cost } & \$ 1,800 & 81 \% \\ \text { Participant Final Cost } & \underline{421} & 19 \% \\ \text { Total } & \$ 2,221 & \end{array}$

Accomplishments: Perceptron successfully developed the technology for a wet-film-measurement (WFM) system using its laser ultrasonics (LU) technology; tested the system at PPG's facility in Flint, Michigan; and installed a prototype for further development at DaimlerChrysler's Windsor, Ontario plant.

Company engineers received the Best Paper Award at the 1998 International Body Engineering Conference for a paper discussing the ATP technology titled, "Non-Contact Real Time Film Thickness Gauge."

Perceptron received the following patents for technologies developed during the ATP project:

- Method and system for processing measurement signals to obtain a value for a physical parameter" (No. 6,092,419: filed November 21, 1997; granted July 25, 2000)

- Method and system for measuring a physical parameter of at least one layer of a multi layer article without damaging the article and sensor head for use therein" (No. 6,128,081: filed November 27, 1997; granted October 3, 2000)
Commercialization Status: Although Perceptron sold a prototype WFM system to DaimlerChrysler after the close of the project, the company has ended its commercial development efforts due to severe financial difficulties caused by the auto industry's weakness in the early and mid 1990s.

Outlook: Currently, Perceptron's weak financial status and the industry's resistance to the new technology prevent the commercial development of the WFM system.

However, the prototype system has demonstrated technical success and holds promise for future commercial development and improvement of the automotive painting process. The WFM system has also sparked interest from the aerospace industry and coil-coating manufacturers.

These industries are currently considering investments in the development of the WFM technology for their applications.

\section{Composite Performance Score: *}

Number of Employees: (figures are for the Autospect division only) 10 employees at project start, 15 as of December 2001

Focused Program: Motor Vehicle Manufacturing Technology, 1995

Company:

Perceptron

47827 Halyard Drive

Plymouth, MI 48170-2461

Contact: Jeffrey White

Phone: (734) 414-6100 


\title{
Philips Laboratories
}

\section{A Novel Microminiature Light Source Technology}

\begin{abstract}
Companies located in the Pacific Rim dominated the market for miniaturized circuitry and lighting applications from the 1980 s to the early 1990s. During that time, U.S. firms fell far enough behind that they had trouble keeping a foothold in the marketplace. In 1993, Philips Laboratories applied for Advanced Technology Program (ATP) support to research a method to use microcavities as small as $1 \mathrm{~mm}$ in the company's microlamp research and to develop a prototype for industrial and consumer applications. Philips' proposed research would focus on creating electrodeless microlamps as well as microlamps with both conventional and thick-film electrodes. Toward the end of the ATP-funded project, Philips focused mainly on thick-film tungsten electrodes in 1-mm cavities, since these showed the most promise. All research and knowledge from the ATP-funded Philips Laboratories project was transferred to Philips Lighting after the close of the project in order to facilitate microlamp commercialization. Ultimately, Philips Lighting could not commercialize the product at prices low enough to compete with microlamps already on the market, so the company abandoned plans to bring a product to market.
\end{abstract}

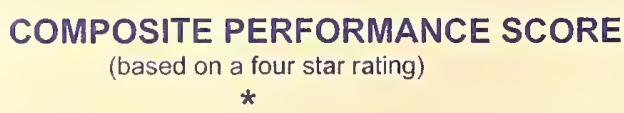

Research and data for Status Report 93-01-0045 were collected during October - December 2001.

Pacific Rim Firms Dominate the Market

Between the late 1970s and the early 1990s, miniaturization emerged as one of the most significant design trends for consumer and military products. Companies with strong technical competencies in miniaturization processes, such as precision machining and micromachining, gained considerable competitive advantages in the marketplace. These companies, largely based in Japan, used their strong miniaturization capabilities to design and manufacture electronic and optical products that were higher performing, lighter, and more rugged than those made by companies who lacked miniaturization expertise. The progress by Pacific Rim-based companies negatively impacted the health and stability of the electronics industry in the United States, which, as of the early 1990s, had not developed a comparable level of competency in miniaturization.

Moreover, because miniaturization technology significantly impacts the manufacturing, machining, lighting, and display industries, companies based in the
Pacific Rim maintained a significant advantage in those industries. In 1993, however, Philips Laboratories developed a research project to use miniaturization technology to create a small, powerful, efficient lamp for lighting and display options.

\section{U.S. Firms Must Improve in Order To Compete}

By the 1990s, microlamps manufactured outside the United States were coming to market in automobile lighting, projection televisions, and backlights for laptop computers. However, the U.S. lighting industry had not been able to capture the benefits of miniaturization. These microlamps were generating significant revenue for non-U.S. businesses. For example, the automotive headlamp market was $\$ 389$ million annually in 1993 and was expected to grow to $\$ 496$ million by 1997 . The projection television and laptop computer marketplaces, while smaller overall, were experiencing even more rapid growth. Without improved miniaturization capabilities, U.S. manufacturers could not produce lamps that were small enough, bright enough, cheap 
enough, or capable of being viewed at a wide enough angle to capture market share from the Asian companies.

\section{Technical Benefits of the Proposed Technology}

Philips Laboratories proposed to develop ultra-miniature light sources that were less than $1 \mathrm{~mm}$ in diameter, which would be significantly smaller than the Japaneseproduced 5-inch lights, the smallest available at the time. This radically new approach would use microfabrication techniques to generate very small sealed cavities in transparent substrates. Those cavities, when created and activated properly, would serve as the ultra-small light sources. The sealed cavities would be formed by etching and wafer-bonding techniques that were already established within other industries.

\section{Miniatnrization emerged as one of the most significant design trends for consnmer and military products.}

The more difficult aspects of the proposed technology involved investigating the emissive properties of electrical discharges within the sealed cavities in both an inert state and when filled (also known as "dosed") with different materials. One of the expected advantages of the miniature cavity was its ability to sustain much higher pressures because of its small size. The cavity was expected to withstand several hundred atmospheres of pressure; and since light output (lumen) efficiency increases at higher pressures, the ultra-small light sources would be highly efficient. Moreover, the smaller size would enable wider viewing angles and more light sources packed onto a substrate, making the light more visible and of better quality.

\section{Philips' Research Project Promises Cost and Environmental Advantages}

Philips determined that there were three areas of potential broad-based benefits that could flow from a successful project. First, given that the Pacific Rim countries' miniaturization skills clearly dominated the world market, any effort to bring market share back to the United States had the potential to create significant economic benefits through increased domestic manufacturing jobs and decreased reliance on imports.

Furthermore, the innovation Philips proposed could also reduce the cost of the ultra-miniature light sources produced in Japan. For example, before the ATPfunded project began in 1994, the typical cost of processing a 5-inch substrate for these light sources, through a sequence of integrated circuit fabrication steps, was $\$ 100$. Since the proposed microlamps were smaller than their Pacific Rim counterparts, and the manufacturing process was simpler, the cost of processing the 1-mm ultra-miniature light source would be approximately 10 cents per lamp, a 99.9-percent decrease in the cost per lamp.

\section{Philips Laboratories proposed to develop nltra- miniatnre light sonrces that were less than $1 \mathrm{~mm}$ in dianeter.}

The second broad-based benefit from Philips' proposed innovation was the impact that would accrue to many downstream U.S. industries. If the proposed technology were successful, the new range of U.S.-manufactured ultra-miniature light sources would be of interest to the lighting, automotive, consumer electronics, and professional equipment industries within the United States. However, in order to remain focused and to have a better chance of success, Philips decided to limit its miniaturization project to research for lighting and display applications.

The third potential benefit of the new technology was environmental. Philips' proposal would create lighting sources that used far less mercury than any lights available on the market. Because even small amounts of mercury in cast-off lamps leech into the soil and pollute large areas, there is a recognized need to reduce mercury usage. If successful, the project would enable effective lighting sources with a significantly lower risk of environmental pollution.

\section{Philips Seeks Public Funds To Help Develop Technology}

Despite these potential benefits, substantial technical and business challenges prevented Philips from funding 
the research internally. In 1990, several years before submitting their ATP proposal, Philips had conducted a preliminary investigation into this new technology. Their research suggested that the fabrication, dosing, and sealing of microcavities were possible for these ultraminiature lighting sources. The technical risks lay with conducting a full-scale examination of the physical phenomenon of generating specific types and strengths of light within very small cavities. The research project called for full investigation of a large variety of discharges in order to minimize the amount of mercury necessary for lighting. In addition, the microcavity walls would need to be engineered precisely to prevent distortion and loss of energy that would adversely affect lumen efficiency. The microcavity engineering risk was substantial because U.S.-based lighting industry knowledge in 1993 was based on assumptions from lighting results in much larger cavities. Putting the physics and models to practice within a 1-mm cavity, however, was significantly more difficult.

The project's business risks were formidable given the complete industry domination by companies based in the Pacific Rim. The cost of manufacturing labor was significantly less in Japan than in the United States. Therefore, savings from a successful project would have to be significant enough to make up for the labor cost disadvantage if U.S. companies' microlamps were to compete in the global marketplace. ATP, satisfied that Philips met the technical criteria for funding, awarded the company cost-shared funds in January 1994.

\section{Project Focuses on Three Types of Lamps}

As part of its process to create an ultra-miniature light source, Philips studied light emission within three forms of lamps: the electrodeless microlamp, the electroded microlamp with conventional electrodes, and the electroded microlamp with thick-film electrodes.

\section{Electrodeless Microlamp}

Philips had fabricated sealed cavities in quartz substrates prior to the start of the ATP-funded project. They believed a similar process could be developed for glass, sapphire, and other substrates. The process used to fabricate the miniature cavities involved four steps. First, a masking layer is deposited on the wafer substrate and is patterned. Second, the quartz substrate is then etched through the openings in the cavity. Third, the cavity is filled with a dosing material. Finally, another wafer, in which similar cavities have been etched, is aligned with the initial wafer and bonded to it in the appropriate ambient gas using fusion-wafer bonding. This process forms a sealed cavity that contains the dosing material and the gas. As a result of the company's research during this ATP project, Philips succeeded in fabricating sealed cavities that contained a dose of mercury and argon gas. Such cavities can be excited with radio frequency or microwave power, thereby creating a discharge microlamp. The microlamp, however, did not produce commercial-quality light. Therefore, Philips continued its research with electroded microlamps.

\section{Electoded Microlamp with Conventional Electrodes} Philips determined that the scientific and technical issues related to these electroded microlamps were more difficult than the electrodeless microlamp, but the potential for efficient lighting was greater. During the process of incorporating the electrode into the sealed cavity, careful steps needed to be taken to ensure that contamination did not occur within the cavity. If contamination did occur, the microlamps would not operate properly, if at all. Furthermore, the temperature within the sealed cavity, when excited by a current, had to be regulated to prevent evaporation of the vapors inside and to prevent the electrodes from melting.

\section{The cost of mannfacturing microlantps within Philips Lighting was too high to effectively compete with other prodncts on the market.}

After developing several designs and prototypes, Philips was able to create three electroded microlamps. The first was an electroded, high-pressure mercury microlamp and the second was an electroded highpressure mercury microlamp that contained arcs of just $1 \mathrm{~mm}$. The 1-mm arcs made the second microlamp well-suited for projection applications. A third microlamp was developed with electrodes located on one side, a design that enabled the microlamp to be illuminated using low electrical current. As a result, small apparatuses that require low-wattage light could incorporate this microlamp. 


\section{Electroded Microlamp with Thick-Film Electrodes}

In order to create microlamps for use in a wider array of lighting applications, Philips also researched electroded microlamps with thick-film electrodes. In its proposal to ATP, Philips indicated that tungsten would be a good electrode candidate because of its high melting point, good conductivity, and electron-emission properties. The key step in the formation of the tungsten thick-film electrodes would be the deposition of tungsten films on quartz substrates without significant warping, cracking, or peeling. Philips simultaneously investigated several different techniques to achieve these requirements, including low-pressure chemical vapor deposition, plasma-enhanced chemical vapor deposition, laser ablation, and sintering of tungsten paste. At the conclusion of the ATP-funded project, Philips Laboratories scientists and engineers had developed an impressive research file on the emissive properties of tungsten thick-film electrodes.

\section{Cost Pressures Limit Commercialization}

The entire body of knowledge developed during this ATP-funded project was transferred to Philips Lighting, a separate company that would work to make the final adjustments on, and commercialization of, the thick-film electroded microlamps and conventional electroded microlamps. Ultimately, however, the cost of manufacturing microlamps within Philips Lighting was too high to effectively compete with other products on the market. Philips Lighting management decided in 1998 not to market any of these products commercially, but to retain them for future internal research and development activities.

\section{Project Knowledge Is Disseminated}

Though Philips Lighting's management decision ended plans to bring products resulting from this ATP-funded research to market, the research conducted at Philips Laboratories was made available to other interested parties through a number of knowledge-dissemination channels. Three patents were granted for knowledge directly related to this ATP project, and applications were submitted for nine others. Moreover, an article was submitted for publication to the professional journal, Applied Physics Letters, and presentations were made at four industry symposia.

\section{Conclusion}

ATP awarded Philips $\$ 1.43$ million in cost-shared funds to pursue miniaturization technology for microlamps. The research project examined electrodeless microlamps and microlamps with traditional and thickfilm electrodes. Tungsten thick-film electroded microlamps showed the most progress, and Philips Laboratories developed a large body of research on this technology. All knowledge was transferred to Philips Lighting for commercialization after the end of the ATPfunded project in 1997. However, the cost of tungsten thick-film electrodes was still too high for commercialization, and no products resulted. 


\section{PROJECT HIGHLIGHTS \\ Philips Laboratories}

Project Title: A Novel Microminiature Light Source Technology

Project: To develop techniques to produce microminiaturized, high-pressure discharge lamps using etched cavities in quartz or sapphire wafers for lighting and display applications.

\section{Duration: 2/15/1994-2/14/1997 \\ ATP Number: 93-01-0045}

Funding $^{\star *}$ (in thousands):

$\begin{array}{lrr}\text { ATP Final Cost } & \$ 1,432 & 28 \% \\ \text { Participant Final Cost } & \underline{3,576} & 72 \% \\ \text { Total } & \$ 5,008 & \end{array}$

Accomplishments: As a result of this ATP project, Philips successfully achieved several broad objectives, which in the future could lead to the development of microminiature, high-intensity discharge lamps. These successes include the development of an electrodeless microlamp and the development of an electroded microlamp fabricated with conventional electrodes. Philips also developed tungsten films as thick as 20 microns with minimal warping, cracking, or peeling by using a plasma-enhanced chemical vapor deposition process. This process is pivotal to the future development of electroded microlamps fabricated with thickfilm electrodes. In addition, Philips acquired significant knowledge from this project, which led to the granting of five patents and the publication of several articles. Patents for technologies related to the ATP project include:

- Microlamp incorporating light collection and display functions"

(No. 5,574,327: filed June 7, 1995, granted

November 12, 1996)

- "Flat panel light source for liquid crystal displays" (No. 5,808,410: filed June 7, 1995, granted September 15, 1998)

- $\quad$ "Gas discharge lamps fabricated by micromachined transparent substrates" (No. 5,965,976: filed December 19, 1997, granted October 12, 1999)
Commercialization Status: Because

manufacturing costs remained too high, commercialization of this breakthrough technology has not been initiated. However, Philips and the industry are ready to provide the technology and its related products when a scale-up need arises.

Outlook: As the demand for microminiature light sources increases, so will the need to provide a scaled-up production method. As a result, the outlook for this microminiature light source technology is promising, especially due to the lighting, automotive, consumer electronics, and professional equipment manufacturers' continuous search for methods to increase product efficiencies. In addition, the knowledge spillover from this ATP project is extensive. By May 2001, 32 additional patents had been spawned from the initial 5 , evidence that the market is very interested in the technology that resulted from this project and that there could be demand for microminiature lamps in the near future.

\section{Composite Performance Score:}

\section{Company:}

Philips Laboratories

345 Scarborough Road

Briarcliff Manor, NY 10510

Contact: David Cammack

Phone: (914) 945-6045

** As of December 9, 1997, large single applicant firms are required to pay $60 \%$ of all ATP project costs.

Prior to this date, single applicant firms, regardless of size, were required to pay indirect costs. 


\section{Sheffield Automation (formerly Giddings \& Lewis)}

\section{Enhanced CMMs To Improve Manufacturing Processes}

Competitive manufacturers have shifted their focus from post-process defect detection to realtime, in-process defect prevention. In 1992, existing coordinate measuring machine (CMM) technology, which was used for quality control purposes, failed to meet the demand for realtime, highly accurate measurement, because the machines had to be located in climatecontrolled rooms. Giddings \& Lewis proposed to bring CMMs to the factory floor to improve process efficiency and product quality. These process improvements would result in fewer errors, thereby decreasing the levels of scrap, down time and the associated potential for large financial losses for the manufacturers.

The company applied for and was awarded cost-shared funding from the Advanced Technology Program (ATP) for a two-year project to develop and place an optical fiber multidegree-of-freedom laser measurement system right on the CMM. This system would be capable of measuring error components within the machine during the manufacturing process on the factory floor so that corrective actions could be taken immediately, thus improving quality and speed.

Working with researchers at the University of Michigan, Giddings \& Lewis sought to develop both a laser optical system to monitor positional deviation of CMMs caused by thermal expansion and an adaptive compensation system to account for those errors in real time. Persistent problems with thermal drift rendered the prototype system incapable of adaptive thermal compensation, so the full technology was never developed. However, the company used this knowledge to develop its Atlas, Discovery, Endeavor, and ProGage factory-floor CMMs.

\footnotetext{
COMPOSITE PERFORMANCE SCORE

(based on a four star rating)

No Stars
}

Research and data for Status Report 92-01-0035 were collected during October - December 2001 and November 2002.

\section{Enhanced CMMs Could Potentially Revolutionize Manufacturing}

A coordinate measuring machine (CMM) measures shapes of known geometry by using a computercontrolled probe tip to map the surface of a part along a predetermined path. Whenever the probe contacts the part surface, the computer control records the instantaneous displacement of the probe with respect to each of the three orthogonal axes ( $x, y$, and $z)$. This produces a measurement of the actual part in terms that can be used to determine the deviation of the part surface from the mathematically correct nominal surface. Manufacturers use CMMs primarily for quality control purposes to ensure that actual part geometry matches the intended specifications.

Because CMMs are made from aluminum, steel, and other metals, they are susceptible to expansion and contraction caused by changes in ambient temperature. These thermal effects cause displacement of CMM positioning and subsequent drift of the probe tip from its programmed path. This affects the precision of the CMM's measurements. When precise dimensional measurements are required, manufacturers usually restrict the use of their CMMs to temperature-regulated quality control labs. 
This requirement has several drawbacks for highprecision parts manufacturers, who need to maintain high-volume, high-speed, cost-efficient production of first-quality parts in order to remain competitive. First, climate-controlled rooms are expensive to construct and maintain. Second, the quality control process is time-intensive, because the measured parts need to reach thermal equilibrium. To reduce scrap levels and achieve labor efficiency, manufacturers require inprocess feedback for immediate detection and correction of dimensional error to avoid an entire production run of defective parts. Yet with existing technology, manufacturers must periodically delay production (or risk unacceptable scrap levels) to take sample parts to the control room for inspection. In a competitive business environment, a CMM that could withstand the environmental instability of the factory floor could potentially revolutionize manufacturing methods. It could provide an early warning system for error and provide quality audits at every step of the process.

\section{Current Thermal Compensation Techniques Are Unsuccessful}

Because thermal effects represent the single largest source of CMM dimensional error and apparent nonrepeatability of equipment, a successful thermal compensation technique could provide appreciable improvement in CMM precision, reliability, and repeatability. In 1995, several existing techniques had attempted to limit the problem of thermal effects. These methods included using uniform materials for all CMM components, rigidly clamping CMM scales, installing insulation pads and reflective foil to protect against temperature change, and using a thermal insulating enclosure and various measures to establish a uniform temperature throughout the machine by active heat flow control. Another approach involved gathering empirical data on displacement under varying temperatures and storing this information in a memory table in the original software. Measurement output readings would refer to this memory table to incorporate thermal error compensation according to an input temperature variable. While this compensation method estimated thermal drift reasonably well, it relied on trend prediction rather than real-time knowledge of machine and environmental conditions and, therefore, lacked the precision of an online monitoring system. Thus, available thermal compensation techniques merely supplied stopgap solutions that improved measurement precision to some degree, but failed to aggressively tackle the thermal drift problem.

\section{Enhanced CMM Technology Could Provide Significant Cost Savings}

The size of the CMM market, boasting sales of $\$ 1.2$ billion in 1995, indicated the importance of these machines in improving manufacturing practices in various industries. CMMs have particular value in enhancing the efficiency of manufacturing processes in automotive, aerospace, and other transportation industries. These industries accounted for $\$ 516$ billion in U.S. revenues and employed 1.5 billion workers according to 1997 Census Bureau statistics. In order to sustain industries of that size, U.S. machine tool makers needed to supply flexible, best-in-class CMM tools to facilitate resourceful and effective manufacturing processes. For example, the loss of a single complex jet engine component with high accumulated value could cost up to $\$ 50,000$ and delay completion of an engine, leading to additional financial penalties. Giddings \& Lewis projected that a factoryfloor CMM could save manufacturing industries hundreds of millions of dollars by eliminating the costs associated with climate-controlled labs and by enhancing CMM precision and speed required for defect prevention.

\section{A CMM that conld withstand the envirommental instability of the factory floor conld potentially revolutionize mannfacturing methods.}

Giddings \& Lewis, in cooperation with the University of Michigan, proposed a solution to enhance CMM precision by developing advanced, adaptive compensation technology for CMMs to allow them to adjust automatically to environmental changes without loss of precision, thus removing a major roadblock to the use of CMMs on the factory floor. Giddings \& Lewis was a small company without the resources to undertake high-risk R\&D. Because they had already invested $\$ 100,000$ and were not able to obtain funding from investors due to the project's high risk and longterm payoff, they submitted a proposal to ATP and were 
awarded $\$ 755,000$ in cost-shared funds. If successful, the project would significantly advance the current CMM technology and contribute to the knowledge base, which would have great potential to positively impact U.S. manufacturing productivity and cost-effectiveness.

\section{Giddings \& Lewis Incorporates Laser Technology and Enhanced Software}

Giddings \& Lewis and the University of Michigan proposed a unique but risky solution that addressed the thermal drift problem. They intended to address the problem from a software perspective instead of a hardware perspective. The research team would attempt to simultaneously characterize four geometric errors (horizontal straightness, vertical straightness, pitch, and yaw) using an original invention provided by the University of Michigan.

The invention had a high-resolution, compact-size, and low-cost multi-degree-of-freedom geometric error measurement system for simultaneously measuring the four geometric errors. The pitch and yaw error measurements were based on a new method of angle measurement, namely angle measurement based on the internal reflection effect. This method utilized the characteristics of internal reflection of a laser beam in the vicinity of the critical angle of an air/glass boundary. They used a differential detection scheme to reduce the inherent non-linearity and measure by the reflectance. The reflectance would be calculated with an online computer-numerical controller (CNC) equipped with sophisticated software, which would account for any positional deviations and would produce adjusted measurements. In addition, the team would use a stable, single-mode optic fiber beam, conditioned through a collimation lens, for increased precision.

Giddings \& Lewis and the University of Michigan proposed a unique but risky solntion that addressed the thermal drift problem.

Prior to the ATP project, state-of-the-art CMMs featured some type of geometric error compensation procedure for adding microprocessor-enhanced accuracy (MEA) to measurement readouts. However, these systems assumed that geometric error information would remain static in field use. The ATP project aimed to improve the precision of a CMM measurement readout obtained on the factory floor by including temperature-variant error components in the measurement compensation formula. To do this, they would construct a laser sensor for online monitoring of changes in dominant error components and would develop a scheme to update the information base in an MEA compensation system.

The research team outlined a unique technical plan:

1. Design and construct an optic fiber multi-degreeof-freedom laser measurement (MDFLM) system to monitor the change of multiple error components simultaneously for each motion axis. Prior to the project, several technical barriers hampered the use of non-interferometric laser technology for sensory systems, including problems with laser beam drift, air turbulence, and low sensor resolution. However, researchers at the University of Michigan had discovered prior to the project that the use of the internal reflection effect and a single mode optic fiber beam solved these problems. This breakthrough cleared the way for the use of laser technology for a CMM sensory system. Thus, the team aimed to develop a conditioning and delivery system for a highly stable single-mode optic fiber laser beam. This laser beam would have superior pointing stability for use in a movement reference system that could provide highprecision angle and straightness measurements of CMM positioning on the $x, y$, and $z$ axes. The system contained a multiple channel data acquisition system to receive information from multiple position-sensing detectors (PSDs).

\section{Identify sound metrological (measurement) bases} for properly mounting the laser optical system on a СMM. The careful selection of stable bases for the MDFLM system was imperative to the system's ability to detect the changes of geometric error components when the CMM experiences thermal distortion. To do this, the team intended to develop an error-sensitivity analysis model. They planned to accomplish this by determining the sensitivity of various structural parts to environmental distortions and then by evaluating the influence of these changes on the identified error sources. This model would inform the selection of a solid base for the MDFLM system. 
3. Develop adaptive compensation software, written to process online error information from the multiple channel data acquisition system. The software would calculate the final positional and angular deviation of a probe tip relative to the worktable reference and would adapt the measurement reading accordingly.

4. Develop a fast, stand-alone calibration device as a byproduct of this project. This low-cost device would provide simultaneous measurement of six geometric-error components to calibrate CMMs and other machine tools, replacing existing devices that are too slow for the calibration of multiple geometric-error components.

\section{Broad Economic Benefits To Result from Improved} CMMs

If successful, Giddings \& Lewis' technical plan promised broad-based economic benefits to CMM builders and to various users, including automotive, aircraft, aerospace, and off-road equipment industries, as well as thousands of their suppliers. The economic benefits would result from increasing the quality and cost-effectiveness of CMM inspection capabilities through increased speed and reduced scrap.

Additionally, the project sought to expand the U.S. knowledge base by demonstrating a successful application of non-interferometric laser measurement methods and thereby increasing the acceptance of this novel technology. Through meetings with CMM technology-sharing organizations, such as the University of Michigan's Industry/University Cooperative Research Center on CMMs, Giddings \& Lewis defined a project goal: to establish a validated technology base for its adaptive compensation method so that the industry could initiate commercialization and bring CMMs to the factory floor rapidly and efficiently, compensating for errors associated with temperature changes.

\section{Significant Problems with Thermal Drift Affect Prototype Viability}

During the project, the research team developed two prototype MDFLM systems using non-polarizing optics and PSDs capable of measuring the four error components simultaneously. The first prototype used helium-neon laser beams and the second used diode lasers. The second prototype was preferred, because it produced less heat. Later, the second system was also able to measure the component of roll, an accomplishment previously unattained by a lasersensing system. Despite the development of the prototype, its laser collimator (a device used to provide desired beam diameter to meet specific beam delivery requirements) and PSDs experienced problems with thermal drift that dramatically impaired the performance of these electro-optical components and hindered validation of the tool concept.

Because this thermal drift prevented the full development of the system, Giddings \& Lewis worked to understand the thermal characteristics of the laser collimator and PSDs to reduce destabilizing drift. They explored enhancements such as the addition of a thermoelectric cooling system to stabilize the relatively low-power PSDs (a design adaptation that created better machine symmetry) and the construction of the system using materials that have low coefficients of thermal expansion, such as Invar (an alloy of iron and nickel).

However, Giddings \& Lewis was unable to accomplish these modifications within the ATP project's time and funding limits. The University of Michigan continued with this research and developed empirical models to compensate for thermal drift as a function of temperature within the laboratory environment. Analyzing the experimental data indicates three directions for future improvements in the main sources of unresolved errors: 1) the inclination of the output collimator of the laser beam, 2) the deformation of the optical apparatus, and 3 ) the heat radiation of the reference stage.

\section{ATP Project Advances Laser Metrology Technology}

Despite roadblocks that prevented the full development of a laser-optical-sensing system for adaptive thermal compensation, the project made significant strides in the area of laser metrology. During the project, researchers confirmed the technical value of noninterferometric lasers by the use of single-mode optic fiber laser beams, achieving an unprecedented beam 
stability of less than one-tenth of a micrometer. The project made another unique advance by validating the ability of laser-sensing systems to measure the error component of roll.

Though the system that Giddings \& Lewis envisioned in its proposal for this ATP project was not fully realized, the company later found ways to incorporate technology developed during the project into its Atlas product to improve the quality and cost-effectiveness of its inspection capabilities. Developments under this project also provided a knowledge base that researchers at the University of Michigan utilized in a collaborative effort with the National Science Foundation to develop a miniature-scale machine tool.

Giddings \& Lewis was mable to accomplish these modifications within the ATP project's time and funding linnits.

Additionally, researchers transferred findings from this project to the industry through paper presentations at major conferences, including a presentation by Dr. Jun $\mathrm{Ni}$ of the University of Michigan at the 1995 Society of Manufacturing Engineers Laser Metrology Workshop and publication of a reference book edited by John A. Bosch, Coordinate Measuring Machines and Systems (Marcel Dekker, 1995). Bosch was a consultant to Sheffield Automation Giddings \& Lewis at the time and is the former president of Sheffield Measurement.

\section{Conclusion}

Although the Giddings \& Lewis research team gained extensive knowledge of and improvement in precision for using lasers to define a metrological system for coordinate measuring machines (CMMs), persistent problems with thermal drift rendered the multi-degreeof-freedom laser measurement (MDFLM) prototype system incapable of adaptive thermal compensation. Thus, the project highlighted areas that required further improvement and pointed to the need for continued research and development of factory-floor CMMs. The University of Michigan was able to develop empirical models to compensate for thermal drift as a function of temperature in the lab environment. Current state-of-the art CMM technology does provide factory-floor CMMs and includes the MDFLM laser technology developed in this ATP-funded project, but it still has not achieved the level of precision and the real-time thermal expansion measurement technique originally proposed. 


\section{PROJECT HIGHLIGHTS \\ Sheffield Automation (formerly Giddings \& Lewis)}

Project Title: Enhanced CMMs To Improve

Manufacturing Processes (Development of an Adaptive

Compensation Technique for Enhancing Coordinate

Measuring Machines (CMM) Accuracy)

Project: To incorporate an innovative laser optical system for monitoring minute dimensional changes in an adaptive control system for CMMs in order to efficiently use them on the factory floor.

Duration: 5/1/1993-4/30/1995

ATP Number: 92-01-0035

Funding (in thousands):

$\begin{array}{lrr}\text { ATP Final Cost } & \$ 755 & 62 \% \\ \text { Participant Final Cost } & 469 & 38 \% \\ \text { Total } & \$ 1,224 & \end{array}$

Accomplishments: Although Giddings \& Lewis did not fully develop a laser-optical-sensing system and adaptive-compensation component, they did achieve the following advances during this project:

- Validation of non-interferometric lasers with single-mode optic fiber laser beams for metrology applications, as confirmed by the achievement of beam stability within a margin of less than one-tenth of a micrometer

- Development of a multi-degree-of-freedom laser measurement system capable of measuring the error components of horizontal straightness, vertical straightness, yaw, pitch, and roll

\section{Commercialization Status: Giddings \& Lewis} was not able to develop a commercial-ready prototype from their work during this project. However, the company applied technology developed during the ATP project to the later development of its Atlas, Discovery, Endeavor, and ProGage series CMMs.
Outlook: The outlook for this project is uncertain; however, research in CMM technology continues within the manufacturing industry. Today, U.S. machine tool manufacturers provide CMMs for use on the factory floor, albeit without the high level of precision sought in this project. For example, Giddings \& Lewis' Endeavor Series CMMs, which incorporate the partial successes of the ATP project, feature real-time temperature compensation in the range of $+/-5^{\circ} \mathrm{C}$, linear accuracy of up to 2 micrometers, and repeatability of 2 micrometers. This does not meet the proposal goals that intended to achieve "accuracy of straightness measurement" better than 0.5 micrometers and accuracy of angular deviation better than 0.05 arcsec. (Precision of angular deviation is not cited in current company literature.) However, factory-floor CMMs are currently available to assist the $\$ 500$ billion U.S. discreteparts industry in the cost-effective manufacturing of highquality parts.

\section{Composite Performance Score: No Stars}

Number of Employees: 300 employees at project start, 150 as of November 2002

\section{Company:}

Sheffield Automation

721 Springfield Street

Dayton, $\mathrm{OH} 45403$

Contact: Jim Henry

Phone: (937) 259-5212

\section{Subcontractors:}

University of Michigan

Department of Mechanical Engineering 


\title{
Development of New Knowledge and Early Commercial Products and Processes
}

\author{
Advanced Materials and Chemicals; Biotechnology; Electronics, Computer Hardware, or \\ Communications; Information Technology; Manufacturing
}

Table A.1 Advanced Materials and Chemicals

A. Awardee Name

Budd Company,

Design Center

Caterpillar

Incorporated

\section{Ebert Composites}

Corporation

EDO Specialty Plastics (formerly Specialty

Plastics, Inc.)

\section{B. Technology Developed}

Low cost disposable film bladder that acts as a vacuum to hollow out parts made from slurry process

Functionally gradient materials for heavy machinery

Five-axis CNC machine that is capable of accurately tracking and machining composite lineals on a continuous basis

Integral flange technology, heat-activated coupling technology, an improved fitting manufacturing technology through intelligent filament winding using optical sensors

Liquid composite molding process

Monomer from corn that potentially could be used in engineering thermoplastics

54-micrometers thick, metallic glass ribbons with $60 \%$ reduction in core loss from that of conventional grain- oriented silicon steel; casting system providing higher cooling rates; established conditions for casting ribbon up to 80 micrometers thick; gained better understanding relationship between casting
C. Products or Processes Commercialized or Expected to be Commercialized Soon

Introduced capability to produce SRIM structural impact bumpers in approximately three minutes per unit which may be practical for industries with low-volume output (heavy truck, recreation vehicle (RV), and watercraft)

Developed a cost-effective processing technology to enhance production

Commercialized technology into composite structures for electric power poles and lattice towers

Marketed resin transfer molded flanges, reducers, and elbows and started to earn revenue. Their chief customers are the Shell Exploration and Production Company, Exxon, and Texaco, in the Gulf of Mexico

\section{Commercialized process}

Unable to commercialize its technology because of scientific and technical failures, the company is continuing its research into creating a viable product

Metallic glass ribbons are currently incorporated into many products that are sold worldwide 
A Awardee Name

Honeywell, Inc.,

Technology Center

Nanophase

Technologies

Corporation

Norton Diamond Film

Praxair Surface

Technologies, Inc.

Strongwell Corporation

\section{B. Technology Developed}

conditions and ribbon properties; crafted 7.6 $\mathrm{cm}$ wide, 75 micrometers thick ribbon with high-quality magnetic properties; constructed equipment and processes for cutting thick ribbon; incorporated process for annealing spooled ribbon

Generated advanced process understanding for neural network controls and sensors for complex materials and established the groundwork for Honeywell's continued development of neural networks

Technology that enabled a 25,000 -fold increase in the development of nanoscale materials and a 20,000-fold reduction in cost
Continued to explore neural network technology and developed related products, such as its Profit Sensor software

NTC titania in cosmetic sunscreens; NTC zirconia, ceria, and yttria in catalysts and near-net-shaped ceramics; iron oxides incorporated into cosmetic pigments, NTC alumina in near-net-shaped ceramics and electronic substrates

Diamond-coating and pretreatment technology for coating complex shapes

Advanced the coatings industry's understanding of the newest form of physical vapor deposition-Linear Magnetron Sputtering

Large cost-effective, high-performance composite shapes that last longer and are maintained more easily than the concrete and steel that is now aging and deteriorating in the country's infrastructure
Commercialized a diamond-coated end-mill product that it currently supplies to the graphite, non-metallic materials, and metalmachining industries

None. Did not achieve all technical goals

Developed a manufacturing process to create high-strength, advanced Fiber-reinforced polymer (FRP) composites that could be used in bridge and building construction 


\section{A. Awardee Name \\ B. Technology Developed}

Genzyme Corporation

(formerly GelTex

Pharamaceuticals,

Inc.)

Continued research for infectious disease
C. Products or Processes Commercialized or Expected to be Commercialized Soon

None. Changes in the healthcare marketplace led Genzyme to abandon its research
Hyseq, Inc.

None. Post-project business considerations have delayed commercialization. Hyseq and Applied Biosystems also spun off a majority-owned subsidiary, Callida Genomics, Inc., to pursue the DNA sequencing upon which Hyseq was founded. If Callida is a success, the company could bring new drugs and sequencing methods to market in the next 10 years (the normal drug development timeframe)

The NanoChip $®$ Molecular Biology Workstation is the first product line in what Nanogen hopes will be a long series of DNA diagnostic tools. Current capabilities include detecting abnormalities in gene sequences. Future diagnostic applications include entries into the oncology, infectious diseases, and genetic testing markets

Nanogen, Inc.

Developed a prototype microchip-sized DNA diagnostic system and desktop computer-sized workstation for analysis

Developed a microchip-sized DNA diagnostic system that uses electric allowing for faster and less expensive DNA diagnostic work
Nanogen has commercialized the NanoChip $®$ Molecular Biology Workstation. An automated multipurpose instrument that facilitates detection of known sequences, such as in the analysis of Single Nucleotide Polymorphisms (SNPs) and Short Tandem Repeats (STRs) using the NanoChip ${ }^{\circledR}$ Electronic Microarray. The unique, open-architecture design permits researchers to define, select, and build their own test panels
Third Wave Technologies, Inc.
Created process known as Cleavase Fragment Length Polymorphism (CFLP) that generates a distinct bar code for every unique DNA sequence
ThirdWave has moved beyond the CFLP and now commercializes the proprietary Invader ${ }^{\circledR}$ Technology, a molecular diagnostic tool that is quickly becoming the industry standard 
A. Awardee Name

ColorLink, Inc.

\section{Digital Optics}

Corporation

Displaytech, Inc.

\section{Eagle-Picher \\ Research Laboratory}

\section{Elsicon (formerly} Alliant Techsystems, Inc.)

Information Storage Industry Consortium (INSIC, formerly NSIC)

\section{Laser Power} Corporation

\section{MicroFab}

Technologies, Inc.

\section{B. Technology Developed}

Underlying technologies for a highefficiency, solid-state, electro-optic tunable filter for color-sequential imaging

Integrated Micro-Optical System (IMOS) for the production of low and mid-volume opto-electronic devices

Developed a manufacturing process for mass production of ferroelectric liquid crystals (FLCs) for displays

Developed blue and green prototype lasers and LEDs exhibiting superior output capabilities. Achieved success in substrate development, laser and LED output power, and substrate quality

Products and services related to optical alignment of Liquid Crystal Displays (LCDs): pre-tilt analysis system for LCDs, an R\&D tool enabling the identification of the process parameters for the optical alignment of LCDs and devices, measurement system for the voltageholding ratio, materials that support the optical alignment of LCDs

Developed technology for giant magnetoresistive (GMR) recording heads capable of writing and reading 10 gigabits per square inch

Development and improvement of Red Green Blue (RGB) microlasers

Development of a high-volume wafer bumping prototype that demonstrated dispensing of 40 to 120 nanometer spheres of molten solders at temperatures of up to 220 degrees Celsius, on-demand, and at rates up to 2,000 per second
C. Products or Processes Commercialized or Expected to be Commercialized Soon

Several technologies are being commercialized in the television and monitor display industries. These technologies include retarder stacks and custom laminations

Photonic Chip $^{\text {TM }}$

Mass produced FLC display chip

None. Eagle-Picher redirected its research into zinc oxide-based lasers and LEDs

Developed a platform for commercialization of the products and services related to the optical alignment of LCDs at Elsicon
The GMR head technology received such broad and fast industry adoption that it became the industry standard in record time

Sold technology to Melles Griot to continue research and development

Licensed technology for use in solder balls 
A. Awardee Name

Micron Optics, Inc.

Physical Optics

Corporation

X-Ray Optical

Systems, Inc.

\section{B. Technology Developed}

Developed High-Speed Fiber FabryPerot Tunable Filters (FFP-TF) for communication networks

New type of diffuser light based on holographic technology. The ATPfunded diffusers are twice as efficient as previous diffusers

Manufacture of capillary x-ray optics, polycapillary optics lenses, and collimators
C. Products or Processes Commercialized or Expected to be Commercialized Soon

Commercialized improved FFP-TF (although all ATP goals not met)

Manufacturing holographic diffusers

Commercialized machines that use polycapillary optics lenses and collimators

\section{Table A.4 Information Technology}

\section{A. Awardee Name}

3M Company Health Information Systems

Accenture (formerly Andersen Consulting)

American Healthware Systems

Hybrithms

Corporation, formerly

Sagent Corporation)

\section{Hynomics (formerly}

\section{B. Technology Developed}

\section{Clinical Data Repository}

Developed and demonstrated the functionality of a healthcare information system that could control costs, eliminate redundant care, and give healthcare providers more time with their patients

Developed a Graphical User Interface that are less complex than the Health Care Plan System

Hybrid systems, automata, and control theory

\section{Developed and demonstrated a business process reengineering information technology application for use by the healthcare industry}

KOOP Foundation, Inc.
Developed an essential middleware framework for the healthcare information infrastructure

\section{Products or Processes Commercialized or Expected to be Commercialized Soon}

Prototype is installed in healthcare facilities throughout the United States

None. Changes in the healthcare industry, however, made a centralized information infrastructure irrelevant, and commercialization did not take place

None. Although the company failed to develop an interface that could prompt physicians to use the care plans in an effective manner, the company continued its research into hospital information systems after the project ended in 1997

Commercialized a workforce optimizer and people scheduler for SAP; one of the largest enterprise solutions providers

None. Changes in the healthcare marketplace prevented the Koop Foundation joint venture from commercializing the ATP-funded technology

None. Aggressive cost cutting had not proved successful for healthcare providers, and a universal approach to healthcare delivery had faded from the national scene 
A. Awardee Name

Kurzweil Applied Intelligence, Inc.

MediaBin (formerly Iterated Systems Incorporated)

PPD Informatics (formerly Belmont Research, Inc.)

Reasoning Systems, Inc.

urgency (formerly Benchmarking

Partners)

TopicalNet (formerly Continuum Software, Inc.) Continuum Software, Inc.)

\section{B. Technology Developed}

Developed voice recognition software as a result of the ATP project

Produced prototypes of compressors and decompressors using a combination of fractal and non-fractal elements.

Addressed the problem of data integration by creating a software tool that would browse and automatically extract healthcare data from scattered databases without altering the existing systems. The Table Trans and Belmont Auto Coder products provide these capabilities

Developed technology that reduced the time, cost, and risk of reengineering across a wide variety of legacy systems

Created the Retail Working Group, the first Internet-based retail business-tobusiness collaboration initiative that served as the forerunner to the formation of the VICS CPFR implementation manual and the widespread use of collaborative practices

Developed MultiPly ${ }^{\mathrm{TM}}$, a technology allowing business programmers to develop scalable business applications without having to learn parallel programming

Developed a software tool using projective visualization that would enable the creation of future databases
C. Products or Processes Commercialized or Expected to be Commercialized Soon

The technology has since been integrated into Lernout \& Hauspie's VoiceXpress ${ }^{\mathrm{TM}}$ product, which allows voice control of Microsoft and Corel Office software products

None. Changes in the market made ISI's innovation obsolete. By the end of the ATP-funded project in 1995, use of the Internet had become widespread, thus reducing the need to store vast image libraries on PCs

PPD Informatics continues to market both Table Trans ${ }^{\mathrm{rm}}$ and Auto Coder to the clinical research industry

None. After a sharp drop-off in the transformational software purchasing that had fueled its explosive pre2000 growth, a leaner Reasoning has refocused its business model, secured an additional $\$ 9$ million in venture funding, and continues to commercially market the software technology developed during the ATP-funded project

Warner-Lambert purchased a pilot version of its collaborative technology, and Kmart, Gillette Corporation, and others paid for executive briefings, access to collaborative process models, and consulting services

None. Venture capital not available at the time because the computer industry was focused on $\mathrm{Y} 2 \mathrm{~K}$ compliance

TopicalNet's ATP-supported technology and its subsequent acquisitions have allowed the company to provide its customers with traffic verification, analysis, and research solutions for the World Wide Web 


\section{A. Awardee Name \\ B. Technology Developed}

Calmac Manufacturing Corporation

Unable to develop an ejector expansion refrigeration cycle (EERC) to increase the efficiency of the cycle by recovering some of the unused energy in the compressed fluid

\section{Corning Tropel}

(formerly Tropel

Corporation

Dana Corporation

GE Corporate

Research \&

Development

No technologies were successfully developed as a result of this project

Octahedral hexapod machine tools

Ingersoll Milling

Machine Company

Magnetic pulse welding process that combines a precision metal-forming step with unconventional welding aluminum and steel load-bearing structures to enable welding tubular steel to aluminum without depositing additional metal. The process requires precisely crafted and machined tubes of metal bonded by heating generated by a rapidly shifting magnetic field

Cylinder metrology instrument based speed, in-process, non-contact measurement of complex shapes such as cylinders and cones in a manufacturing environment

After durability testing at OEM sites, Dana expects to commercialize the magnetic welding process for use in manufacturers of U.S. and European vehicles
None. Scientific and technical failures prevented Calmac from successfully developing the EERC technology. Calmac did, however, advance the refrigeration industry's body of knowledge for modernizing the vapor compression process, and future industry efforts may potentially expand on the inroads made by Calmac

\section{Commercialized Cylinder Master ${ }^{\mathrm{TM}}$ product}

C. Products or Processes Commercialized or Expected to be Commercialized Soon
None. Although the company did not achieve its goal of developing mercury-free fluorescent lighting for existing sockets, it did advance the state-of-the-art of mercury-free fluorescent lighting

Sold three high-precision, multi-axis machine tools based on an octahedron frame and a "Stewart platform" actuator

M\&M Precision Systems Corporation

Perceptron (formerly Autospect, Inc.)
Automatic computer-controlled error correction software, rotary-axis technology enabling smoother and faster gear measurements, and new control technology enabling a smoother, more precise gear motion during measurement

Using its Laser Ultrasonic technology, developed non-contact method for online measuring of wet-paint thickness to enable a high-quality painting process for the automotive industry
Sold prototype wet film measurement (WFM) system to DaimlerChrysler. No commercialization after that initial sale 
A. Awardee Name

B. Technology Developed

Philips Laboratories

Fabricated sealed cavities that contained a dose of mercury and argon ambient. Created 3 electrode microlamps:

- 1 high-pressure mercury microlamp

- 1 high-pressure mercury microlamp with arcs of $1 \mathrm{~mm}$ suited for projection applications

- 1 with electrodes on one side, a design enabling the microlamp to be illuminated using low electrical current for low-wattage applications

Sheffield Automation (formerly Giddings \& Lewis)
Validation of non-interferometric lasers with single-mode optic fiber laser beams for metrology applications and development of a multi-degree-offreedom laser measurement system
C. Products or Processes Commercialized or Expected to be Commercialized Soon

None. Philips Lighting could not commercialize the product at prices low enough to compete with microlamps already on the market, so the company abandoned plans to bring a product to market

Unable to develop a commercial-ready prototype from their work, but applied technology developed to the later development of its Atlas, Discovery, Endeavor, and ProGage series CMMs 


\section{Reasons for Terminating ATP Projects}

At the end of an ATP competition, projects are selected for award and the winners are announced. Most of these projects proceed through their multi-year research plans to completion. Some are not carried through to completion for a variety of reasons. These projects are collectively called "terminated projects."

Between 1990 and September 2004, there were 768 ATP awards issued, of which 77 projects ended before completion. Below is a percentage distribution by category of the reasons for termination.

Of the 77 terminated projects:

Change in goals

- 56 percent ended because of changes in the strategic goals of the companies, changes in the business climate or markets, changes in company ownership, or other business-related facts.

Lack of technical progress

- 14 percent ended because of lack of technical progress, which sometimes occurs at go/no-go decision points recommended by the participant(s).

Project no longer meets ATP criteria

- 12 percent ended because changes in scope, membership, performance, or other factors meant that the project no longer met ATP's technical and/or economic criteria.

Lack of agreement among joint venture members

- 3 percent ended because the joint venture members could not reach an agreement on some issues.
Financial distress

- 10 percent ended due to the financial distress of a key participant.

\section{Early success}

- 5 percent ended due to early success of the project!

Although projects may end early, it is not necessarily an indication of total failure. Projects that ended early produced important knowledge gains; involved integrated planning for research, development, and business activities that may have some benefit to participating companies; and entailed substantive crossdisciplinary contact among scientists and other researchers, cross-talk among technical and business staff, and negotiations among executives at different companies.

These characteristics still benefit the economy by stretching the thinking and horizons of participants in the process. Companies may learn about new opportunities and apply integrated planning of research and business activities to other projects. In summary, terminated projects may have some positive impact even though they incur costs. 


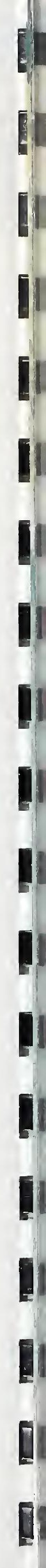




\section{Composite Performance Rating System (CPRS) Star Ratings-First 100 Completed Projects}

Projects are grouped by star rating, listed alphabetically. For a complete description of the CPRS components and calculation procedure, please see: Ruegg, R., A Composite Performance Rating System for ATP-Funded Completed Projects, NIST GCR 03-851 (Gaithersburg, MD: National Institute of Standards and Technology, Forthcoming.)

\begin{tabular}{|c|c|c|c|}
\hline Project Number & $\begin{array}{l}\text { Project Identifier } \\
\text { (Title/Lead Organization) }\end{array}$ & Data Set & Overall Project Success \\
\hline $91-01-0243$ & Aastrom Biosciences, Inc. & 1 st 50 & 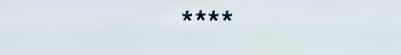 \\
\hline $91-01-0146$ & $\begin{array}{l}\text { American Superconductor } \\
\text { Corporation }\end{array}$ & 1 st 50 & 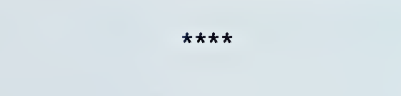 \\
\hline $96-01-0263$ & ColorLink, Inc. & 2nd 50 & $* * * *$ \\
\hline $91-01-0256$ & Cree Research, Inc. & 1 st 50 & 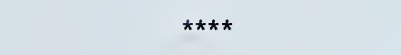 \\
\hline $91-01-0184$ & Engineering Animation, Inc. & 1 st 50 & $\star * * *$ \\
\hline $93-01-0085$ & Integra LifeSciences & 1 st 50 & $\star * * *$ \\
\hline $91-01-0041$ & $\begin{array}{l}\text { Nanophase Technologies } \\
\text { Corporation }\end{array}$ & 2nd 50 & $\star \star \star \star *$ \\
\hline $90-01-0154$ & $\begin{array}{l}\text { National Center for Manufacturing } \\
\text { Sciences (NCMS) }\end{array}$ & 1 st 50 & 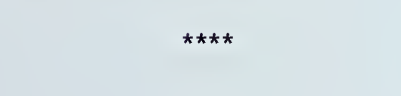 \\
\hline $94-05-0012$ & Third Wave Technologies, Inc. & 2nd 50 & 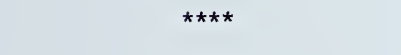 \\
\hline $92-01-0133$ & Tissue Engineering, Inc. & 1 st 50 & $* \star \star *$ \\
\hline $94-06-0024$ & $\begin{array}{l}\text { Torrent Systems, Inc. (formerly } \\
\text { Applied Parallel Technologies, Inc.) }\end{array}$ & 1 st 50 & 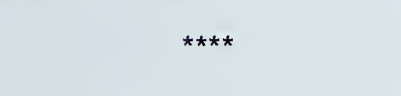 \\
\hline $91-01-0112$ & X-Ray Optical Systems, Inc. & 2nd 50 & 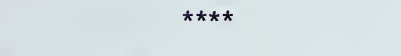 \\
\hline $93-01-0113$ & $\begin{array}{l}\text { Amersham Pharmacia Biotech } \\
\text { (formerly U.S. Biochemical } \\
\text { Corporation) }\end{array}$ & 1 st 50 & $* * *$ \\
\hline $91-01-0177$ & Auto Body Consortium & 1st 50 & $\star * *$ \\
\hline
\end{tabular}


Project Number

$\begin{array}{ll}94-01-0115 & \text { Calimetrics, Inc. } \\ 93-01-0055 & \text { Caterpillar Corporation } \\ 95-01-0022 & \begin{array}{l}\text { Corning Tropel (formerly Tropel } \\ \text { Corporation) }\end{array}\end{array}$

92-01-0136 Cynosure, Inc.

95-02-0055 Dana Corporation

92-01-0115 Diamond Semiconductor Group, LLC

98-02-0034 Digital Optics Corporation

94-01-0402 Displaytech, Inc.

90-01-0064

$94-02-0025$

95-11-0012

$91-01-0178$

92-01-0116

95-09-0052

94-05-0018

92-01-0017 Illinois Superconductor Corporation

$91-01-0016$

$91-01-0262$

93-01-0101 Kurzweil Applied Intelligence, Inc

93-01-0183 MicroFab Technologies, Inc.

91-01-0224 (formerly Biosym Technologies, Inc.)

E.I. Du Pont de Nemours \& Company

Corporation, formerly Sagent

Corporation)

Information Storage Industry
Consortium (INSIC, formerly NSIC)
Data Set

Overall Project Success

1st 50

2nd 50

2nd 50

1 st 50

2nd 50

1 st 50

2nd 50

2nd 50

1 st 50

2nd 50

2nd 50

2nd 50

2nd 50

2nd 50

2nd 50

1st 50

2nd 50

1 st 50

2nd 50

2nd 50

1 st 50

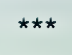

$\star \star \star$

$\star \star \star$

$\star \star \star$

$\star \star \star$

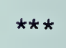

***

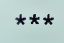

$\star \star \star$

$\star * *$

$\star \star \star$

$\star \star \star *$

$\star \star \star$

$\star \star *$

$* \star *$

$\star \star \star$ 


\begin{tabular}{|c|c|c|c|}
\hline Project Number & $\begin{array}{l}\text { Project ldentifier } \\
\text { (Title/Lead Organization) }\end{array}$ & Data Set & Overall Projec \\
\hline $96-01-0172$ & Nanogen, Inc. & 2nd 50 & 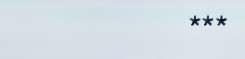 \\
\hline $90-01-0166$ & Nonvolatile Electronics, Inc. & 1 st 50 & $* * *$ \\
\hline $93-01-0071$ & Perceptron, Inc. & 1 st 50 & $\star \star \star *$ \\
\hline $93-01-0205$ & Physical Optics Corporation & 2nd 50 & $\star \star \star \star ~$ \\
\hline $94-04-0024$ & $\begin{array}{l}\text { PPD Informatics (formerly Belmont } \\
\text { Research, Inc.) }\end{array}$ & 2nd 50 & $\star \star \star \star$ \\
\hline $92-01-0123$ & Sage and $3 \mathrm{M}$ Corporation & 1 st 50 & $\star \star \star$ \\
\hline $94-02-0010$ & Strongwell Corporation & 2nd 50 & *** \\
\hline $94-04-0046$ & $\begin{array}{l}\text { Surgency (formerly Benchmarking } \\
\text { Partners) }\end{array}$ & 2nd 50 & 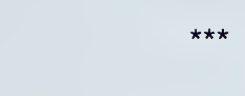 \\
\hline $97-01-0087$ & $\begin{array}{l}\text { TopicalNet (formerly Continuum } \\
\text { Software, Inc.) }\end{array}$ & 2nd 50 & 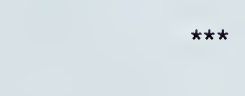 \\
\hline $93-01-0124$ & Vitesse Semiconductor Corporation & 1 st 50 & $\star \star \star \star ~$ \\
\hline $94-04-0027$ & $\begin{array}{l}\text { 3M Company, Health Information } \\
\text { Systems }\end{array}$ & 2nd 50 & $\star \star \star$ \\
\hline $91-01-0187$ & AlliedSignal, Inc. & 1st 50 & $\star \star$ \\
\hline $90-01-0060$ & American Display Consortium & 1st 50 & ** \\
\hline $91-01-0142$ & AstroPower, Inc. & 1 st 50 & $\star \star$ \\
\hline $93-01-0250$ & BioTraces, Inc. & 1 st 50 & ** \\
\hline $90-01-0210$ & $\begin{array}{l}\text { Communication Intelligence } \\
\text { Corporation }\end{array}$ & 1 st 50 & $\star \star$ \\
\hline $93-01-0211$ & $\begin{array}{l}\text { Communication Intelligence } \\
\text { Corporation }\end{array}$ & 1 st 50 & $\star \star$ \\
\hline $93-01-0091$ & $\begin{array}{l}\text { Elsicon (formerly Alliant } \\
\text { Techsystems, Inc.) }\end{array}$ & 2nd 50 & ** \\
\hline $92-01-0022$ & FSI International, Inc. & 1 st 50 & ** \\
\hline $92-01-0074$ & Geltech Incorporated & 1 st 50 & ** \\
\hline $94-01-0147$ & $\begin{array}{l}\text { Genzyme Corporation (formerly } \\
\text { GelTex Pharmaceuticals, Inc.) }\end{array}$ & 2nd 50 & ** \\
\hline $91-01-0034$ & $\begin{array}{l}\text { HelpMate Robotics, Inc. (formerly } \\
\text { Transitions Research Corporation) }\end{array}$ & 1 st 50 & $\star \star *$ \\
\hline
\end{tabular}




\begin{tabular}{|c|c|c|c|}
\hline Project Number & $\begin{array}{l}\text { Project Identifier } \\
\text { (Title/Lead Organization) }\end{array}$ & Data Set & Overall Project Success \\
\hline $94-01-0133$ & Laser Power Corporation & 2nd 50 & $\star \star$ \\
\hline $90-01-0212$ & Light Age, Inc. & 1st 50 & ** \\
\hline $90-01-0121$ & Lucent Technologies Inc. & 1 st 50 & ** \\
\hline 93-01-0191 & $\begin{array}{l}\text { M\&M Precision Systems } \\
\text { Corporation }\end{array}$ & 2nd 50 & 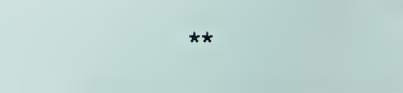 \\
\hline $92-01-0053$ & Mathematical Technologies Inc. & 1 st 50 & ** \\
\hline $91-01-0088$ & Michigan Molecular Institute & 1 st 50 & ** \\
\hline $93-01-0027$ & Micron Optics, Inc. & 2nd 50 & $\star \star$ \\
\hline $95-08-0009$ & Nanogen, Inc. & 2nd 50 & $\star \star$ \\
\hline $94-01-0357$ & Norton Diamond Film & 2nd 50 & $\star \star$ \\
\hline $94-06-0026$ & Reasoning Systems, Inc. & 2 nd 50 & ** \\
\hline $90-01-0232$ & Saginaw Machine Systems, Inc. & 1 st 50 & $\star \star$ \\
\hline $91-01-0263$ & Spire Corporation & 1 st 50 & ** \\
\hline $94-06-0034$ & $\begin{array}{l}\text { TopicalNet, Inc. (formerly } \\
\text { Continuum Software, Inc.) }\end{array}$ & 2nd 50 & ** \\
\hline $94-01-0063$ & Union Switch and Signal, Inc. & 1 st 50 & $\star \star$ \\
\hline $91-01-0261$ & Westinghouse Plasma Corporation & 1 st 50 & $\star \star$ \\
\hline 94-04-0017 & American Healthware Systems & 2nd 50 & * \\
\hline $94-02-0040$ & Budd Company, Design Center & 2nd 50 & * \\
\hline $92-01-0132$ & $\begin{array}{l}\text { GE Corporate Research and } \\
\text { Development }\end{array}$ & 2nd 50 & * \\
\hline $91-01-0069$ & Honeywell, Inc., Technology Center & 2nd 50 & * \\
\hline $92-01-0034$ & Ingersoll Milling Machine Company & 2nd 50 & * \\
\hline 94-04-0037 & KOOP Foundation, Inc. & 2nd 50 & * \\
\hline $95-10-0067$ & KOOP Foundation, Inc. & 2nd 50 & * \\
\hline $91-01-0258$ & Microelectronics Center of NC & 1 st 50 & * \\
\hline 95-02-0005 & $\begin{array}{l}\text { Perceptron (formerly Autospect, } \\
\text { Inc.) }\end{array}$ & 2nd 50 & * \\
\hline
\end{tabular}




93-01-0045 Philips Laboratories

2nd 50

91-01-0267 PreAmp Consortium

1 st 50

93-01-0109 Thomas Electronics, Inc.

1 st 50

94-04-0025

Accenture (formerly Andersen Consulting)

2nd 50

92-01-0055 Accuwave Corporation

1st 50

91-01-0135 Aphios Corporation (formerly

1 st 50

91-01-0025 Armstrong World Industries, Inc.

1 st 50

92-01-0007 Calmac Manufacturing Corporation

2nd 50

92-01-0109 Eagle-Picher Research Laboratory

2nd 50

$92-01-0122$

ETOM Technologies, Inc. (formerly

Optex Communications, Inc.)

1st 50

95-05-0031 General Electric Company

2nd 50

90-01-0126 Hampshire Instruments, Inc.

1 st 50

$91-01-0017$

IBM Corporation

1 st 50

92-01-0103 IBM Corporation

1 st 50

$91-01-0057$

MediaBin (formerly Iterated Systems Incorporated)

2nd 50

92-01-0124 NetOptix Corporation (formerly Galileo Corporation)

1 st 50

95-07-0006 Praxair Surface Technologies, Inc.

2nd 50

92-01-0035

Sheffield Automation (formerly

Giddings \& Lewis)

2nd 50

$91-01-0071$

Thermo Trilogy Corporation

1 st 50 


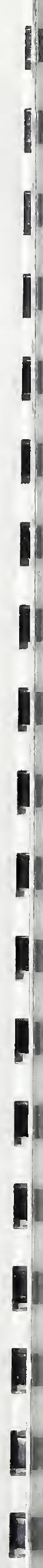


